\title{
ATTACHMENT STYLE AND OBESITY: EXAMINATION OF EATING BEHAVIOURS AS MEDIATING MECHANISMS IN A COMMUNITY SAMPLE OF ONTARIO YOUTH
}

\author{
by \\ Danijela Maras \\ BA, University of Ottawa, 2010 \\ BSc, University of Ottawa, 2008
}

A thesis submitted to the Faculty of Graduate and Postdoctoral Affairs

in partial fulfillment of the requirements for the degree of

Master of Arts
in

Psychology

Carleton University

Ottawa, Canada

C2013 Danijela Maras 


\begin{abstract}
Obesity and being overweight are characterized by excess body weight from fat, and are associated with many negative health outcomes. Attachment style has been implicated in the etiology of obesity in youth. The present study examined the relationship between attachment style and body mass index (BMI) in a large community sample of Ontario youth, as well as examined possible mediating mechanisms of this relationship (restrained, emotional, and external eating), while controlling for covariates. Results indicate that insecure attachment was associated with increased BMI, and that this relationship was significantly mediated by restrained eating behaviour. This mediational pathway was moderated by gender; the pathway was stronger for girls than for boys, but was significant for both. These findings suggest that it may be important to take attachment history into account when designing treatment and prevention strategies for obesity in youth.

Keywords: overweight, obesity, attachment, restrained eating
\end{abstract}




\section{Acknowledgments}

I would like to express my deepest appreciation and gratitude to my supervisors, Dr. Gary Goldfield and Dr. Mary Gick. Their support, patience, and understanding have been instrumental in the completion of this thesis. I would also like to thank my committee members, Dr. Patrick Hill and Dr. Amina Mire, for generously giving their time to offer me valuable feedback to improve this project. A special thank you to Dr. Gary Goldfield, and the $R E A L$ team, who provided me with the opportunity to participate in a meaningful research endeavour, and gave me the pleasure of working with such a wealthy dataset. A sincere thank you to Dr. Nicole Obeid for always being available to lend her expertise, and for being an exceptional role model.

There are no words to convey how grateful I am to my parents, Nenad and Vera Maras, my brother Boris, and sister Nadia, for their unwavering encouragement, support, and love. Thank you for always being there. Finally, I thank with love, my husband, Alexander Dyck. His support and understanding have gotten me through the most challenging times. Thank you for your endless support, love, and laughter. 
Table of Contents

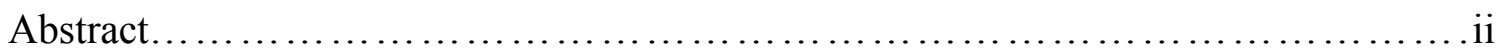

Acknowledgements..................................................

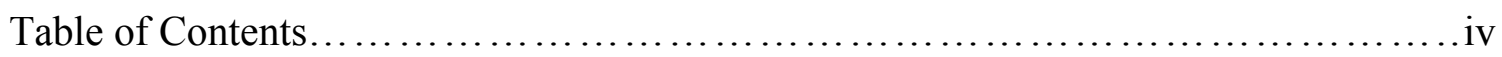

List of Tables........................................................

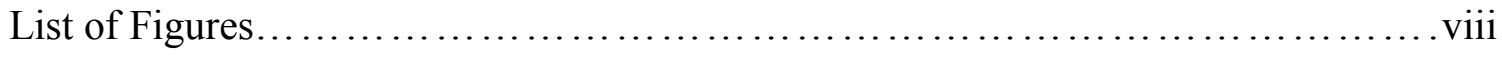

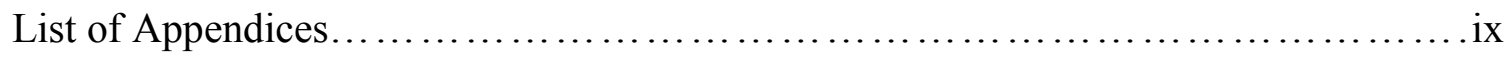

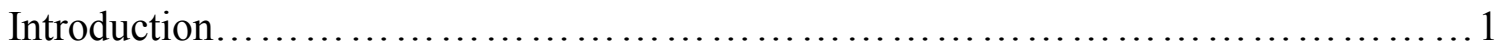

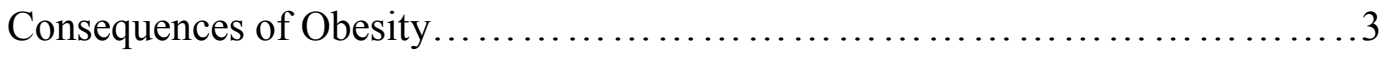

Contributing Factors of Childhood and Adolescent Obesity................. 5

Regulation of Eating Behaviour.................................. 10

Regulation of Eating: The Role of Attachment and the

Mother-Infant Relationship.................................. 15

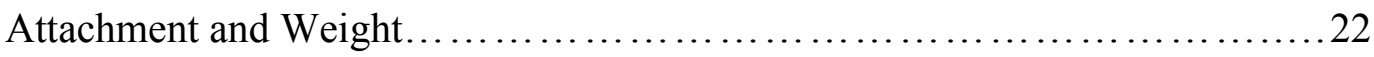

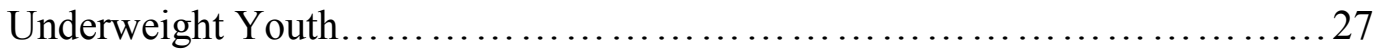

The Present Study ............................................ 29

Method............................................................. 34

Participants................................................... 34

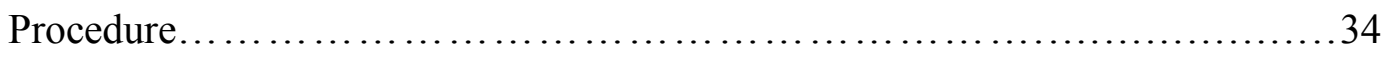

Measures..................................................... 35

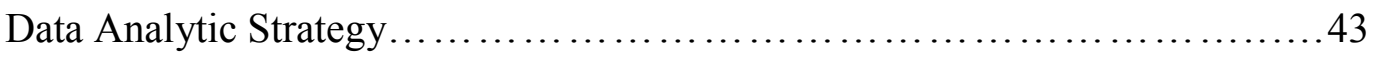

Results........................................................... 46 
ATTACHMENT AND OBESITY $\quad$ V

Data Cleaning.................................................... 46

Main Analyses................................................48

Attachment as a Predictor of Body Mass Index (Objective 1)................52

Parallel Multiple Mediation Analysis (Objectives 2 and 3)...................58

Moderated Multiple Mediation Analysis (Objective 4)....................64

Underweight Sample (Objective 5)..............................6 67

Discussion....................................................... 76

Attachment Predicting Body Mass Index (Main Sample) ................... 76

Mediation Analyses (Main Sample) .................................. 79

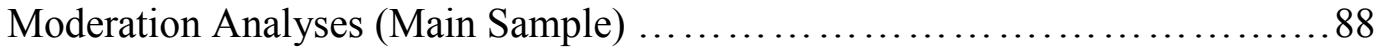

Hierarchical Multiple Regression (Main Sample) ....................... 89

Mediation Analyses (Underweight Sample) $\ldots \ldots \ldots \ldots \ldots \ldots \ldots \ldots \ldots \ldots \ldots . \ldots \ldots$

Validity of the Relationship Questionnaire........................... 91

Limitations and Strengths..................................... 92

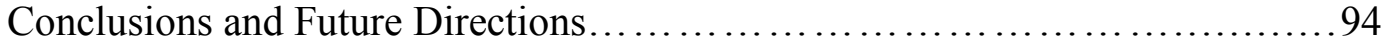

References......................................................... 98

Appendices....................................................... 125 


\section{List of Tables}

Table 1: Descriptives of the Final Sample for Categorical Variables.

Table 2: Descriptives of the Final Sample for Continuous Variables .49

Table 3: Correlations between Dichotomous Attachment and Untransformed

Variables of Interest of the Final Sample 50

Table 4: Correlations between Continuous Attachment and Untransformed

Variables of Interest of the Final Sample

Table 5: Means and (Standard Deviations) of Three Eating Behaviours by Weight

Category

Table 6: Hierarchical Multiple Regression Analysis Predicting BMI from Dichotomous

Attachment.......................................................... 54

Table 7: Hierarchical Multiple Regression Analysis Predicting BMI from Dichotomous

Attachment

Table 8: Hierarchical Multiple Regression Analysis Predicting BMI from Continuous

Attachment

Table 9: Total and Specific Indirect Effects of Dichotomous Attachment Style on Body Mass Index through Eating Behaviours (restrained, external, and emotional eating) presented with Bias Corrected and Accelerated (BCa) 95\% Confidence Intervals (CI)....

Table 10: Total and Specific Indirect Effects of Continuous Attachment Style on Body Mass Index through Eating Behaviours (restrained, external, and emotional eating) presented with Bias Corrected and Accelerated 
ATTACHMENT AND OBESITY

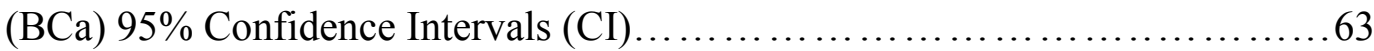

Table 11: Parameter Estimates of Interaction Effects Predicting the Eating

Behaviour Mediators and the Outcome of Body Mass Index.................66 66

Table 12: Conditional Specific Indirect Effects for Restrained Eating by Gender and Socioeconomic Status............................................ 67

Table 13: Descriptives of the Underweight Sample for Categorical Variables..........67

Table 14: Descriptives of the Underweight Sample for Continuous Variables ..........68

Table 15: Correlations between Dichotomous Attachment and Untransformed Variables of Interest of the Underweight Sample...........................69

Table 16: Correlations between Continuous Attachment and Untransformed Variables of Interest of the Underweight Sample ..........................70

Table 17: Total and Specific Indirect Effects of Dichotomous Attachment Style on Body Mass Index through Eating Behaviours (restrained, external, and emotional eating) presented with Bias Corrected and Accelerated (BCa) 95\% Confidence Intervals (CI), for Underweight Youth................73

Table 18: Total and Specific Indirect Effects of Continuous Attachment Style on Body Mass Index through Eating Behaviours (restrained, external, and emotional eating) presented with Bias Corrected and Accelerated (BCa) 95\% Confidence Intervals (CI), for Underweight Youth................75 
List of Figures

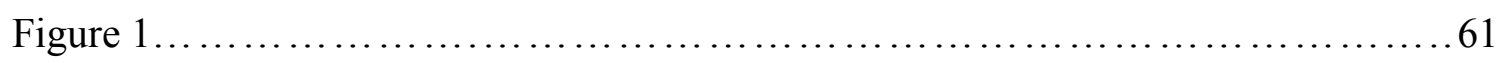

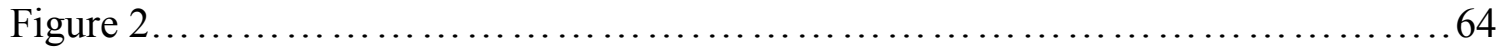

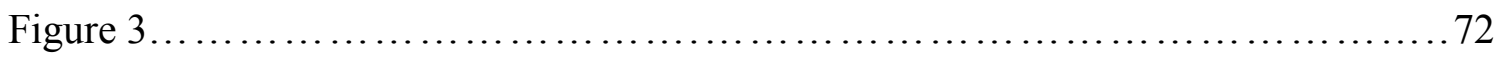

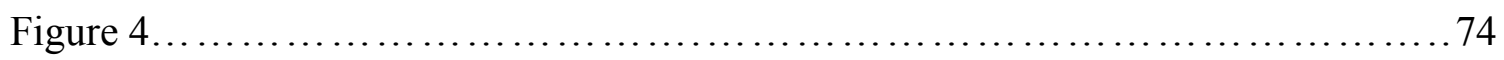


List of Appendices

Appendix A: Relationship Questionnaire............................... 125

Appendix B: Dutch Eating Behavior Questionnaire........................ 126

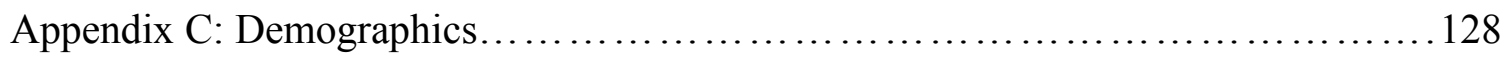

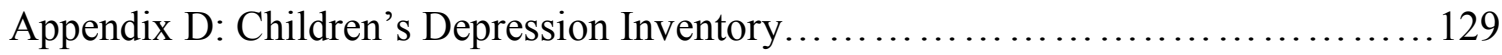

Appendix E: Multidimensional Anxiety Scale for Children $\ldots \ldots \ldots \ldots \ldots \ldots \ldots \ldots \ldots \ldots 131$

Appendix F: Body Esteem Scale for Adolescents and Adults ................... 132

Appendix G: Godin Leisure-Time Exercise Questionnaire..................... 133 
Attachment Style and Obesity: Examination of Eating Behaviours as Mediating Mechanisms in a Community Sample of Ontario Youth

Overweight ${ }^{1}$ and obesity are characterized by excess body weight from fat, and are associated with many negative health consequences. Rates of overweight and obesity have increased at an alarming rate among Canadian children and adolescents over the past 30 years, but have shown some stability in the last 10 years (Roberts, Shields, de Groh, Aziz, \& Gilbert, 2012; Russell-Mayhew, McVey, Bardick, \& Ireland, 2012; Shields, 2006). Despite the levelling off of prevalence rates, it is of great concern that the percentage of overweight in 12 to 17 year olds in Westernized countries has more than doubled in the past 30 years, and the percentage of obesity has tripled (International Obesity Task Force, IOTF, cut-off values), as childhood and adolescent overweight and obesity track into adulthood (Shields, 2006; Wang, Chyen, Lee, \& Lowry, 2008). The Canadian Health Measures Survey recently released their second cycle of data that were collected across 18 Canadian cities from August 2009 to December 2011. Questionnaires were administered and physical measurements (height and weight) were taken of 2,123 youth aged 5 to 17 years (Roberts et al., 2012). Results indicate that $69.0 \%$ of girls aged 12 to 17 years were within the normal weight range (World Health Organization, WHO, cut-off values), 20.9\% were overweight, and 9.6\% were obese (Roberts et al., 2012). Results were similar for normal weight, overweight, and obese boys in that age range: $65.6 \%, 18.9 \%$, and $10.7 \%$, respectively (Roberts et al., 2012). These elevated rates of overweight and obesity are alarming given that a systematic review found that both child and adolescent overweight and obesity track into adulthood, but tracking is stronger

\footnotetext{
${ }^{1}$ By convention, overweight is used as a noun in the literature.
} 
among adolescents compared to children (Singh, Mulder, Twisk, van Mechelen, \& Chinapaw, 2008).

Overweight and obesity are commonly assessed using body mass index (BMI), which is a ratio of weight in kilograms $(\mathrm{kg})$ to height in metres squared $\left(\mathrm{m}^{2}\right)$. This is the most commonly used anthropometric measure of adiposity and is recommended by many experts as it is easily measured, strongly correlates with body fat percentage, and is only weakly associated with height (Krebs et al., 2007). In adults, a BMI of $25 \mathrm{~kg} / \mathrm{m}^{2}$ or greater is considered overweight, and a BMI of $30 \mathrm{~kg} / \mathrm{m}^{2}$ or greater is considered obese (WHO, 2013). The classification of overweight and obesity in children and youth is slightly more challenging as height and weight can change significantly with normal development, growth, and maturation (Katzmarzyk, Janssen, Morrison, \& Tremblay, 2007). For this reason, age- and sex-specific reference populations are used to define overweight and obesity in children and youth. Using a large international sample of children and youth, the IOTF developed age- and sex-specific BMI cut-off values to help define underweight, normal weight, overweight, and obesity in youth (Cole, Bellizzi, Flegal, \& Dietz, 2000). BMI threshold values were developed by identifying BMI percentile levels at age 18 years that corresponded to the adult BMI cut-off values of 17 $\mathrm{kg} / \mathrm{m}^{2}$ (thinness grade 2), $18.5 \mathrm{~kg} / \mathrm{m}^{2}$ (thinness grade 1 ), $25 \mathrm{~kg} / \mathrm{m}^{2}$ (overweight), and 30 $\mathrm{kg} / \mathrm{m}^{2}$ (obese), then projecting backwards into childhood (Cole et al., 2000). This method links child and youth BMI cut-off values with adult cut-offs allowing for comparisons between youth and adults, as well as facilitating comparisons internationally (Cole et al., 2000). Other approaches exist to classify weight categories, for example, a distributional 
approach can be utilized where a $\mathrm{BMI}<3^{\text {rd }}$ percentile defines thinness grade 2 ; BMI $\geq$ $3^{\text {rd }}-<16^{\text {th }}$ percentile defines thinness grade $1 ; \mathrm{BMI} \geq 16^{\text {th }}-<85^{\text {th }}$ percentile defines normal weight; $\mathrm{BMI} \geq 85^{\text {th }}-<95^{\text {th }}$ percentile defines overweight; and $\mathrm{BMI} \geq 95^{\text {th }}$ percentile defines obesity, for children of the same age and sex (Katzmarzyk et al., 2007). Although prevalence rates vary slightly depending on which methodology is used, the trend is consistent; rates of overweight and obesity have reached dangerously high proportions.

\section{Consequences of Obesity}

\section{Medical Consequences}

Not only are overweight and obesity becoming increasingly common in our youth, but the health consequences associated with these conditions are also increasing in severity. Overweight and obesity have long been associated with many chronic illnesses in adults, and many of these health conditions are now being detected in youth (Holterman, Holterman, \& Browne, 2012). Some of the medical comorbidities associated with pediatric obesity include insulin resistance and type 2 diabetes mellitus, hypertension, hypercholesterolemia (high cholesterol), dyslipidemia (abnormal lipids), cardiovascular disease, asthma, polycystic ovary syndrome, sleep apnea, non-alcoholic fatty liver disease, orthopedic disease conditions, just to name a few (for a review, see Lobstein, Baur, \& Uauy, 2004). The medical complications associated with childhood overweight and obesity are amplified, as research has demonstrated that overweight and obesity during childhood tracks into adulthood (Wang et al., 2008). Because overweight or obese youth are more likely to become obese adults (Freedman et al., 2005), the 
burden on the health care system is long-lasting.

\section{Economic Burden}

The economic burden of obesity (BMI $\left.>30 \mathrm{~kg} / \mathrm{m}^{2}\right)$ in Canadian adults has increased from an estimated $\$ 4.3$ billion in 2001 (Katzmarzyk \& Janssen, 2004) to \$6.0 billion in 2006 (Anis et al., 2010), and is expected to rise (Waters et al., 2011). Health care burden values were determined using the prevalence-based approach, meaning that these cost estimates are largely theoretical versus concrete, and are at the population level instead of the individual level. Studies linking BMI to healthcare expenditure data provide a more concrete estimate of economic burden. Two such studies linking data from the 2000/2001 Canadian Community Health Survey (CCHS) to the Ontario Health Insurance Plan (OHIP) providers' database confirmed that average physician costs (Janssen, Lam, \& Katzmarzyk, 2009), hospitalization costs, and total health care costs are significantly higher in obese individuals when compared with normal-weight adults (Tarride et al., 2012).

\section{Psychosocial Consequences}

The effects of overweight and obesity extend beyond serious medical consequences; overweight and obese youth fall victim to multiple psychosocial issues such as weight-based teasing, bullying, and stigma (Goldfield et al., 2010b; Puhl \& Latner, 2007). Moreover, youth with higher BMIs typically have higher levels of body dissatisfaction and poorer body image (Austin, Haines, \& Veugelers, 2009; Field et al., 2003). These issues can all contribute to poorer emotional well-being (Tiffin, Arnott, Moore, \& Summerbell, 2011), increased risk of low physical activity (Trost, Sirard, 
Dowda, Pfeiffer, \& Pate, 2003) as well as further weight gain (Latner \& Stunkard, 2003). The majority of research examining psychosocial correlates of pediatric obesity are crosssectional in nature and represent basic associations versus a directional relationship. Therefore, many psychosocial factors could be both contributors and consequences of obesity. This will be discussed in more detail later. It is clear that the persistence of overweight and obesity has significant psychological comorbidity and physical health implications. It is therefore important to understand what factors contribute to the development of overweight and obesity in youth.

\section{Contributing Factors of Childhood and Adolescent Obesity}

Obesity is multifactorial in nature, and its development is influenced in part by genetic, environmental, behavioural, and psychological factors, as well as the interaction of these factors (Silventoinen, Rokholm, Kaprio, \& Sørensen, 2010). There is a plethora of literature on genetic and environmental contributors to obesity; however, the research on psychological contributors lags behind slightly.

\section{Genetic Factors}

There is consensus in the literature that genes play a major role in the development of obesity. Twin studies have found that identical twins of obese parents are more likely to become obese when compared with twins of non-obese parents (Maffeis, 2000). Adoption studies also support the role of genetics; adopted children resemble their biological parents in terms of body weight more so than their adopted parents (Maffeis, 2000). Studies conducted before and after the obesity epidemic have found that genetics account for approximately $61 \%$ to $77 \%$ of the variance in body weight in children and 
adolescents, and environmental effects account for approximately $23 \%$ to $25 \%$ of the variance (Koeppen-Schomerus, Wardle, \& Plomin, 2001; Wardle, Carnell, Haworth, \& Plomin, 2008). Even though obesity is strongly influenced by genes, because human genes have evolved very little in the past 40 years, and the prevalence of obesity has skyrocketed, it is important to consider non-genetic contributors.

\section{Environmental Factors}

In addition to genetic predisposition, the environment also plays a role in the development of obesity. Genes and the environment are unlikely to contribute independently, but research examining gene-environment interactions are missing (Davison \& Birch, 2001). Although gene-environment research is growing rapidly, this is beyond the scope of this study.

Built environment. Features of a neighbourhood's built environment such as land use (e.g. parkland, open space), street connectivity, transportation availability, and access to recreational facilities are cross-sectionally and longitudinally related to childhood and adolescent obesity (Epstein et al., 2012; Gilliland et al., 2012; Rahman, Cushing, \& Jackson, 2011). Neighbourhood attributes such as walkability, bikeability, availability of transit, accessible destinations, and mixed land use increase physical activity (Rahman et al., 2011). The food environment is also related to obesity; access to calorie-dense foods and convenience stores increases risk of overweight and obesity in children, whereas proximity to farmer's markets decreases obesity prevalence (Gilliland et al., 2012; Rahman et al., 2011). 
Family environment. Past studies have typically thought of the family environment as a shared environment, i.e. an environment that affects all family members the same way or is experienced the same by all family members, but this is not always the case (Davison \& Birch, 2001). Socioeconomic status (SES) is an example of a shared family factor that has been associated with the development of overweight and obesity. There is compelling evidence that low SES in industrialized countries is a risk factor for obesity (Due et al., 2009; Moore \& Cunningham, 2012), but there is some variability of results between studies in children, i.e. some studies report no relationship between SES and obesity (Sobal \& Stunkard, 1989). This variability is likely due to differing operational definitions of SES, with some studies defining SES as family income, education level, material wealth, or perceived family affluence. Parental modeling of eating behaviour is another shared factor that can contribute to the development of obesity (Cutting, Fisher, Grimm-Thomas, \& Birch, 1999; Pike \& Rodin, 1991).

Research studies have reported that the majority of non-genetic effects are accounted for by non-shared factors that are unique to the individual (Davison $\&$ Birch, 2001; Wardle et al., 2008). Examples of non-shared family factors that may play a role in the development of overweight and obesity include child feeding practices (Clark, Goyder, Bissell, Blank, \& Peters, 2007; Cooper \& Warren, 2011), and parenting style (Karavasilis, Doyle, \& Markiewicz, 2003). Considering that parent-child interactions are bidirectional, non-shared family effects are common, and it is not surprising that parenting practices within a family may differ considering that children within a family 
differ in terms of age, gender, birth order, temperament, special abilities, and weight status (Holden \& Miller, 1999).

Sociocultural environment. It is important to acknowledge that sociocultural factors can influence many areas related to eating, which could then contribute to the development of obesity. Different cultures have different practices and rituals around food. For example, some cultures have communal gatherings that are centered around religion or politics, and involve an abundance of food (McCabe, Waqa, Dev, Cama, \& Swinburn, 2013). Moreover, different religious and cultural backgrounds can have a wide-spread effect on many areas related to eating such as child feeding practices (e.g. Negayama, Norimatsu, Barratt, \& Bouville, 2012), parenting style (e.g. SotomayorPeterson, De Baca, Figueredo, \& Smith-Castro, 2012), body image (e.g. McCabe et al., 2013), and self-regulation of eating (e.g. Luomala, Sirieix, \& Tahir, 2009). Although sociocultural contributors were beyond the scope of this project, ethnicity was considered as a covariate in the statistical analyses.

\section{Psychological and Behavioural Factors}

In addition to genetic predisposition and environmental factors, psychological and behavioural factors may also contribute to both the development and maintenance of overweight and obesity in youth. Because overweight and obesity have historically been viewed as medical conditions, the psychological contributions to these conditions are often overlooked.

Along with the correlates previously mentioned, the following psychological and behavioural variables have been cross-sectionally identified as risk factors for obesity: 
depression (Blaine, 2008; Goldfield et al., 2010a; Goodman \& Whitaker, 2002; Pine, Goldstein, Wolk, \& Weissman, 2001), anxiety (Anderson, Cohen, Naumova, \& Must, 2006; Britz et al., 2000; Rofey, Silk, \& Dahl, 2010), body dissatisfaction (Austin et al., 2009; Neumark-Sztainer, Paxton, Hannan, Haines, \& Story, 2006), perceived stress (Johnson, Cohen, Kasen, \& Brook, 2002; Schneiderman, Mennen, Negriff, \& Trickett, 2012), dieting behaviour (Field et al., 2003; Stice, Cameron, Killen, Hayward, \& Taylor, 1999; Stice, Presnell, Shaw, \& Rohde, 2005) binge eating (Stice, Presnell, \& Spangler, 2002), conduct disorder symptoms (Pine, Cohen, Brook, \& Coplan, 1997), unhealthy diet and nutrition (Piernas \& Popkin, 2011), low physical activity (Alberga et al., 2012; O'Loughlin, Gray-Donald, Paradis, \& Meshefedjian, 2000), and high levels of sedentary behaviour (Boone, Gordon-Larsen, Adair, \& Popkin, 2007; Carson, Pickett, \& Janssen, 2011).

As previously mentioned, the majority of research examining psychosocial correlates of overweight and obesity are cross-sectional in nature. Longitudinal studies have demonstrated a directional relationship between symptoms of depression in children and adolescents, and the development of obesity or increase in BMI in later life (Goodman \& Whitaker, 2002; Pine et al., 2001). Some studies have shown that anxiety (Rofey, Silk, \& Dahl, 2010) and body dissatisfaction (Neumark-Sztainer et al., 2006) also predict later obesity, but more longitudinal studies are needed. Research has also consistently demonstrated that higher levels of physical activity decrease the risk of overweight and obesity (Janssen \& Leblanc, 2010). 


\section{Summary}

Although genetic, environmental, psychological and behavioural factors all contribute to the development of obesity, the accumulation of excess body fat is ultimately caused by long-term imbalance between energy intake and energy expenditure. Positive energy balance and weight gain result when energy intake exceeds energy expenditure, and negative energy balance and weight loss occur when energy expenditure exceeds energy intake. Energy expenditure, in the form of physical activity, has an important role in body weight regulation (Alberga et al., 2012), but the main focus of this study will be the other side of energy balance: positive energy balance through eating behaviour.

\section{Regulation of Eating Behaviour}

Eating is typically thought to operate at an automatic level, much like breathing, and starts in response to hunger, then stops in response to satiety (Graziano, Calkins, \& Keane, 2010; Herman \& Polivy, 2008). However, if this were the case for all individuals, weight regulation problems and obesity would not exist. Maladaptive eating behaviours can lead to positive energy balance and weight gain over time. Emotional eating, external eating, and restrained eating have been identified as forms of maladaptive eating behaviours that can lead to excess weight gain (van Strien, Frijters, Bergers, \& Defares, 1986). These three types of eating behaviours were derived from three theories that are often used in obesity research: psychosomatic theory, externality theory, and restraint theory, respectively. 


\section{Emotional Eating}

Psychosomatic theory postulates that emotional eating, defined as excessive eating in response to emotional arousal, plays a role in the etiology of obesity (Kaplan \& Kaplan, 1957;Van Strien, Frijters, Bergers, \& Defares, 1986). According to

psychosomatic theory, there are two mechanisms responsible for overeating in response to emotions: (1) overeating due to the inability to distinguish between feelings of hunger, satiety, and emotional arousal, often called poor interoceptive awareness, or (2) overeating because food is used to reduce emotional distress (Kaplan \& Kaplan, 1957).

Physiological responses to high states of arousal can manifest in various ways across individuals, ranging from increased food intake, to a loss of appetite or decreased eating. Biologically speaking, high states of emotional arousal should result in decreased food intake because arousal inhibits gastric motility (stomach muscle contractions that promote food digestion; Cannon, 1915, as cited in Van Strien \& Ouwens, 2003). However for some individuals, emotional arousal or stress can lead to increased food intake (Cannon, 1915, as cited in Van Strien \& Ouwens, 2003).

Several laboratory studies have found that obese individuals tend to overeat in the presence of negative emotions, such as stress or anxiety, when compared with normal weight individuals and when the food is palatable (for a review, see Stroebe, 2008). Therefore, emotional eating is seen as a maladaptive response to emotional arousal, and often occurs in individuals with poor interoceptive awareness (Van Strien \& Ouwens, 2003). Individuals with poor interoceptive awareness have difficulty discriminating between feelings of hunger, satiety, or states of emotional arousal. Because individuals 
with poor interoceptive awareness are not capable of accurately recognizing whether they are hungry, full, or experiencing another form of discomfort, they may overeat in response to an aroused state, and ultimately gain weight (Bruch, 1975; Van Strien \& Ouwens, 2003). Laboratory studies have shown that the eating behaviour of obese individuals is not regulated by internal cues, and that gastric motility is not perceived as hunger in obese individuals but is in normal weight individuals (for a review, see Stroebe, 2008). The present study will help determine if emotional eating is associated with overweight or obesity.

\section{External Eating}

Like psychosomatic theory, externality theory posits that obesity develops due to overeating as a result of poor interoceptive awareness (Robbins \& Fray, 1980), but instead of eating being triggered by a state of arousal, externality theory suggests that overeating is triggered by external food cues (Schachter \& Rodin, 1974). Examples of external food cues include the sight or smell of food, as well as environmental aspects that are associated with food, such as mealtimes (Schachter \& Rodin, 1974). Therefore, externality theory postulates that obesity develops due to external eating. As externality theory suggests that overeating occurs as a result of food cues rather than biological cues of hunger, this theory may explain why some individuals overeat in today's food-rich environment.

Laboratory research supports externality theory. Studies have consistently provided evidence that overweight and obese individuals are overly responsive to external food-related cues and that this strongly influences their food intake (for a review, 
see Stroebe, 2008). The prevalence of obesity has increased drastically over the past 30 years (Roberts et al., 2012; Russell-Mayhew et al., 2012), and our obesogenic environment is partly to blame (Brownell, Schwartz, Puhl, Henderson, \& Harris, 2009). The number of environmental cues that encourage the consumption of calorie-dense, nutrient-poor foods are abundant. For example, youth are exposed to numerous advertisements promoting unhealthy foods which are abundantly available, and less costly than healthier food options (Brownell et al., 2009). The prevalence of obesity has increased in direct proportion to the obesogenic environment lending further support to externality theory. However, the support for externality theory is mixed as some studies have not supported externality theory (Lluch, Herbeth, Méjean, \& Siest, 2000; Snoek, Van Strien, Janssens, \& Engels, 2007; Wardle, 1987). The present study will help determine if external eating is an eating behaviour that is associated with overweight and obesity in youth.

\section{Restrained Eating}

Restraint theory postulates that the constant restriction of food for the purpose of weight loss will reach a breaking point and result in disinhibited eating and subsequent weight gain. This cycle can further confuse the body's hunger and satiety cues, and can lead an individual to rely on contextual cues for eating (Herman \& Polivy, 1975).

There is conflicting evidence about whether or not restrained eating behaviour is a response to weight gain or a risk factor for weight gain. There is cross-sectional literature supporting positive, negative, and null associations between restrained eating and BMI (Johnson, Pratt, \& Wardle, 2012). Even the longitudinal research is mixed. There is an 
abundance of research demonstrating that restrained eating predicts BMI (Field et al., 2003; Stice et al., 1999, 2005); however, there is emerging evidence showing that the opposite relationship may also be true (Forrester-Knauss, Perren, \& Alsaker, 2012; Snoek, Van Strien, Janssens, \& Engels, 2008). Despite the many inconsistencies in the literature, research has consistently shown that the association between dietary restraint and BMI differs between normal weight and overweight individuals (Goldfield et al., 2010a; Johnson et al., 2012). In general, there is a positive relationship between restraint and BMI for normal weight individuals, but the relationship is negative in obese individuals such that higher restraint is associated with lower weight (Johnson et al., 2012). The present study will contribute to the literature on restrained eating behaviour, and will help determine what the relationship between restrained eating and BMI is in a pediatric sample.

\section{Summary}

There is some evidence to suggest that emotional, external, and restrained eating behaviours are associated with overweight and obesity in children and adolescents. Previous research in adults has found that higher levels of emotional and restrained eating, but not external eating, moderate the relationship between overeating and obesity (van Strien, Herman, \& Verheijden, 2009). However, mixed results have been found in youth. For example, one study concluded that external and restrained eating were positively associated with overweight in adolescents aged 11 to 16 years (Snoek et al., 2007), whereas another study found that only restrained eating, and not external or emotional eating, were associated with BMI in adolescents aged 13 to 15 years (Snoek, 
Engels, van Strien, \& Otten, 2013). These discrepant findings suggest that more research is needed to understand how dysregulated eating behaviours contribute to BMI in youth. Moreover, the difference in results between youth and adult studies suggests that youth are not simply "mini-adults" and have to be studied separately.

Based on the three theories discussed, it is possible that emotional, external, and restrained eating behaviours would all be related to obesity in youth, thus warranting further examination. Moreover, because these maladaptive eating behaviours are modifiable risk factors, and therefore possible intervention targets, understanding their role could help guide future obesity intervention and prevention efforts in youth.

\section{Regulation of Eating: The Role of Attachment and the Mother-Infant Relationship}

The study of self-regulation is increasing in popularity in the field of pediatric obesity (Tan \& Holub, 2011). Broadly speaking, self-regulation can be defined as a conscious or unconscious effort by an individual to change his or her inner states (Baumeister \& Vohs, 2004). Attachment has long been implicated in regulatory behaviours in normal development, such as emotion regulation (Bowlby, 1970) and the regulation of feeding and eating (Bruch, 1975). The way in which attachment can contribute to the regulation of hunger and feeding was first described by Bruch (1975), who was also the first to introduce the importance of the child-parent relationship in the development of overweight and obesity. Most youth can self-regulate their eating behaviour by relying on internal cues of hunger (e.g. Birch \& Deysher, 1985), however individual differences exist. Understanding these differences and how they develop is crucial to understanding the role that self-regulation of eating plays in obesity 
development.

Although eating is typically thought to be automatically regulated by biological needs (Graziano et al., 2010), Hilde Bruch (1975) suggested that eating regulation is also comprised of a psychological component. For healthy development of hunger-, satietyand self-awareness, it is crucial that a child's biological and emotional cues or needs are responded to appropriately (Bruch, 1975). Because the development of global selfregulation begins in infancy, and develops in the family context, it may be useful to view the development of self-regulatory eating behaviours within the framework of attachment theory.

\section{Attachment Theory}

Attachment theory is based on the work of John Bowlby (1970) and later contributions by Mary Ainsworth (Ainsworth \& Bowlby, 1991). Attachment theory posits that human beings have an innate need to form attachment bonds with others (Hazan \& Shaver, 1987). The formation of the attachment bond between an infant and his or her caregiver begins early on in life, and functions as a way of gaining the attention and physical proximity of the primary caregiver during times of perceived internal or external distress (Hazan \& Shaver, 1987). Each child is equipped with an attachment behavioural system that consists of behavioural cues such as clinging or reaching, and emotional cues such as crying or angry protest, to communicate his or her wants, needs, or discomforts (Hazan \& Shaver, 1987). Development of the attachment bond between a child and primary caregiver is largely influenced by how the caregiver responds to the child's cues, and can be secure or insecure (Hazan \& Shaver, 1987). A secure attachment 
bond is adaptive in Western society, and develops when the caregiver responds to the child's cues of distress in a consistent manner (Hazan \& Shaver, 1987). If the caregiver is not accessible or not responsive, over time an insecure attachment will develop (Hazan \& Shaver, 1987).

Psychobiology of attachment. Hofer's (1970) early laboratory research with rats expanded on the notion of a unitary attachment bond, and found that within the motherinfant interaction, there were several transactions involving touch, taste, temperature exchange, smells, and sounds, that each helped to regulate the infant rat's behaviour and biological functions. Through a series of laboratory experiments, Hofer added to attachment theory by determining that the infant-mother relationship helped to maintain and regulate biological systems (Hofer, 2006). Separation from the mother can cause physiological stress, resulting in mostly permanent dysregulated biological functions and behaviours in the baby rat (e.g. a decrease in body temperature and heart rate, and an increase non-nutritional sucking; Hofer, 2006). Further research by Kuhn and Schanberg (1998) extended Hofer's rat studies to human infants and mothers, and found that early interactions involving touch, taste, smell, etc., between infant and mother regulated the human infant's biological functions. These interactions between infant and mother shape the development of the infant's brain and behaviour during the pre-weaning period, and over time, serve to regulate healthy development of behaviour and physiology (Hofer, 2006). The idea that the infant-mother relationship is a regulator of the infant's future behaviour and physiology is in line with the idea that the infant-mother relationship can contribute to dysregulated eating behaviour (Bruch, 1975). 
Maternal feeding practices. During the first year of life, the majority of the infant-mother interaction is observed during feeding (Bruch, 1975; Hofer, 2006). The bidirectional exchange of emotional signals and sharing of affect that promote communication of needs, desires, and pleasure during the feeding process is a fundamental experience during infancy, and helps stabilize biological rhythms (Ammaniti, Ambruzzi, Lucarelli, Cimino, \& D’Olimpio, 2004; Bruch, 1975; Hofer, 2006). The feeding process during infancy is bidirectional in that the infant gives cues or signals, typically crying, to communicate wants, needs, and discomforts, and in turn, the mother must recognize the infant's cues and respond appropriately (Bruch, 1975). The manner by which the infant's cues are responded to, fulfilled, or neglected is critical for the infant to become aware of his or her needs (Bruch, 1975). For instance, when the mother offers the infant food in response to signals of nutritional need only, the infant will develop a concept of hunger that is distinct from other needs (Bruch, 1975). Alternatively, if the mother's response is neglecting, inconsistent, or over-bearing, the child may develop a confusing concept of hunger, or may not be able to discriminate between feelings of hunger, satiety, or emotional discomfort (Bruch, 1975). Inconsistent responding by the mother over time can result in dysregulation such as not being able to differentiate between biological cues of disturbance, and emotional or interpersonal stress (Bruch, 1975). Dysregulated eating behaviour likely develops in parallel with the development of the attachment bond. When Hofer and Bruch's work are considered together, one can begin to see how a neglectful or non-responsive mother can influence not only the broad attachment bond between infant and mother, but can also affect the 
specific regulatory function of eating behaviour. There is some literature on breastfeeding that supports the idea that the early interactions between infant and mother can affect eating behaviours and possibly weight regulation.

Breastfeeding. It has been well established that breastfeeding in infancy is protective against later obesity (Harder, Bergmann, Kallischnigg, \& Plagemann, 2005; Singhal \& Lanigan, 2007). Observational studies have shown that risk of obesity during childhood is $15 \%$ to $20 \%$ lower in infants who were breastfed compared to those who were formula-fed (Owen, Martin, Whincup, Smith, \& Cook, 2005). Although the exact mechanism by which this association exists is unclear, one proposed avenue is that breastfeeding may result in more responsive feeding styles, such that the mother is more attuned to the infant's cues for hunger and satiety, and the infant develops healthy selfregulation of energy intake (Li, Fein, \& Grummer-Strawn, 2010; Taveras et al., 2004). Differences in the physiologic process between breastfeeding and bottle-feeding may contribute to the different self-regulatory eating behaviours seen in breastfed versus bottle-fed infants. That is, when breastfed, the infant has no visual cues and feeds when hungry, whereas bottle-feeding may be more influenced by the caregiver (i.e. if there is milk left in the bottle the caregiver may continue feeding the infant). The caregiver's influence may disrupt or override the healthy development of the infant's self-regulation of energy intake.

One study found that in a sample of 1250 infant and mother pairs, those infants who were breastfed during early infancy were better able to self-regulate their milk intake in late infancy when compared to infants who were bottle-fed, regardless of whether they 
were bottle-fed formula or breast milk (Li et al., 2010). Moreover, mothers who were breastfeeding their child were more inclined to want to interact with their child during moments of distress when compared to mothers who were bottle-feeding (Wiesenfeld, Whitman, Granrose, \& Uili, 1985). Another possible explanation for why breastfeeding may protect against obesity is that it may be the basis of several regulatory interactions between infant and mother, as described by Hofer (2006).

Breastfeeding has been shown to be protective against later development of obesity in youth (e.g. Gillman et al., 2001; Kramer, 1981). A cohort study comprised of 15,431 boys and girls ranging in age from 9 to 14 years, found that children who were breastfed instead of formula-fed during the first 6 months of infancy, or who were breastfed for longer periods, had a lower risk of obesity $\left(\mathrm{BMI}>95^{\text {th }}\right.$ percentile, CDC growth reference for the United States) during later childhood and adolescence (Gillman et al., 2001). These studies provide further support how early mother-child feeding practices that promote self-regulation, such as breastfeeding, may have a long-lasting impact on body weight throughout development.

Attachment in late childhood and adolescence. Attachment orientation has been shown to remain highly stable. A 20-year longitudinal study reported the stability of attachment between the ages of 12 to 18 months and 20 years to be $70 \%$, meaning that $70 \%$ of individuals had the same attachment style (Waters, Merrick, Treboux, Crowell, \& Albersheim, 2000). Overall, adolescence is a time of many transitions, including seeking autonomy from parents in favour of peer relationships. Despite relationship changes, the attachment system is thought to have reached stability by this point in life, and provides a 
prototype for future relationships (Allen, 2008). Furthermore, primary attachment figures continue to play a role in the youth's life, as many youth are still dependent on their parents, and turn to them for help (Hendry, Roberts, Glendinning, \& Coleman, 1992). An adolescent's perceived quality of attachment to parents remains stable across the adolescent years (Greenberg, Siegal, \& Leitch, 1983).

Not only does the early child-parent attachment relationship remain relevant throughout adolescence, and serves as a prototype for future relationships, it also influences how the child's model of him or herself develops. Research has shown that attachment is positively related to development of the self (e.g. Pipp, Easterbrooks, \& Harmon, 1992). The process of attachment and separation during infancy and childhood are part of self-development, and therefore individuals without a secure attachment foundation may develop negative views of the self, and may be more susceptible to negative outcomes (Pipp et al., 1992). Therefore, attachment style is an individual factor that begins to develop in the context of the family, remains relevant in the family context, is important in future relationships (i.e. peers, romantic partners), and shapes a youth's self-development.

Summary. When the work of Hofer and Bruch are framed within attachment theory, we can begin to understand how an unhealthy attachment relationship may contribute to the development of pediatric overweight and obesity. If the mother is not attuned to the infant, and does not consistently and appropriately respond to the child's needs, the child may develop a confusing concept of hunger and satiety, and hence dysregulated eating behaviours. Additionally, because a healthy infant-mother 
relationship promotes the development of healthy regulatory behaviours, the absence of an attentive mother may result in permanent changes in the child's behaviour and physiology, causing dysregulated eating. Self-regulated eating behaviour is considered a relatively stable characteristic (Tan \& Holub, 2011), as is attachment style (Waters et al., 2000), therefore measuring attachment style in later childhood or early adolescence is likely representative of that individual's early interactions with his or her primary caregiver. Because self-regulatory behaviours begin to develop in infancy, and because a secure attachment bond is thought to promote healthy self-regulated eating behaviours, examination of how attachment style is related to overweight and obesity is warranted, and is reviewed next.

\section{Attachment and Weight}

As previously mentioned, attachment is important to the healthy development of regulatory behaviours. Various types of self-regulation skills that develop within the attachment framework, such as emotion regulation (Bowlby, 1970; Graziano et al., 2010), the regulation of feeding and eating (Bruch, 1975), low inhibitory control (Francis \& Susman, 2009), and high reward sensitivity (Graziano et al., 2010), have been recognized as risk factors for obesity in youth. In general, it is known that impaired self-regulatory behaviours are a risk factor for obesity, but it is important to dig deeper to understand the role of specific dysregulated behaviours, such as dysregulated eating. Despite Bruch (1975) and Hofer (1970) drawing attention to the importance of attachment in the development of overweight and obesity, very few studies have actually examined this relationship in the pediatric population. 
Anderson and Whitaker (2011) examined the relationship between attachment style and obesity in a sample of 6,650 US children born in 2001. Results of this prospective cohort study indicate that two-year old children with an insecure attachment pattern were at increased risk for obesity $\left(\mathrm{BMI} \geq 95^{\text {th }}\right.$ percentile, Centres for Disease Control and Prevention [CDC] growth reference), at 4.5 years of age, even after accounting for confounding factors (Anderson \& Whitaker, 2011). More specifically, the risk of obesity at the 4.5 year mark was higher among insecurely attached children, after adjusting for maternal interaction with the child, child interaction with the mother, parenting practices, maternal health and socio-demographic characteristics (Anderson \& Whitaker, 2011). This was the first study to longitudinally examine the role of attachment security in the development of obesity. The authors reasoned that because a secure attachment style is a reliable measure of healthy emotion regulation and responses to stress, then insecure attachment (poorer emotion regulation and stress responses) could be a risk factor for childhood obesity (Anderson \& Whitaker, 2011). This study provides valuable information as it was the first to longitudinally examine the relationship between attachment style and BMI in children. Additionally, given that there are several subtypes of insecure attachment, it would be interesting to determine if the relationship between insecure attachment and BMI manifests itself differently based on whether a youth's attachment style is more preoccupied, dismissing, or fearful. The present study will add to Anderson and Whitaker's (2011) findings by examining possible mediators of the relationship between attachment style and body weight, as well as controlling for confounding factors. 
A more recent study examining the quality of the early mother-child relationship found that a poorer mother-child relationship in childhood was associated with a higher prevalence of obesity in adolescence (Anderson, Gooze, Lemeshow, \& Whitaker, 2012). Attachment between mother and infant was assessed at 15, 24, and 36 months of age. Researchers found that insecure attachment during childhood predicted adolescent obesity at 15 years of age $\left(\mathrm{BMI} \geq 95^{\text {th }}\right.$ percentile, $\mathrm{CDC}$ growth reference). Similar results were found by Stenhammar et al. (2010), who used the Relationship Questionnaire (RQ; the attachment measure used in the present study) to measure parental attachment style; parental insecure attachment was associated with overweight in children. In general, studies have shown that the quality of the early mother-child relationship is related to obesity in adolescence (Anderson et al., 2012), but the mechanism is still unknown. Some researchers (Anderson \& Whitaker, 2011) have proposed that poor emotional regulation is the underlying mechanism; however, pediatric studies have not examined potential mediators of the relationship between attachment style and obesity.

There is a paucity of research on the role of attachment in the development of pediatric obesity, and there is only slightly more research in adults. A cross-sectional study looking at a sample of 200 students (65 males and 135 females) with a mean age of 22.4 years found that attachment anxiety was significantly related to higher BMI, and that the relationship was mediated by disinhibited eating, after controlling for age and gender (Wilkinson, Rowe, Bishop, \& Brunstrom, 2010). Disinhibited eating was defined as the failure to maintain dietary restriction, but authors did not specify whether disinhibited eating was in response to emotions or external cues. Wilkinson and colleagues (2010) 
also found that avoidant attachment was not related to higher BMI or disinhibited eating. Authors qualified results by proposing that anxiously attached individuals overexaggerate their emotions and possibly attempt to regulate their emotions externally through eating, whereas avoidantly attached individuals tend to suppress their emotions and therefore do not engage in emotional eating in an attempt to self-regulate. However, authors did not look at differences between the two attachment styles that are characterized by high anxiety, namely preoccupied and fearful, nor did they examine differences between the two attachment styles that are associated with avoidant behaviours: dismissing and fearful. Of note, a fearful attachment style, according to Bartholomew's model of attachment, is characterized by both high anxiety and high avoidance. It would be interesting to see how this attachment style relates to eating behaviour. Moreover, Wilkinson and colleagues (2010) only examined the mediating role of disinhibited eating using the Three-Factor Eating Questionnaire. It is important to examine additional types of disinhibited eating such as emotional or external eating, as well as other types of eating behaviour such as restrained eating.

Furthermore, results from adult studies are not necessarily transferable to a pediatric population. Disinhibited eating has been shown to be a predictor of obesity in adults, but the prevalence of external and restrained eating tend to be higher than emotional eating in the pediatric population (Goldfield et al., 2010a). Because external and restrained eating seem to be more common in children and youth, a novel approach may be to explore several dysregulated eating behaviours in the context of attachment theory. 


\section{Parenting Style, Attachment, and Weight}

Research has demonstrated an association between parenting style and attachment. An authoritative parenting style, characterized by warm involvement, behavioural monitoring, and granting psychological autonomy, is significantly associated with secure attachment across childhood and adolescence (Karavasilis et al., 2003), and is optimal for a child's development of self-efficacy and emotional maturity (Baumrind, 1991; Baumrind, Larzelere, \& Owens, 2010). Conversely, children of parents with an authoritarian (high control, low warmth) or permissive (low control, high warmth) parenting style tend not to develop adequate self-regulatory behaviours or emotional maturity, as these types of parenting styles do not foster the development of healthy coping in the child (Baumrind, 1991; Baumrind et al., 2010).

Parenting styles have also been association with child overweight and obesity. A 10-year follow-up study of a cohort of 1258 Danish students aged 9 to 10 years found that parental neglect, as reported by teachers, significantly increased the risk of obesity (BMI $>95^{\text {th }}$ percentile) in young adulthood by 7 -fold, as compared to children who had harmonious support from parents (Lissau \& Sørensen, 1994). Although not statistically significant, overprotective parental support tended to increase the risk of obesity compared to harmonious support, after controlling for age, sex, baseline BMI, and social background (Lissau \& Sørensen, 1994).

Although parenting styles map onto the theoretical constructs that are relevant to attachment, and have also been shown to predict obesity, parenting style may not be as relevant to the development of overweight and obesity. Parenting style may be more 
relevant in much younger children who are still very reliant on parents, but as children develop, they naturally seek autonomy from their parents, and often rely more on their own cues for behaviour. Hence it may be more appropriate to look at how a youth's individual characteristics contribute to eating behaviour. Attachment style has been shown to be more important than parenting style across age groups in other behaviours, such as externalizing behaviours (Bosmans, Braet, Leeuwen, \& Beyers, 2006). Therefore, it is more relevant to examine how a youth's attachment style contributes to eating behaviour and subsequent weight gain, as it is an individual difference that develops within the family environment and is stable throughout life.

\section{Underweight Youth}

Although less prevalent than overweight and obesity, approximately 3 to $8 \%$ of youth in developing countries are underweight (Jansen et al., 2012). Similar to overweight and obesity, underweight tends to track into adulthood (Greco, Power, \& Peckham, 1995), and is associated with negative health outcomes (Cole, Flegal, Nicholls, \& Jackson, 2007) such as coronary heart disease (Eriksson, Forsen, Tuomilehto, Osmond, \& Barker, 2001), malnutrition, and poorer physical and psychological functioning (Tomlinson \& Landman, 2007).

Research has shown that insecure attachment is associated with eating psychopathology (O’Kearney, 1996; Shanmugam, Jowett, \& Meyer, 2012), and that underweight children tend to have an insecure attachment pattern (Stenhammar et al., 2010; Yalenzuela, 1990). It is therefore possible that insecure attachment in underweight youth may be more strongly associated with dysregulated eating behaviour in the present 
study. One study found that a preoccupied attachment style (insecure) in mothers was significantly associated with underweight in children (Stenhammar et al., 2010).

Although an insecure attachment style may contribute to dysregulated eating behaviours, the pathway by which insecure attachment predicts underweight in youth may be different than the pathway that predicts overweight and obesity. Therefore, the three eating behaviours that are proposed to lead to obesity, may act differently in an underweight sample. For this reason, a sub-sample of underweight youth were examined separately, so as not to confound the results of the primary objectives of the present study.

\section{Summary}

The intricacies of how attachment style influences the development of pediatric overweight and obesity are poorly understood, and there is evidence to support further exploration of this potential etiological pathway. Research examining the role of attachment style and eating behaviour on overweight and obesity is minimal, and is also quite segmented. The present study will strive to connect these two areas of research in hopes of narrowing the research gap on the development of pediatric obesity. If further inquiry reveals that attachment is related to obesity in youth, attachment may be recognized as an etiological factor in the development of obesity. Moreover, if the dysregulated eating behaviours are found to mediate the relationship between attachment and obesity, then it may be necessary to take attachment history, and how it relates to various eating behaviours, into account when designing and implementing prevention and treatment programmes. 


\section{The Present Study}

The etiology of obesity is multifactorial and complex. Since family-based behavioural intervention represents the gold standard treatment, but is only moderately effective (Goldfield, Raynor, \& Epstein, 2002; Skelton, Buehler, Irby, \& Grzywacz, 2012), gaining further understanding of parent-child relationships and family dynamics may improve treatment outcomes. The majority of research on family-related risk factors has focused on family genetic contributors (see Graziano et al., 2010), feeding styles (e.g. using food as rewards, punishment, or bribes, or instructing the child how to eat), (Clark et al., 2007), parenting style (Karavasilis, 2003), food environment in the home (Burke, Beilin, \& Dunbar, 2001), as well as role modelling eating and activity habits (i.e. sedentary versus active lifestyle; Wardle, Guthrie, Sanderson, Birch, \& Plomin, 2001). Although the numerous ways the family environment influences children's eating patterns cannot be ignored, it is also important to examine how individual factors that develop in the family context contribute to the development of overweight and obesity. This is particularly relevant because as children develop and seek autonomy from their parents, individual factors may become more important in regulating healthy and unhealthy behaviours. A relatively understudied individual factor that can contribute to excessive fat accumulation is the self-regulation of energy intake.

Research has recognized the importance of understanding self-regulation skills in relation to obesity development. Even though we already know that impaired selfregulatory behaviours are a risk factor for obesity, without completely understanding which specific domain of self-regulation (i.e. eating behaviour) plays a role in obesity 
development, and how these dysregulated behaviours develop, we cannot begin to target these modifiable risk factors or implement appropriate preventive strategies.

Healthy self-regulatory behaviours begin to develop during infancy (Calkins \& Leerkes, 2004) and are promoted by a healthy attachment relationship between infant and caregiver (Bowlby, 1970; Bruch, 1975). Therefore, it may be useful to conceptualize the development of healthy and unhealthy self-regulated eating behaviours within the broader theoretical framework of attachment theory. As previously discussed, attachment theory posits that the way in which the primary caregiver responds to an infant's cues of distress will help shape the nature of the attachment bond between infant and caregiver (Hazan \& Shaver, 1987).

Hilde Bruch (1975) was the first to describe the importance of the child-parent relationship in the development of self-regulated eating behaviour and how it relates to obesity. Bruch (1975) proposed that the exchange of emotional signals between the infant and mother, as well as the manner in which the mother responds to her child's emotional cues, are fundamental for the infant to develop accurate hunger and satiety awareness. Parallel to attachment theory, if the mother is not attuned to her infant and does not consistently and appropriately soothe her child, the child may develop a confusing concept of hunger, or may not be able to discriminate feelings of hunger, satiety, or other feelings of discomfort such as emotional distress (Bruch, 1975). Bruch (1975) theorized that inconsistent responding by the caregiver over time can result in dysregulation such as not being able to differentiate between biological cues of disturbance, and emotional or interpersonal stress. Similarly, Bruch (1975) suggested that if the caregiver is attuned to 
the infant's needs, and consistently soothes the infant in an appropriate way, the infant will develop healthy regulatory eating behaviours and will be able to discriminate between feelings of hunger, satiety, and emotional distress.

In tandem with self-regulation, three disordered eating behaviours have been postulated to contribute to the development and maintenance of human obesity through poor interoceptive awareness (i.e. inability to detect hunger and satiety): emotional eating, external eating, and restrained eating (van Strien et al., 1986). Recall that emotional and external eating are thought to contribute to obesity through overeating, whereas restrained eating is thought to contribute through dieting and subsequent disinhibited eating (Van Strien \& Ouwens, 2003). Although emotional, external, and restrained eating behaviours have all been linked to obesity, some of the evidence is mixed, and most of the research is in adults. Therefore, further exploration of these maladaptive eating behaviours in youth is needed, as is including all three behaviours in the same model. Impaired self-regulatory behaviours have also been linked to obesity. To date, no pediatric research studies have examined dysregulated eating behaviours within the broader theoretical framework of attachment theory.

Given that rates of pediatric overweight and obesity have increased dramatically over the past 30 years, it is important to examine risk factors that begin earlier in life, in order to better understand what types of treatments and preventive measures might be successful. Because self-regulatory behaviours begin to develop in infancy, and because a secure attachment bond is thought to promote healthy self-regulated eating behaviours, examination of how attachment style relates to overweight and obesity is warranted. It is 
also important to determine if the relationship between attachment style and weight is mediated by dysregulated eating behaviours, and if so, which one: emotional, external, or restrained eating. Inquiry into whether attachment style contributes to the development of overweight and obesity and whether this relationship is mediated by eating behaviour may provide useful information about possible prevention and intervention targets as well as raise awareness to possible barriers to current treatments.

Overall, there is some evidence suggesting that attachment style may contribute to, or increase the risk of, developing overweight and obesity, as well as play a role in the treatment outcomes of obesity. However, the relationship is still poorly understood in youth, and the mechanisms by which attachment style may lead to obesity have yet to be elucidated.

\section{Objectives and Hypotheses}

There is a paucity of research examining if attachment style is related to BMI in youth, and possible mediators of this relationship. Objectives 1 through 4 involve the main sample of normal, overweight, and obese youth, and objective 5 involves a subsample of underweight youth.

- Objective 1: The first objective of this study was to determine if attachment predicts BMI, with and without controlling for several sets of covariates. The first set of covariates includes the socio-demographic variables of age, gender, ethnicity, and SES. The second set of covariates includes the socio-demographic variables mentioned, as well as the psychological and behavioural variables of body esteem, depression, anxiety, and physical activity. 
- Hypothesis 1: It was hypothesized that a secure attachment style will be more strongly associated with lower (healthier) BMIs, and that insecure attachment styles will be associated with higher BMIs.

- Objective 2: The second objective of this study was to determine if the set of eating behaviours (emotional, external, and restrained eating) mediate the relationship between attachment style and BMI with and without controlling for covariates.

- Hypothesis 2: It was hypothesized that the set of eating behaviours (emotional, external, and restrained) would significantly mediate the relationship between attachment style (measured both categorically and continuously) and BMI.

- Objective 3: The third objective was to examine the specific indirect mediating effect of each of the three eating behaviours, while controlling for the other two eating behaviours.

- Hypothesis 3: It was hypothesized that emotional eating would emerge as the strongest independent mediator of attachment style and BMI. It was predicted that youth who scored lower on attachment security would exhibit higher scores on emotional eating behaviours, and that higher scores on emotional eating would be associated with higher BMI.

- Objectives 4 and 5 were exploratory in nature; therefore, no specific hypotheses are stated.

- Objective 4: The fourth objective of the present study was to examine possible moderating effects of socio-demographic variables (age, gender, ethnicity, and SES) on the relationship between attachment style and BMI. 
O Objective 5: The fifth objective of the present study was to examine a small subsample of underweight participants, and test the mediational model of dysregulated eating behaviours in this sample.

\section{Method}

\section{Participants}

Participants in this study included 2482 English-speaking grade 7 to 12 students. The overall sample was comprised of 1048 males (42.2\%) and 1434 females (57.8\%), ranging in age from 11.08 to 20.75 years, with a mean age of 14.10 years $(S D=1.59)$. The final sample size after deleting multivariate outliers and excluding participants in the thinness grades 1 or 2 categories, was $n=2281$, with a mean age of 14.08 years $(S D=1.57$; see results in Table 1 for more information). Data were collected between November 2004 and May 2008 from 31 Ottawa-area schools as part of a larger study: the Research on Eating and Adolescent Lifestyles (REAL) study. Epidemiological research shows that this sample is representative of the Ottawa region, as participants were drawn from public and private urban, suburban, and rural schools (Flament, Henderson, Buchholz, Obeid, Vitoroulis, \& Goldfield, 2013).

\section{Procedure}

All schools within three school boards (Ottawa-Carleton District and Catholic School Boards, and Upper Canada District School Board) and several private schools were invited to participate in the REAL study. The REAL study is a six-year prospective longitudinal study of two cohorts of students. Cross-sectional data are used in the present study. Within each participating school, the principal or representative permitted study 
recruitment in one or several classrooms, based on feasibility. Research staff visited each participating classroom twice, first to present the study, answer questions, and distribute consent forms, then to administer the survey to consenting participants and supervise survey completion. Informed assent and consent was sought from students and parents.

This study has been approved by the research ethics boards at the Children's Hospital of Eastern Ontario, The Royal Ottawa Health Care Group, and the University of Ottawa. Incentives, such as movie gift certificates or a pizza lunch for classrooms with at least a $70 \%$ consent rate, were offered to increase student participation. Students who reported elevated levels of depression or eating disorder symptomatology were followedup with within two weeks of survey completion. Students who endorsed suicidal ideation were provided with appropriate resources, and a clinical research staff ensured that the student was seen within 48 hours.

\section{Measures}

\section{Predictors and outcomes.}

Body mass index. BMI is a measure that is used to estimate an individual's body composition. BMI $\left(\mathrm{kg} / \mathrm{m}^{2}\right)$ was calculated by dividing each patient's weight in kilograms by their respective heights in metres squared. Height and weight were objectively measured by a research staff in a private space using an HM200P Portable Stadiometre (Quick Medical Equipment and Supplies, U.S.A.), and a UC-321 Digital Weighing Scale (Quick Medical Equipment and Supplies, U.S.A.), respectively. Height was measured in centimetres to the nearest $0.1 \mathrm{~cm}$, and weight in kilograms to the nearest $0.1 \mathrm{~kg}$. Participants were asked to remove shoes before measurements were taken. A percentile 
approach according to the IOTF age- and sex-specific cut-offs was used to identify underweight youth under the age of 18 . For instance, youth with a BMI at or above the $16^{\text {th }}$ percentile for sex were analyzed in the main sample, and youth with a BMI lower than the $16^{\text {th }}$ percentile were analyzed as the underweight (thinness grades 1 and 2) sample. For youth older than 18 years, the adult cut-off values were used, so a BMI of $18.5 \mathrm{~kg} / \mathrm{m}^{2}$ or lower was used to define the underweight sample, and above $18.5 \mathrm{~kg} / \mathrm{m}^{2}$ the main sample.

Attachment. The Adolescent Relationship Questionnaire (ARQ) was used to assess attachment (See Appendix A; Bartholomew \& Horowitz, 1991). The ARQ is the same as the Relationship Questionnaire (RQ; Bartholomew \& Horowitz, 1991), but the language has been revised for adolescents (E. Scharfe, personal communication, April 26, 2012). Henceforth, the ARQ will be referred to as the RQ, for clarity. The RQ presents four different items, each reflecting one of the following attachment styles: secure, fearful, preoccupied, or dismissing. The participant is asked to rate each item on a 7-point Likert scale: 1 (not at all like me) to 7 (very much like me). The questionnaire also includes a forced-choice question, where participants are asked to identify one attachment style description that most closely resembles them. Thus, the questionnaire obtains one continuous score for each attachment style, generating an attachment profile. Instead of examining attachment in relation to a specific relationship (i.e. parent, peer, or romantic partner), the RQ has the advantage of assessing attachment style globally. Although the RQ is not the gold standard measure of attachment, it was used in the REAL study because it is relatively brief to administer, is widely used in the literature, and is less 
susceptible to self-deceptive bias compared to other measures of attachment (Attachment Style Questionnaire and the Adult Attachment Scale; Leak \& Parsons, 2001).

The RQ is a widely used measure of global attachment in youth and adults (e.g. D’Argenio et al., 2009; Karavasilis et al., 2003; Lanciano, Curci, Kafetsios, Elia, \& Zammuner, 2012; Matsuoka et al., 2006; Perrine \& King, 2004; Ross, McKim, \& DiTommaso, 2006; Tanaka et al., 2008). It has been used to assess attachment in middle childhood and adolescence, and has demonstrated predictive validity for parenting style in children and adolescents; secure attachment was associated with authoritative parenting (Karavasilis et al., 2003). Another study using the RQ found that attachment anxiety and avoidance were positively associated with depression-related rumination (Lanciano et al., 2012). Overall, many studies have effectively used the RQ, including studies of children and adolescents.

Although some have questioned the reliability of the RQ, the questionnaire has demonstrated good psychometric properties (Bartholomew \& Horowitz, 1991; Griffin \& Bartholomew, 1994; Scharfe \& Bartholomew, 1994). The RQ has demonstrated moderate test-retest reliability over 8 months, with $71 \%$ of females $(k=.42)$ and $61 \%$ of males $(k=$ .20) being judged as stable on the secure/insecure classification (Scharfe \& Bartholomew, 1994). The continuous rating of attachment has also demonstrated test-retest reliability comparable to other methods such as interview with correlations between time 1 and time 2 measures ranging from .39 to .58 (Scharfe \& Bartholomew, 1994). The insecure scales are negatively correlated with secure attachment (Griffin \& Bartholomew, 1994; Karavasilis et al., 2003). The RQ has also been shown to correlate with other measures of 
attachment: the Family Attachment Interview and the Peer Attachment Interview in a sample of undergraduate students (Griffin \& Bartholomew, 1994), as well as the Vulnerable Attachment Style Questionnaire in a sample of adults (Bifulco, Mahon, Kwon, Moran, \& Jacobs, 2003). Further studies have found that the RQ is also correlated with other attachment measures in a sample of 40 Flemish children aged 9 to 12 years (Bosmans, Braet, Soenens, \& Verschuere, 2008, as cited in Bosmans, Braet, Koster, \& De Raedt, 2009).

The RQ can be scored in several ways. A categorical approach can be used such that participants are categorized as either securely attached or insecurely attached (where insecure $=$ fearful, preoccupied, or dismissing). Participants can also be categorized according to their best fitting attachment pattern by classifying them according to the attachment prototype they rated the highest. In the present study, youth were considered securely attached if they circled option A (secure) on the forced choice portion of the RQ (Appendix A), and were considered insecurely attached if they chose either option B (fearful), C (preoccupied), or D (dismissing). If the forced choice question was skipped by the youth, the Likert questions were used to determine attachment style; if youth scored highest on Likert question A, then they were considered securely attached, and if they scored highest on Likert questions B, C, or D, they were considered insecurely attached. In the event of a tie between a secure and insecure Likert score, that participant's data were not used. A continuous attachment score (Total Attachment Style score; TAS) can also be computed from the RQ. Higher scores on the TAS indicate a more secure attachment style, and lower scores indicate a more insecure attachment style 
(Matsuoka et al., 2006). The TAS score is computed by subtracting all insecure scores from the secure score: $(\mathrm{TAS}=$ secure score - fearful score - preoccupied score dismissing score; Liu, 2009; Matsuoka et al., 2006; Tanaka et al., 2008). Attachment will be examined both dichotomously (secure versus insecure) and continuously (TAS score) in the present study.

Eating behaviours. The Dutch Eating Behaviour Questionnaire (DEBQ) is a 33item self-report questionnaire measuring three dimensions of eating: emotional eating (13 items), restrained eating (10 items), and external eating (10 items), (See Appendix B; Van Strien et al., 1986). Each eating dimension is a subscale on the questionnaire. A total subscale score is computed by taking the mean response to the subscale items, which are all rated on a Likert scale ranging from 1 (never) to 5 (very often). Higher scores are indicative of more disordered eating. The emotional eating subscale taps into the tendency to eat in response to negative emotions (van Strien et al., 1986). Restrained eating measures tendency to restrict food intake to control body weight, and external eating assesses the degree to which food cues such as sight and smell trigger eating (van Strien et al., 1986). Example questions include: 'Do you have a desire to eat when you are emotionally upset?' (emotional subscale); 'Do you try to eat less at mealtimes than you would like to eat?' (restrained subscale); and 'If you see others eating, do you also have a desire to eat?' (external subscale). The DEBQ is a reliable and valid measure, with Cronbach alpha coefficients ranging from .79 to .95 (van Strien et al., 1986). All three subscales have high factorial validity (van Strien et al., 1986). Construct and discriminant validity has also been established (Wardle, 1987). The DEBQ has also been validated in 
adolescent girls (Halvarsson \& Sjoden, 1998), and has proven useful among children and adolescents ranging in age from 7 to 17 years (e.g. Goossens, Braet, Van Vlierberghe, \& Mels, 2009; Lattimore \& Halford, 2003). For the sample in the current study, Cronbach's alpha for the emotional eating subscale was .94, Cronbach's alpha for the restrained eating subscale was .92, and external eating was .87. Inter-item correlations for the restrained eating subscale ranged from .31 to .77 . The inter-item correlation on the emotional eating subscale ranged from .36 to .78 , and from .08 to .77 on the external eating subscale.

\section{Covariates.}

Socio-demographics. Age, gender, ethnicity, and SES were included as covariates in the present study (see Appendix C). Age was controlled for as both height and weight tend to increase with normal development (Katzmarzyk et al., 2007). The Canadian Health Measures Survey (Roberts et al., 2012) found that the prevalence of overweight and obese boys exceeded the prevalence of overweight and obese girls, so gender was also controlled for. Ethnic differences in overweight and obesity are well documented in the literature, and were therefore controlled for as well (Ogden et al., 2006). Finally, research has shown that low SES is a risk factor for obesity (Due et al., 2009; Moore \& Cunningham, 2012), and is associated with insecure attachment (Bradley \& Corwyn, 2002), so SES was also controlled for. Because the REAL study does not have data on family/household income, parental education was used as a proxy measure of SES in the present study. SES was dichotomized such that low SES was defined as both parents had not attended college or higher education, and high SES was defined as at least one parent 
had attended college or higher education.

Depression. The Children's Depression Inventory (CDI) is a self-report questionnaire consisting of 27 items reflecting cognitive, affective, and behavioural signs of depression (See Appendix D; Kovacs, 1992). The CDI assesses the severity of depressive symptoms in children 6 to 17 years of age, and is composed of five factors: negative mood, interpersonal difficulties, negative self-esteem, ineffectiveness, and anhedonia (Kovacs, 1992). For each item on the questionnaire children are required to choose one of three statements that best describes them for the past two weeks. For example, a child would be required to choose one of three options: I am sad once in a while; I am sad many times; or I am sad all the time (Kovacs, 1992). Each item is assigned a score from 0 to 2 , with the higher number being attributed to the most depressive statement (Kovacs, 1992). The total score can range from 0 to 54, and is computed by adding the value assigned to each item. This widely used inventory has ample evidence supporting its psychometric properties and displays high internal consistency scores ranging from $r=.71$ to $r=.89$, and test-retest reliability coefficients ranging from $r=.50$ to $r=.83$, with a time interval of two to three weeks, and good concurrent validity (Kovacs, 1992). In the present study, Cronbach's alpha for the total score of the CDI was .89, and inter-item correlations ranged from .04 to .57 .

Anxiety. The Multidimensional Anxiety Scale for Children-10 (MASC-10) is a 10-item, 4-point Likert-style, self-report scale that is a short and efficient global measure of anxiety symptoms (See Appendix E; March \& Sullivan, 1999). The MASC-10 is a unifactorial measure that was designed to tap anxiety symptoms across the four basic anxiety 
dimensions assessed by the original (39-item) MASC (physical symptoms, harm avoidance, social anxiety and separation anxiety/panic; March, Parker, Sullivan, Stallings, \& Conners, 1997). The MASC-10 has demonstrated satisfactory internal reliability and excellent stability in adults and youth (March \& Sullivan, 1999; Osman et al., 2008). Cronbach's alpha in the present sample was .76, and inter-item correlations ranged from .10 to .52 .

Body esteem. The Body Esteem Scale for Adolescents and Adults (BESAA) is comprised of three subscales: (1) general feeling about appearance (appearance esteem); (2) weight satisfaction (weight esteem), and; (3) evaluations attributed to others about body and appearance (attribution; See Appendix F; Mendelson, Mendelson, \& White, 2001). This questionnaire consists of 23 items, each rated on a 5-point Likert scale from 0 (never) to 4 (always). Higher scores indicate more positive body esteem on a particular subscale. The BESAA is valid and reliable in individuals ranging in age from 12 to 25 years (Mendelson et al., 2001). Cronbach's alpha for the appearance esteem, weight esteem, and attribution subscales were $.87, .85$, and .81 , respectively. Inter-item correlations ranged from .04 to .76 for the appearance esteem subscale, from .12 to .82 for the weight esteem subscale, and from .27 to .75 for the evaluations attributed to others subscale.

Physical activity. The Godin Leisure-Time Exercise Questionnaire (GODIN) was used to assess leisure-time exercise (See Appendix G; Godin \& Shephard, 1985). The GODIN is comprised of 4 items asking about intensity and frequency of leisure-time exercise. Higher total leisure-time exercise scores are indicative of more frequent 
exercise. The GODIN is reliable and valid; correlations between subjective and objective data are significant at $r=.38$ for strenuous exercise, $r=.24$ for total exercise and $r=.26$ for self-rating of sweat-inducing exercise (Godin \& Shephard, 1985). Two-week testretest reliability coefficients varied between .46 and .94 (Godin \& Shephard, 1985).

\section{Data Analytic Strategy}

The statistical package for the social sciences (SPSS Inc.) version 20.0 with an alpha level of $p<.05$ was used for all analyses. Frequency and descriptive statistics were used to examine sample demographics. Pearson correlations were used for correlations between two continuous variables, point-biserial correlations between one continuous and one categorical variable, and the phi coefficient was used for two dichotomous variables. Although data were drawn from multiple schools, multilevel modeling was not required as we were only interested in level 1 (individual) data. Three separate analysis of variance (ANOVA) analyses were conducted to examine mean differences in the three dysregulated eating behaviours across the following weight categories: underweight, normal weight, overweight, and obese. Post hoc tests using Hochberg's GT2 and Dunnett's T3 procedures were conducted. Hochberg's GT2 test was used as this test copes well with different sample sizes, and Dunnett's T3 test was used in case population variances differed (Field, 2009). Conclusions between the two tests did not differ.

Given the novelty of the present study, hierarchical regression and multiple mediation analyses were conducted in three stages; first without controlling for covariates, then controlling for socio-demographic covariates only, and finally controlling for socio-demographic, psychological, and behavioural covariates. Moreover, 
analyses were first conducted using dichotomous attachment (secure versus insecure), followed by a continuous measure of attachment (TAS).

To test whether attachment style (dichotomous and continuous) predicted BMI (hypothesis 1), a linear regression was conducted. Subsequent hierarchical regression analyses were conducted when controlling for covariates. To test if the set of eating behaviours (emotional, restrained, and external eating) mediated the relationship between attachment style (dichotomous and continuous) and BMI (hypothesis 2), multiple parallel mediation analyses were performed, with and without covariates in the model. Numerous methods for testing mediational hypotheses have been proposed, and although the causal steps strategy made popular by Baron and Kenny in 1986 was the most commonly used, the bootstrapping approach by Preacher and Hayes is gaining popularity and was utilized in this study as it confers several advantages over the Baron and Kenny method (Preacher \& Hayes, 2008). The main advantage is that bootstrapping is more precise and less biased than the Baron and Kenny Sobel test. A problem with the Sobel test is that it assumes that the product of the $a b$ path is normally distributed, when it is not. The bootstrapping method overcomes this problem.

An advantage of using the multiple mediator model is that the extent to which specific variables mediate the relationship between the predictor and outcome, taking into account the presence of the other mediators in the model, can be determined. Also, when multiple mediators are included in the same model, relative magnitudes of the specific indirect effects associated with all mediators can be determined. In other words, when the three eating behaviours are included in the model simultaneously, we can determine 
which of the three accounts for most of the variance (hypothesis 3). It is important to note that a specific indirect effect in a multiple mediation model is not the same as that mediator's indirect effect in the absence of other mediators; the specific indirect effect of a mediator in the context of multiple mediation is conditional on the inclusion of the other mediators as well as any covariates in the model (Preacher \& Hayes, 2008). This methodological approach will help elucidate which theory of dysregulated eating may be more valid in pediatric obesity: psychosomatic theory (emotional eating), externality theory (external eating), or restraint theory (restrained eating).

Hayes and Preacher (2008) have developed a macro for SPSS (called Indirect) that bootstraps in the multiple mediator case, and generates nonparametric approximate estimates of the sampling distributions of the indirect effects. Ninety-five percent biascorrected and accelerated confidence intervals (BCa 95\% CI) are generated with this method. The Indirect macro allows the independent variable to be dichotomous; therefore attachment can be dichotomized as secure versus insecure, as well at continuous. This macro was used to test hypotheses 2 and 3, and to test the mediational model in the underweight sample (objective 5).

To explore if the socio-demographic variables of age, gender, ethnicity, and SES moderate any of the mediational models (objective 4), several moderated multiple mediation analyses were conducted. Hayes (2013) has more recently developed a macro for SPSS (called Process) that can test for moderated multiple mediation by generating 95\% BCa CIs using bootstrapping. This method generates estimates of the total indirect effect and specific indirect effects at different levels of the moderator. Both the Indirect 
and Process macros are available at the following website: http://afhayes.com/spss-sasand-mplus-macros-and-code.html. All analyses were conducted with transformed and untransformed variables, where warranted. Because overall pattern of results did not differ, results using untransformed variables are presented to maintain interpretability of the findings.

\section{Results}

\section{Data Cleaning}

Univariate outliers and normality. All variables of interest were assessed for univariate outliers, skewness, and kurtosis. Univariate outliers were identified by visually examining distributions as well as assessing standardized scores. Outliers on BMI (7 outliers), the CDI (3 outliers), and the GODIN (11 outliers) were identified and adjusted to one value above the next closest non-outlying score (Field, 2009; Tabachnick \& Fidell, 2007). All scores appeared connected to the distribution after adjusting outliers. Outliers on the appearance and weight esteem subscales of the BESAA, and the restrained and emotional eating subscales of the DEBQ, were not adjusted as all scores appeared connected to the distribution. No outliers were identified on the attribution subscale of the BESAA, the external eating subscale of the DEBQ, and the MASC.

Although skewness and kurtosis are typically assessed by dividing each value by its respective standard error and examining its significance, in large samples (200 or more) it is more appropriate to visually examine the distribution for skewness and kurtosis, as larger samples result in small standard errors (Field, 2009; Tabachnick \& Fidell, 2007). For this reason, variables of interest were visually assessed for skewness 
and kurtosis. The BESAA appearance subscale was slightly negatively skewed and was improved using a reflection and square root transformation. The DEBQ restrained and emotional eating subscales, along with the CDI and GODIN distributions were all positively skewed, and were improved by conducting square root transformations. The appearance and attribution subscales of the BESAA were only slightly negatively skewed and were therefore left as is. The DEBQ external eating subscale and MASC distributions were approximately normal and were also left unadjusted.

The TAS score was computed by subtracting all insecure scores on the RQ from the secure value. Because this resulted in some negative values, TAS was linearly transformed to render all scores positive. Four minor outliers were identified, but were left as is as they did not appear disconnected from the distribution. The distribution appeared slightly negatively skewed, but improved after a reflection and square root transformation.

Linearity and homoscedasticity. Linearity was examined between the predictor variable of attachment style (dichotomous and continuous) and the outcome variable of BMI using a standardized scatterplot of ŷ plotted against residuals $(y-\hat{y})$. Linearity was also examined between all predictor variables and the outcome variable of BMI using scatterplots. It did not appear that the assumption of linearity was violated. Homoscedasticity was assessed by examining several normal p-p plots. Based on these plots, the normality of residuals assumption holds.

Multivariate outliers. A linear regression was conducted with untransformed and transformed variables of interest, and with dichotomous and continuous attachment, in 
order to identify multivariate outliers. Multivariate outliers associated with untransformed variables were excluded from all analyses involving untransformed variables, and multivariate outliers associated with transformed variables were excluded from analyses involving transformed variables. A cut-off value of $\chi^{2}(14)=36.12, p=.001$ (Tabachnick \& Fidell, 2007) was used as there were fourteen variables of interest. Given the large sample size and small number of multivariate outliers (ten), multivariate outliers associated with dichotomous and continuous attachment were excluded from respective analyses to minimize any distortion of the results. Participants who were in the thinness grades 1 or 2 categories (underweight sample) were analyzed separately to avoid skewing the results.

\section{Main Analyses}

Descriptive characteristics of the main sample are presented in Tables 1 and 2.

Table 1

Descriptives of the Final Sample for Categorical Variables

\begin{tabular}{lc}
\hline \multicolumn{1}{c}{ Indicator } & $n(\%)$ \\
\hline Gender $(n=2281)$ & $966(42.3)$ \\
$\quad$ Male & $1315(57.7)$ \\
Female & \\
Parental Education (proxy measure of SES) $(n=1931)$ & $248(12.8)$ \\
$\quad$ Neither parent completed college or higher & $1683(87.2)$ \\
$\quad$ At least one parent complete college or higher & \\
Ethnicity $(n=2238)$ & $1619(72.3)$ \\
$\quad$ White-Caucasian & $619(27.7)$ \\
Other & \\
Attachment style $(n=2177)$ & $1568(72.0)$ \\
Secure & $609(28.0)$ \\
Insecure &
\end{tabular}

Note. Underweight sample was excluded. SES = socioeconomic status. 
Table 2

Descriptives of the Final Sample for Continuous Variables

\begin{tabular}{lcccc}
\hline \multicolumn{1}{c}{ Indicator } & $n$ & $M$ & $S D$ & Range \\
\hline Age (years) & 2281 & 14.08 & 1.57 & $11.08-20.58$ \\
Body mass index $\left(\mathrm{kg} / \mathrm{m}^{2}\right)$ & 2281 & 21.35 & 3.51 & $15.61-35.95$ \\
Eating behaviours (DEBQ) & & & & \\
$\quad$ Restrained & 2273 & 1.70 & .72 & $1.0-5.0$ \\
$\quad$ Emotional & 2275 & 1.74 & .76 & $1.0-5.0$ \\
$\quad$ External & 2274 & 2.61 & .76 & $1.0-5.0$ \\
Body esteem (BESAA) & & & & \\
$\quad$ Appearance & 2240 & 3.56 & .75 & $1.0-5.0$ \\
$\quad$ Weight & 2238 & 3.85 & .81 & $1.0-5.0$ \\
$\quad$ Attribution & 2236 & 3.45 & .82 & $1.0-5.0$ \\
Depression (CDI) & 2184 & 7.77 & 6.88 & $0-39.0$ \\
Anxiety (MASC) & 2135 & 9.96 & 5.15 & $0-27.0$ \\
Physical activity (GODIN) & 2024 & 62.08 & 37.66 & $0-262.0$ \\
Attachment (TAS) & 2158 & 16.86 & 4.11 & $1.0-23.0$ \\
\hline
\end{tabular}

Note. Underweight sample was excluded. DEBQ = Dutch Eating Behavior Questionnaire; BESAA = Body Esteem Scale for Adults and Adolescents; CDI = Children's Depression Inventory; MASC = Multidimensional Anxiety Scale for Children; GODIN = Godin Leisure-Time Exercise Questionnaire; TAS = Total Attachment Style Score as derived from the Relationship Questionnaire.

Bivariate correlations between the variables were examined and these are presented in Tables 3 and 4 for dichotomous and continuous attachment, respectively. Because none of the correlations exceeded .90 , it is unlikely that the assumption of no multicollinearity was violated (Field, 2009). 
Table 3

Correlations between Dichotomous Attachment and Untransformed Variables of Interest of the Final Sample

\begin{tabular}{|c|c|c|c|c|c|c|c|c|c|c|c|c|c|c|}
\hline & 1 & 2 & 3 & 4 & 5 & 6 & 7 & 8 & 9 & 10 & 11 & 12 & 13 & 14 \\
\hline 1. Attachment & - & & & & & & & & & & & & & \\
\hline 2. BMI & $.075^{* * *}$ & - & & & & & & & & & & & & \\
\hline 3. Age & $.108^{* * *}$ & $.260^{* * *}$ & - & & & & & & & & & & & \\
\hline 4. Gender & -.034 & -.011 & -.035 & - & & & & & & & & & & \\
\hline 5. Ethnicity & .010 & .004 & .013 & .026 & - & & & & & & & & & \\
\hline 6. SES & $-.055^{*}$ & $-.081^{* * *}$ & $-.117^{* * *}$ & $.053^{*}$ & -.007 & - & & & & & & & & \\
\hline 7. BESAA-A & $-.285^{* * *}$ & $-.196^{* * *}$ & $-.117^{* * * *}$ & $.273^{* * *}$ & $.045^{*}$ & $.052^{*}$ & - & & & & & & & \\
\hline 8. BESAA-W & $-.252^{* * *}$ & $-.407^{* * *}$ & $-.149^{* * *}$ & $.248^{* * *}$ & .027 & $.091^{* * *}$ & $.728^{* * *}$ & - & & & & & & \\
\hline 9. BESAA-At & $-.129^{* * *}$ & $-.107^{* * *}$ & -.009 & .012 & .008 & .026 & $.205^{* * *}$ & $.289^{* * *}$ & - & & & & & \\
\hline 10. DEBQ-R & $.154^{* * *}$ & $.313^{* * *}$ & $.097^{* * *}$ & $-.247^{* * *}$ & .039 & .004 & $-.488^{* * *}$ & $-.623^{* * *}$ & -.015 & - & & & & \\
\hline 11. DEBQ-Ex & $.085^{* * *}$ & $-.072^{* * *}$ & $.276^{* * *}$ & $-.043^{*}$ & .039 & $.046^{*}$ & $-.228^{* * *}$ & $-.112^{* * *}$ & $.067^{* * *}$ & $.076^{* * *}$ & - & & & \\
\hline 12. DEBQ-Em & $.179^{* * *}$ & $.051^{*}$ & $.215^{* * *}$ & $-.301^{* * *}$ & -.021 & -.040 & $-.393^{* * *}$ & $-.312^{* * *}$ & .014 & $.302^{* * *}$ & $.540^{* * *}$ & - & & \\
\hline 13. CDI & $.391^{* * *}$ & $.110^{* * *}$ & $.168^{* * *}$ & $-.129^{* * *}$ & .011 & $-.115^{* * *}$ & $-.579^{* * *}$ & $-.495^{* * *}$ & $-.242^{* * *}$ & $.311^{* * *}$ & $.190^{* * *}$ & $.340^{* * *}$ & - & \\
\hline 14. MASC & $.226^{* * *}$ & .014 & .029 & $-.280^{* * *}$ & -.005 & .000 & $-.401^{* * *}$ & $-.319^{* * *}$ & $-.110^{* * *}$ & $.315^{* * *}$ & $.213^{* * *}$ & $.367^{* * *}$ & $.363^{* * *}$ & - \\
\hline 15. GODIN & $-.075^{* * *}$ & -.005 & $-.057^{* *}$ & $.191^{* * *}$ & $-.049^{*}$ & .036 & $.108^{* * *}$ & $.092^{* * *}$ & $.107^{* * *}$ & -.016 & -.028 & $-.088^{* * *}$ & $-.082^{* * *}$ & $-.128^{* * *}$ \\
\hline
\end{tabular}

Note. Participants in the underweight sample were excluded. Attachment $(0=$ secure; $1=$ insecure $) ; \mathrm{BMI}=$ body $\mathrm{mass}$ index $\left(\mathrm{kg} / \mathrm{m}^{2}\right)$; age in years; gender $(0=$ female; $1=$ male $)$; ethnicity $(1=$ White; $2=$ Other $)$; SES $=$ socioeconomic status $(0=10 w ; 1=$ high $)$;

BESAA-A = Body Esteem Scale for Adolescents and Adults - appearance esteem subscale; BESAA-W = weight esteem subscale; BESSA-At $=$ attribution subscale; DEBQ-R $=$ Dutch Eating Behavior Questionnaire - restrained eating subscale; DEBQ-Ex $=$ external eating subscale; DEBQ-Em = emotional eating subscale; CDI = Children's Depression Inventory; MASC = Multidimensional Anxiety Scale for Children; GODIN = Godin Leisure-Time Exercise Questionnaire.

$* p \leq .05$, two-tailed. $* * p \leq .01$, two-tailed. $* * * p \leq .001$, two-tailed. 
Table 4

Correlations between Continuous Attachment and Untransformed Variables of Interest of the Final Sample

\begin{tabular}{|c|c|c|c|c|c|c|c|c|c|c|c|c|c|c|}
\hline & 1 & 2 & 3 & 4 & 5 & 6 & 7 & 8 & 9 & 10 & 11 & 12 & 13 & 14 \\
\hline 1. TAS & - & & & & & & & & & & & & & \\
\hline 2. BMI & $-.060^{* *}$ & - & & & & & & & & & & & & \\
\hline 3. Age & $-.093^{* * *}$ & $.261^{* * *}$ & - & & & & & & & & & & & \\
\hline 4. Gender & .003 & -.010 & -.033 & - & & & & & & & & & & \\
\hline 5. Ethnicity & .011 & .003 & .010 & .027 & - & & & & & & & & & \\
\hline 6. SES & .021 & $-.074^{* * *}$ & $-.112^{* * *}$ & $.052^{*}$ & -.001 & - & & & & & & & & \\
\hline 7. BESAA-A & $.387^{* * *}$ & $-.195^{* * *}$ & $-.117^{* * *}$ & $.273^{* * *}$ & $.043^{*}$ & $.046^{*}$ & - & & & & & & & \\
\hline 8. BESAA-W & $.326^{* * *}$ & $-.406^{* * *}$ & $-.148^{* * *}$ & $.248^{* * *}$ & .025 & $.087^{* * *}$ & $.729^{* * *}$ & - & & & & & & \\
\hline 9. BESAA-At & $.179^{* * *}$ & $-.110^{* * *}$ & -.011 & .014 & .005 & .030 & $.208^{* * *}$ & $.291^{* * *}$ & - & & & & & \\
\hline 10. DEBQ-R & $-.204^{* * *}$ & $.310^{* * *}$ & $.099^{* * *}$ & $-.246^{* * *}$ & .038 & .007 & $-.485^{* * *}$ & $-.620^{* * *}$ & -.014 & - & & & & \\
\hline 11. DEBQ-Ex & $-.141^{* * *}$ & $-.072^{* * *}$ & $.272^{* * *}$ & $-.043^{*}$ & .039 & $.049^{*}$ & $-.230^{* * *}$ & $-.116^{* * *}$ & $.063^{* *}$ & $.075^{* * *}$ & - & & & \\
\hline 12. DEBQ-Em & $-.223^{* * *}$ & $.052^{*}$ & $.210^{* * *}$ & $-.301^{* * *}$ & -.024 & -.036 & $-.394^{* * *}$ & $-.314^{* * *}$ & .012 & $.305^{* * *}$ & $.538^{* * *}$ & - & & \\
\hline 13. CDI & $-.520^{* * *}$ & $.114^{* * *}$ & $.167^{* * *}$ & $-.129^{* * *}$ & .013 & $-.113^{* * *}$ & $-.582^{* * *}$ & $-.499^{* * *}$ & $-.244^{* * *}$ & $.313^{* * *}$ & $.192^{* * *}$ & $.339^{* * *}$ & - & \\
\hline 14. MASC & $-.329^{* * *}$ & .017 & .027 & $-.280^{* * *}$ & -.004 & .002 & $-.404^{* * *}$ & $-.323^{* * *}$ & $-.112^{* * *}$ & $.317^{* * *}$ & $.214^{* * *}$ & $.367^{* * *}$ & $.364^{* * * *}$ & - \\
\hline 15. GODIN & $.056^{*}$ & -.007 & $-.058^{* *}$ & $.188^{* * *}$ & $-.049^{*}$ & .028 & $.110^{* * *}$ & $.093^{* * *}$ & $.107^{* * *}$ & -.019 & -.025 & $-.085^{* * *}$ & $-.083^{* * *}$ & $-.128^{* * *}$ \\
\hline
\end{tabular}

Note. Participants in the underweight sample were excluded. TAS = Total Attachment Style Score as derived from the Relationship Questionnaire (lower scores = less secure); BMI = body mass index $\left(\mathrm{kg} / \mathrm{m}^{2}\right)$; age in years; gender $(0=$ female; $1=$ male $)$; ethnicity $(1$ $=$ White; 2 = Other $)$ SES = socioeconomic status $(0=$ low; $1=$ high $)$; BESAA-A = Body Esteem Scale for Adolescents and Adults appearance esteem subscale; BESAA-W = weight esteem subscale; BESSA-At = attribution subscale; DEBQ-R = Dutch Eating Behavior Questionnaire - restrained eating subscale; DEBQ-Ex = external eating subscale; DEBQ-Em = emotional eating subscale; $\mathrm{CDI}=$ Children's Depression Inventory; MASC = Multidimensional Anxiety Scale for Children; GODIN = Godin Leisure-Time Exercise Questionnaire.

${ }^{*} p \leq .05$, two-tailed. $* * p \leq .01$, two-tailed. $* * * p \leq .001$, two-tailed. 
Results of the three one-way ANOVAs are presented in Table 5. There was a significant effect of restrained eating across weight categories, $F(3,2421)=57.76, p<$ .001 , and a significant effect of external eating across weight categories, $F(3,2423)=$ $20.14, p<.001$. There was no statistically significant effect of emotional eating across weight categories, $F(3,2424)=1.21, p=.31$. Post-hoc comparisons revealed that restrained eating was lowest in the underweight group, and increased significantly across groups. The opposite trend was observed for external eating, where post-hoc comparisons showed that external eating was highest in the underweight group, followed by the normal weight group. External eating was lowest in the overweight and obese groups, and external eating scores did not differ significantly between the higher weight groups.

Table 5

Means and (Standard Deviations) of Three Eating Behaviours by Weight Category

\begin{tabular}{ccccc}
\hline Eating behaviour & Underweight & Normal weight & Overweight & Obese \\
\hline Restrained & $1.27^{*}(.34)$ & $1.62^{+}(.69)$ & $1.90^{\dagger}(.75)$ & $2.15^{\S}(.81)$ \\
External & $2.88^{*}(.72)$ & $2.67^{+}(.75)$ & $2.49^{\dagger}(.75)$ & $2.30^{\dagger}(.73)$ \\
Emotional & $1.81(.73)$ & $1.75(.78)$ & $1.70(.74)$ & $1.70(.84)$ \\
\hline
\end{tabular}

Note. The different symbols $\left({ }^{*+\dagger \S}\right)$ indicate significant differences between groups. Standard deviations are presented in parentheses. $p<.01$.

\section{Attachment as a Predictor of Body Mass Index (Objective 1)}

Recall that analyses were conducted without controlling for any covariates, controlling for socio-demographic variables, and finally controlling for sociodemographic (age, gender, ethnicity, and SES), psychological, and behavioural variables (body esteem, depression, anxiety, and physical activity). 
The primary hypothesis of this study was that attachment style would predict BMI, such that insecure attachment would more strongly predict unhealthy or higher BMIs, and secure attachment would predict lower, healthy BMIs.

Dichotomous attachment. Results of a simple linear regression indicate that dichotomous attachment significantly predicts BMI, $F(1,2175)=12.26, p<.001$, with $R^{2}$ at .006 (adjusted $R^{2}=.005$ ). Specifically, youth with an insecure attachment style had higher BMIs compared to youth with a secure attachment style, $B=.587, S E=.168$, $t(2175)=3.50, p<.001,95 \% \mathrm{CI}=[.258, .916], s r^{2}=.006$.

The relationship between attachment style and BMI holds even after controlling for the socio-demographic variables of age, gender, ethnicity, and SES, $F(1,1826)=$ $33.76, p<.001, R^{2}=.085$ (adjusted $R^{2}=.082$ ). Although statistically significant, attachment only uniquely contributed approximately $0.24 \%$ of the variance in this model, $B=.394, S E=.178, t(1826)=2.209, p=.027,95 \% C I=[.044, .743], s r^{2}=.0024$. Results are presented in Table 6. 
Table 6

Hierarchical Multiple Regression Analysis Predicting BMI from Dichotomous Attachment

\begin{tabular}{lccccccc}
\hline & $B$ & $S E$ & $\beta$ & $t$ & $p$ & $95 \%$ CI & $s r^{2}$ \\
\hline Block 1 & & & & & & & \\
\hline Age & .599 & .049 & .275 & 12.146 & $<.001$ & {$[.503, .696]$} & .0740 \\
Gender & .095 & .160 & .013 & .595 & .552 & {$[-.218, .408]$} & .0002 \\
Ethnicity & .120 & .179 & .015 & .670 & .503 & {$[-.231, .471]$} & .0002 \\
SES & -.584 & .241 & -.055 & -2.424 & .015 & {$[-1.057,-.112]$} & .0029 \\
\hline Block 2 & & & & & & & \\
\hline Age & .586 & .050 & .268 & 11.792 & $<.001$ & {$[.488, .683]$} & .0697 \\
Gender & .100 & .160 & .014 & .627 & .531 & {$[-.213, .413]$} & .0002 \\
Ethnicity & .126 & .179 & .016 & .704 & .482 & {$[-.225, .476]$} & .0003 \\
SES & -.566 & .241 & -.053 & -2.348 & .019 & {$[-1.038,-.093]$} & .0028 \\
Attachment & .394 & .178 & .050 & 2.209 & .027 & {$[.044, .743]$} & .0024 \\
\hline
\end{tabular}

Note: Participants in the underweight sample were excluded. Control variables include age (years), gender $(0=$ female; $1=$ male $)$, ethnicity $(1=$ White; $2=$ Other $)$, and SES = socioeconomic status $(0=$ low; $1=$ high $)$; attachment $(0=$ secure and $1=$ insecure $) ; C I=$ confidence interval; $s r^{2}=$ squared semi-partial correlation.

Although the overall model was still significant once psychological and behavioural correlates (body esteem, anxiety, depression, and physical activity) were entered in the model, $F(1,1588)=53.58, p<.001$, with $R^{2}$ at .271 , attachment style no longer significantly predicted BMI $B=.00, S E=.187, t(1588)=-.002, p=.999,95 \% C I$ $=[-.367, .367], s r^{2}=.00$. 
Table 7

Hierarchical Multiple Regression Analysis Predicting BMI from Dichotomous Attachment

\begin{tabular}{|c|c|c|c|c|c|c|c|}
\hline & $B$ & $S E$ & $\beta$ & $t$ & $p$ & $95 \% \mathrm{CI}$ & $s r^{2}$ \\
\hline \multicolumn{8}{|l|}{ Block 1} \\
\hline Age & .609 & .053 & .277 & 11.43 & $<.001$ & {$[.505, .714]$} & .0751 \\
\hline Gender & .196 & .170 & .028 & 1.153 & .249 & {$[-.137, .529]$} & .0008 \\
\hline Ethnicity & .101 & .190 & .013 & .531 & .595 & {$[-.272, .474]$} & .0002 \\
\hline SES & -.604 & .258 & -.057 & -2.337 & .020 & {$[-1.111,-.097]$} & .0031 \\
\hline \multicolumn{8}{|l|}{ Block 2} \\
\hline Age & .491 & .049 & .223 & 10.097 & $<.001$ & {$[.396, .586]$} & .0467 \\
\hline Gender & .637 & .164 & .090 & 3.874 & $<.001$ & {$[.314, .959]$} & .0069 \\
\hline Ethnicity & .163 & .171 & .021 & .956 & .339 & {$[-.171, .498]$} & .0004 \\
\hline SES & -.468 & .233 & -.044 & -2.009 & .045 & {$[-.924,-.011]$} & .0018 \\
\hline BESAA-A & .739 & .162 & .158 & 4.566 & $<.001$ & {$[.422,1.057]$} & .0096 \\
\hline BESAA-W & -2.507 & .141 & -.584 & -17.810 & $<.001$ & {$[-2.783,-2.231]$} & .1459 \\
\hline BESAA-At & -.007 & .098 & -.002 & -.075 & .940 & {$[-.200, .186]$} & .0000 \\
\hline MASC & -.049 & .017 & -.070 & -2.906 & .004 & {$[-.081,-.016]$} & .0038 \\
\hline CDI & -.045 & .014 & -.089 & -3.186 & .001 & {$[-.073,-.017]$} & .0046 \\
\hline GODIN & .003 & .003 & .035 & 1.562 & .118 & {$[-.001, .007]$} & .0011 \\
\hline \multicolumn{8}{|l|}{ Block 3} \\
\hline Age & .491 & .049 & .223 & 10.077 & $<.001$ & {$[.395, .586]$} & .0467 \\
\hline Gender & .637 & .165 & .090 & 3.862 & $<.001$ & {$[.313, .960]$} & .0069 \\
\hline Ethnicity & .163 & .171 & .021 & .955 & .340 & {$[-.172, .498]$} & .0004 \\
\hline SES & -.468 & .233 & -.044 & -2.009 & .045 & {$[-.924,-.092]$} & .0018 \\
\hline BESAA-A & .739 & .162 & .158 & 4.561 & $<.001$ & {$[.421,1.057]$} & .0096 \\
\hline BESAA-W & -2.507 & .141 & -.584 & -17.798 & $<.001$ & {$[-2.783,-2.231]$} & .1452 \\
\hline BESAA-At & -.007 & .098 & -.002 & -.075 & .940 & {$[-.201, .186]$} & .0000 \\
\hline MASC & -.049 & .017 & -.070 & -2.892 & .004 & {$[-.082,-.016]$} & .0038 \\
\hline CDI & -.045 & .015 & -.089 & -3.077 & .002 & {$[-.074,-.016]$} & .0044 \\
\hline GODIN & .003 & .002 & .035 & 1.561 & .119 & {$[-.001, .007]$} & .0011 \\
\hline Attachment & .000 & .187 & .000 & -.002 & .999 & {$[-.367, .367]$} & .0000 \\
\hline
\end{tabular}

Note: Underweight participants were excluded. Control variables include age, gender (0 $=$ female; $1=$ male $)$, ethnicity $(1=$ White; $2=$ Other $)$ SES $=$ socioeconomic status $(0=$ low; 1 = high), BESAA-A = Body Esteem Scale for Adolescents and Adults - appearance esteem subscale; BESAA-W = weight esteem subscale; BESSA-At $=$ attribution subscale; MASC = Multidimensional Anxiety Scale for Children; CDI = Children's Depression Inventory; GODIN = Godin Leisure-Time Exercise Questionnaire; attachment ( secure $=0$ versus insecure $=1) ; C I=$ confidence interval; $s r^{2}=$ squared semipartial correlation. 
Continuous attachment. Continuous attachment (TAS) scores ranged from 1 to 23 , and had a mean of $16.86(S D=4.11)$. TAS was also found to significantly predict BMI, $F(1,2156)=7.72, p=.006$, with $R^{2}$ at .004 , and adjusted $R^{2}$ at .003 . Recall that lower scores on TAS are indicative of less secure attachment. Youth with lower scores on TAS were more likely to have higher BMI values than more securely attached youth, $B=$ $-.051 S E=.018, t(2156)=-2.78, p=.006,95 \% \mathrm{CI}=[-.087,-.015], s r^{2}=.0036$. For every unit increase on the TAS scale, that is, moving toward secure attachment, BMI decreases by $.051 \mathrm{~kg} / \mathrm{m}^{2}$.

The relationship between attachment style and BMI holds even after controlling for the socio-demographic variables of age, gender, ethnicity, and SES, $F(1,1814)=$ $33.83, p<.001, R^{2}=.085$, (adjusted $\left.R^{2}=.083\right)$. Insecure attachment was associated with higher BMIs, $B=-.042, S E=.019, t(1814)=-2.189, p=.029,95 \% C I=[-.080,-.004]$, $s r^{2}=.0024$. Even though this was statistically significant, attachment style only uniquely contributed $0.24 \%$ of the variance.

The overall model remained significant after controlling for socio-demographic variables, as well as psychological and behavioural covariates, $F(1,1577)=51.57, p<$ $.001, R^{2}=.265$ (adjusted $R^{2}=.259$ ), but attachment did not contribute over and above the socio-demographic, psychological, and behavioural predictors, $B=-.001, S E=.022$, $t(1577)=-.037, p=.971,95 \% C I=[-.045, .043], s r^{2}=.0000$ (see Table 8). 
Table 8

Hierarchical Multiple Regression Analysis Predicting BMI from Continuous Attachment

\begin{tabular}{|c|c|c|c|c|c|c|c|}
\hline & $B$ & $S E$ & $\beta$ & $t$ & $p$ & $95 \% \mathrm{CI}$ & $s r^{2}$ \\
\hline \multicolumn{8}{|l|}{ Block 1} \\
\hline Age & .617 & .053 & .283 & 11.64 & $<.001$ & {$[.513, .721]$} & .0784 \\
\hline Gender & .202 & .169 & .029 & 1.196 & .232 & {$[-.129, .533]$} & .0008 \\
\hline Ethnicity & .088 & .189 & .011 & .466 & .641 & {$[-.282, .458]$} & .0001 \\
\hline SES & -.433 & .257 & -.042 & -1.723 & .085 & {$[-.948, .061]$} & .0017 \\
\hline \multicolumn{8}{|l|}{ Block 2} \\
\hline Age & .501 & .049 & .229 & 10.307 & $<.001$ & {$[.405, .596]$} & .0497 \\
\hline Gender & .630 & .164 & .090 & 3.835 & $<.001$ & {$[.308, .952]$} & .0069 \\
\hline Ethnicity & .128 & .170 & .016 & .753 & .451 & {$[-.205, .462]$} & .0003 \\
\hline SES & -.344 & .233 & -.032 & -1.481 & .139 & {$[-.801, .112]$} & .0010 \\
\hline BESAA-A & .734 & .161 & .159 & 4.551 & $<.001$ & {$[.418,1.051]$} & .0096 \\
\hline BESAA-W & -2.444 & .141 & -.574 & -17.371 & $<.001$ & {$[-2.720,-2.168]$} & .1406 \\
\hline BESAA-At & -.013 & .099 & -.003 & -.127 & .899 & {$[-.206, .181]$} & .0000 \\
\hline MASC & -.049 & .017 & -.071 & -2.905 & .004 & {$[-.081,-.016]$} & .0040 \\
\hline CDI & -.044 & .014 & -.086 & -3.087 & .002 & {$[-.072,-.016]$} & .0045 \\
\hline GODIN & .003 & .002 & .029 & 1.284 & .199 & {$[-.001, .007]$} & .0008 \\
\hline \multicolumn{8}{|l|}{ Block 3} \\
\hline Age & .501 & .049 & .229 & 10.298 & $<.001$ & {$[.405, .596]$} & .0493 \\
\hline Gender & .629 & .166 & .090 & 3.779 & $<.001$ & {$[.303, .956]$} & .0067 \\
\hline Ethnicity & .128 & .170 & .016 & .754 & .451 & {$[-.206, .462]$} & .0003 \\
\hline SES & -.345 & .233 & -.033 & -1.480 & .139 & {$[-.802, .112]$} & .0010 \\
\hline BESAA-A & .735 & .162 & .159 & 4.541 & $<.001$ & {$[.417,1.052]$} & .0096 \\
\hline BESAA-W & -2.444 & .141 & -.574 & -17.361 & $<.001$ & {$[-2.720,-2.168]$} & .1406 \\
\hline BESAA-At & -.012 & .099 & -.003 & -.124 & .901 & {$[-2.06, .182]$} & .0000 \\
\hline MASC & -.049 & .017 & -.071 & -2.861 & .004 & {$[-.082,-.015]$} & .0038 \\
\hline CDI & -.044 & .015 & -.087 & -2.885 & .004 & {$[-.074,-.014]$} & .0038 \\
\hline GODIN & .003 & .002 & .029 & 1.284 & .199 & {$[-.001, .007]$} & .0008 \\
\hline TAS & -.001 & .022 & -.001 & -.037 & .971 & {$[-.045, .043]$} & .0000 \\
\hline
\end{tabular}

Note: Underweight participants were excluded. Control variables include age, gender (0 $=$ female; $1=$ male $)$, ethnicity $(1=$ White; $2=$ Other $)$ SES $=$ socioeconomic status $(0=$ low; 1 = high), BESAA-A = Body Esteem Scale for Adolescents and Adults - appearance esteem subscale; BESAA-W = weight esteem subscale; BESSA-At = attribution subscale; MASC $=$ Multidimensional Anxiety Scale for Children; CDI $=$ Children's Depression Inventory; GODIN = Godin Leisure-Time Exercise Questionnaire; TAS = Total Attachment Style Score as derived from the Relationship Questionnaire (lower scores $=$ less secure); $C I=$ confidence interval; $s r^{2}=$ squared semi-partial correlation. 


\section{Parallel Multiple Mediation Analyses (Objectives 2 and 3)}

To investigate whether emotional, external, or restrained eating mediate the relationship between attachment style and BMI, six multiple parallel mediation analyses (Preacher \& Hayes, 2008) were conducted with dichotomous (models 1a, 2a, 3a) and continuous (models 1b, 2b, 3b) attachment. Models 1a and 1b did not control for any covariates; models $2 \mathrm{a}$ and $2 \mathrm{~b}$ controlled for the socio-demographic variables of age, gender, ethnicity, and SES; and models $3 \mathrm{a}$ and $3 \mathrm{~b}$ controlled for socio-demographic variables as well as the psychological and behavioural covariates of body esteem, depression, anxiety, and physical activity.

Dichotomous attachment. Boostrapped estimates for the total indirect effect and specific indirect effects, as well as BCa 95\% CIs are presented in Table 9. The total indirect effect of attachment style on BMI through the set of dysregulated eating behaviours (model 1a) was significant, $F(4,2159)=65.15, p<.001$, with $R^{2}=.108$ (adjusted $\left.R^{2}=.106\right)$. The total indirect effect remained significant after controlling for socio-demographic variables (age, gender, ethnicity, and SES; model 2a), $F(8,1813)=$ 57.09, $p<.001$, with $R^{2}=.201$ (adjusted $\left.R^{2}=.198\right)$.

In models $1 \mathrm{a}$ and $2 \mathrm{a}$, the specific indirect effects of restrained eating and external eating were significant, as demonstrated by BCa 95\% CIs that did not contain zero. Emotional eating was not significant. Results of model 1a will not be formally discussed because model $2 \mathrm{a}$ is more robust as it controlled for socio-demographic factors. In model 2a, restrained eating was a significant mediator such that insecure attachment was positively related to increased restrained eating behaviour $(B=.26)$, which was positively 
related to increased BMI $(B=1.51)$. External eating was also a significant mediator such that insecure attachment was positively related to increased external eating $(B=.09)$, which, in turn, was negatively associated with BMI $(B=-.84)$. Pairwise contrasts of the specific indirect effects were also conducted to test if two specific indirect effects are equal in size. Restrained eating was a significantly stronger mediator than external eating, which, in turn, was significantly stronger than emotional eating (see Table 9).

When socio-demographic, psychological, and behavioural correlates were controlled for (model 3a), the overall model was significant $F(14,1579)=48.06, p<$ $.001, R^{2}=.299$ (adjusted $R^{2}=.293$ ), but the total indirect effect of attachment on BMI was no longer statistically significant as the BCa 95\% CI contained zero. Even though the total indirect effect was not significant in model 3a, it is still possible to have significant specific indirect effects, so these were examined next (Preacher \& Hayes, 2008). None of the specific indirect effects were significant as all BCa 95\% CIs contained zero. Therefore, the relationship between attachment style and BMI was not significantly mediated by the set of dysregulated eating behaviours after controlling for sociodemographic, psychological, and behavioural correlates. 
Table 9

Total and Specific Indirect Effects of Dichotomous Attachment Style on Body Mass Index through Eating Behaviours (restrained, external, and emotional eating) presented with Bias Corrected and Accelerated (BCa) 95\% Confidence Intervals (CI)

\begin{tabular}{|c|c|c|c|}
\hline \multirow{2}{*}{ Effect } & \multirow{2}{*}{ Parameter Estimate $(S E)$} & \multicolumn{2}{|c|}{$B C a 95 \% C I$} \\
\hline & & Lower & Upper \\
\hline \multicolumn{4}{|l|}{ Model 1a $(n=2164)$} \\
\hline Total indirect effect & $.3027 *(.0666)$ & .1801 & .4390 \\
\hline Restrained Eating & $.3760 *(.0627)$ & .2604 & .5083 \\
\hline External Eating & $-.0671 *(.0242)$ & -.1257 & -.0285 \\
\hline Emotional Eating & $-.0062(.0343)$ & -.0709 & .0636 \\
\hline \multicolumn{4}{|l|}{ Contrasts } \\
\hline Restrained versus External & $.4431 *(.0677)$ & .3178 & .5807 \\
\hline Restrained versus Emotional & $.3822 *(.0751)$ & .2429 & .5394 \\
\hline External versus Emotional & $-.0609(.0490)$ & -.1678 & .0258 \\
\hline \multicolumn{4}{|l|}{ Model 2a $(n=1822)$} \\
\hline Total indirect effect & $.3465 *(.0790)$ & .1937 & .5057 \\
\hline Restrained Eating & $.4034 *(.0693)$ & .2758 & .5527 \\
\hline External Eating & $-.0776 *(.0347)$ & -.1566 & -.0180 \\
\hline Emotional Eating & $.0207(.0325)$ & -.0373 & .0891 \\
\hline \multicolumn{4}{|l|}{ Contrasts } \\
\hline Restrained versus External & $.4810 *(.0773)$ & .3346 & .6384 \\
\hline Restrained versus Emotional & $.3827 *(.0788)$ & .2412 & .5520 \\
\hline External versus Emotional & $-.0983 *(.0525)$ & -.2166 & -.0111 \\
\hline \multicolumn{4}{|l|}{ Model 3a $(n=1594)$} \\
\hline Total indirect effect & $.0387(.0388)$ & -.0381 & .1142 \\
\hline Restrained Eating & $.0053(.0196)$ & -.0311 & .0503 \\
\hline External Eating & $.0328(.0328)$ & -.0335 & .1006 \\
\hline Emotional Eating & $.0006(.0062)$ & -.0084 & .0199 \\
\hline \multicolumn{4}{|l|}{ Contrasts } \\
\hline Restrained versus External & $-.0275(.0380)$ & -.1021 & .0477 \\
\hline Restrained versus Emotional & $.0047(.0203)$ & -.0347 & .0480 \\
\hline External versus Emotional & $.0322(.0354)$ & -.0391 & .1037 \\
\hline
\end{tabular}

Note. Based on 5,000 bootstrap samples. Model 1a does not control for any covariates. Model 2a controls for age, gender, ethnicity, and socioeconomic status. Model 3a controls for age, gender, ethnicity, socioeconomic status, body esteem, depression, anxiety, and physical activity. $S E=$ standard error; $B C a=$ bias corrected and accelerated; $\mathrm{CI}=$ confidence interval.

$* p \leq .05$. 

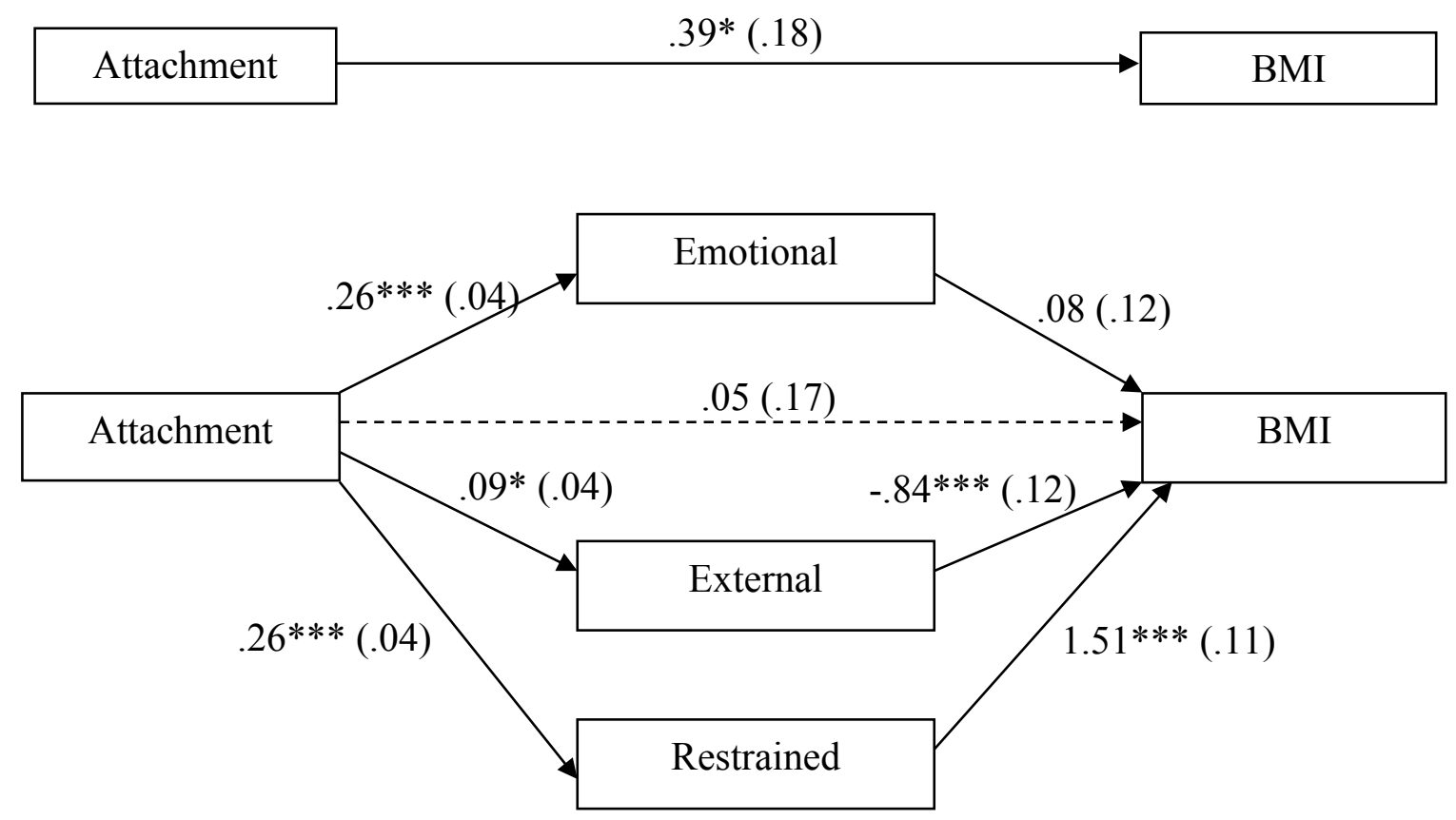

Figure 1. Multiple parallel mediation model 2a examining eating behaviours (emotional, external, and restrained) as mediating mechanisms between dichotomous attachment style (secure $=0$ versus insecure $=1$ ) and body mass index (BMI). Control variables include age, gender, ethnicity, and socioeconomic status. Sample size, $N=1822$. Unstandardized regression coefficients ( $B$ values or slopes) generated using bootstrapping with 5,000 samples with replacement are presented, and standard errors are presented in parentheses. ${ }^{*} p \leq .05 . * * p \leq .01 . * * * p \leq .001$.

Continuous attachment. Table 10 presents all parameter estimates for the total indirect effect and specific indirect effects, as well as BCa 95\% CIs. The overall model of attachment style predicting BMI through the set of dysregulated eating behaviours $\left(\right.$ model 1b) was significant, $F(4,2142)=63.26, p<.001, R^{2}=.106$, adjusted $R^{2}=.104$. Examination of the $\mathrm{BCa} 95 \% \mathrm{CI}$ indicates that, just as for dichotomous attachment, restrained and external eating significantly mediated the relationship between continuous attachment and BMI, whereas emotional eating did not. These results hold after 
controlling for socio-demographic variables (model $2 \mathbf{b})$, but once psychological and behavioural correlates are added to the model (model 3b), the total indirect and specific indirect effects are no longer significant. Results of model $1 \mathrm{~b}$ will not be formally discussed because model $2 \mathrm{~b}$ is more robust as it controlled for socio-demographic factors.

In model $2 \mathrm{~b}$, restrained eating was a significant mediator such that insecure attachment was related to increased restrained eating behaviour $(B=-.039)$, which was related to increased BMI $(B=1.49)$. External eating was also a significant mediator such that insecure attachment was associated with increased external eating $(B=-.022)$, which was related to lower BMIs $(B=-.82)$. Examination of pairwise contrasts of the specific indirect effects revealed that, like for the dichotomous attachment models, restrained eating was the strongest mediator, followed by external eating, and then emotional eating. 
Table 10

Total and Specific Indirect Effects of Continuous Attachment Style on Body Mass Index through Eating Behaviours (restrained, external, and emotional eating) presented with Bias Corrected and Accelerated (BCa) 95\% Confidence Intervals (CI)

Effect

Parameter Estimate $(S E) \quad B C a 95 \% C I$

\begin{tabular}{llcc} 
& & Lower & Upper \\
\hline Model 1b $(n=2147)$ & & & \\
\hline Total indirect effect & $-.0422^{*}(.0083)$ & -.0595 & -.0270 \\
Restrained Eating & $-.0550^{*}(.0076)$ & -.0708 & -.0408 \\
External Eating & $.0116^{*}(.0035)$ & .0055 & .0194 \\
Emotional Eating & $.0012(.0047)$ & -.0080 & .0106 \\
Contrasts & & & \\
Restrained versus External & $-.0666^{*}(.0083)$ & -.0838 & -.0520 \\
Restrained versus Emotional & $-.0561^{*}(.0094)$ & -.0762 & -.0388 \\
External versus Emotional & $.0105(.0070)$ & -.0034 & .0244 \\
\hline Model 2b $(n=1811)$ & & & \\
\hline Total indirect effect & $-.0428^{*}(.0097)$ & -.0627 & -.0246 \\
Restrained Eating & $-.0583^{*}(.0083)$ & -.0761 & -.0433 \\
External Eating & $.0182^{*}(.0045)$ & .0106 & .0289 \\
Emotional Eating & $-.0026(.0046)$ & -.0119 & .0058 \\
Contrasts & & & \\
Restrained versus External & $-.0765^{*}(.0093)$ & -.0960 & -.0595 \\
Restrained versus Emotional & $-.0558^{*}(.0099)$ & -.0754 & -.0369 \\
External versus Emotional & $.0208^{*}(.0074)$ & .0079 & .0037 \\
\hline Model 3b $(n=1584)$ & & & \\
\hline Total indirect effect & $.0002(.0049)$ & -.0096 & .0099 \\
Restrained Eating & $-.0011(.0024)$ & -.0065 & .0036 \\
External Eating & $.0014(.0042)$ & -.0064 & .0104 \\
Emotional Eating & $-.0001(.0008)$ & -.0028 & .0007 \\
Contrasts & & & \\
Restrained versus External & $-.0024(.0048)$ & -.0124 & .0065 \\
Restrained versus Emotional & $-.0010(.0025)$ & -.0062 & .0040 \\
External versus Emotional & $.0014(.0045)$ & -.0066 & .0114 \\
\hline Note Based & & & \\
\hline
\end{tabular}

Note. Based on 5,000 bootstrap samples. Model 1b does not control for covariates. Model $2 \mathrm{~b}$ controls for age, gender, ethnicity, and socioeconomic status. Model $3 \mathrm{~b}$ controls for age, gender, ethnicity, socioeconomic status, body esteem, depression, anxiety, and physical activity. $S E=$ standard error; $B C a=$ bias corrected and accelerated; $\mathrm{CI}=$ confidence interval.

${ }^{*} \mathrm{p} \leq .05$. 

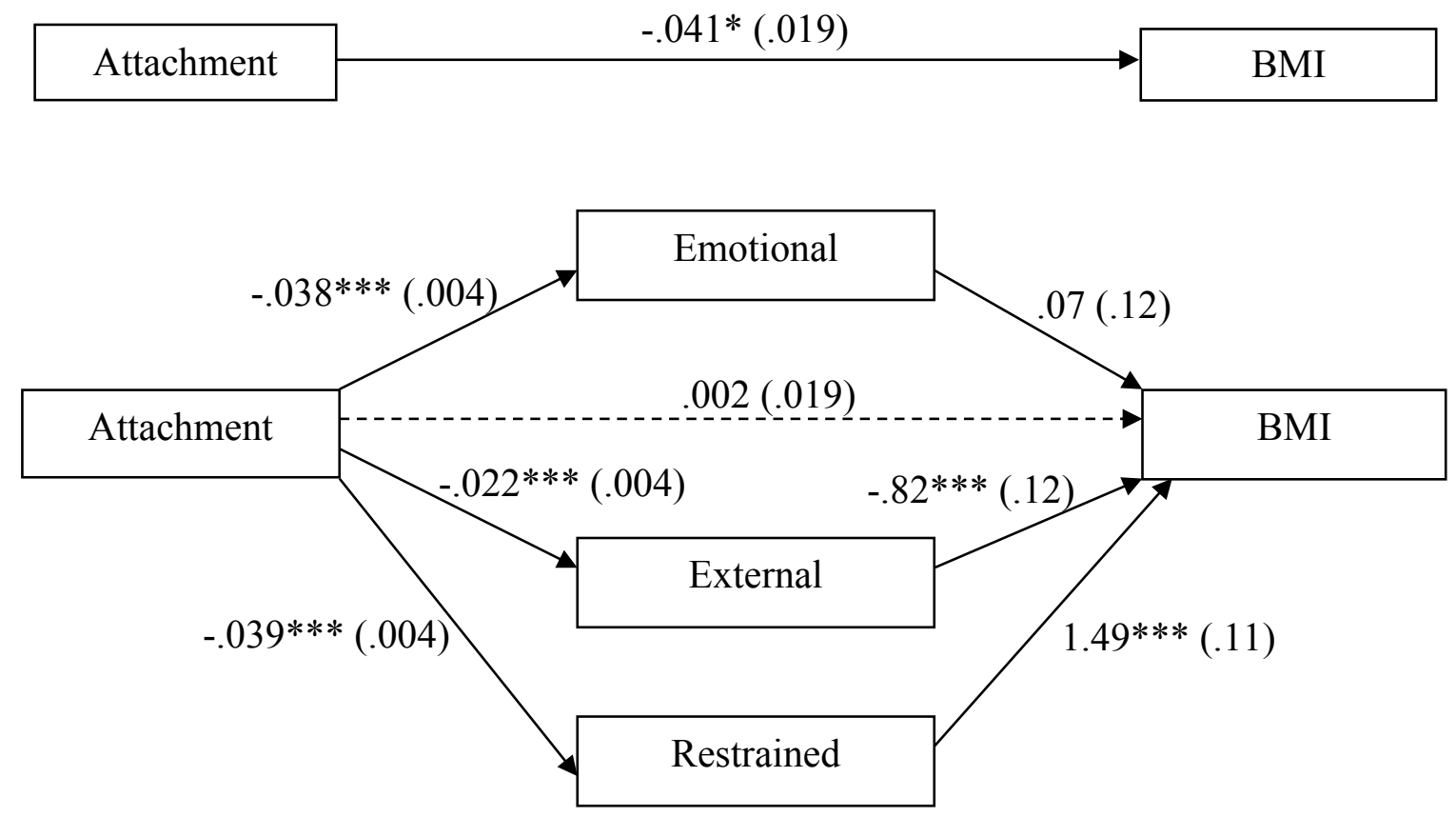

Figure 2. Multiple parallel mediation model $2 \mathrm{~b}$ examining eating behaviours (emotional, external, and restrained) as mediating mechanisms between continuous attachment style (lower scores $=$ less secure) and body mass index (BMI). Control variables include age, gender, ethnicity, and socioeconomic status. Sample size, $N=1811$. Unstandardized regression coefficients ( $B$ values or slopes) generated using bootstrapping with 5,000 samples with replacement are presented, and standard errors are presented in parentheses. $* p \leq .05 . * * p \leq .01 . * * * p \leq .001$.

\section{Moderated Multiple Mediation Analyses (Objective 4)}

To test whether the socio-demographic variables of age, gender, ethnicity, or SES moderated any of the mediational pathways, several moderated multiple parallel mediation analyses were also conducted. Moderated multiple parallel mediation analyses were conducted for models $2 \mathrm{a}$ and $2 \mathrm{~b}$, to test if any of the socio-demographic variables moderated the relationship between attachment and any of the three mediators (restrained, external, and emotional eating), or between attachment and BMI with the three mediators in the model. Moderated mediation analyses were not conducted for 
models $3 \mathrm{a}$ and $3 \mathrm{~b}$ because there was no evidence of mediation in these models. All results are presented in Tables 11 and 12.

Age as moderator. Early ( $<15$ years) versus late $(\geq 15$ years) adolescence, while controlling for gender, ethnicity, and SES, was tested as a moderator. This age cut-off was chosen as it represents the transition from elementary school to high school in Ontario. Bootstrapping tests revealed that the specific indirect effects of attachment on BMI through restrained, external, and emotional eating were not moderated by age, for dichotomous or continuous attachment, as none of the interaction terms were significant; all BCa 95\% CIs contained zero.

Gender as moderator. Bootstrapping tests revealed that the specific indirect effect of attachment on BMI through restrained eating was significantly moderated by gender while controlling for age, ethnicity, and SES in the dichotomous $(B=-.2552)$ and continuous $(B=.0285)$ attachment models. Examination of the conditional specific indirect effects by gender revealed that although the restrained eating pathway was significant for both genders, it was significantly stronger for females (coded as 0 ) than for males (coded 1). The specific indirect effects through external and emotional eating, and the direct effect of attachment on BMI were not moderated by gender (all BCa 95\% CIs contained zero).

Ethnicity as moderator. Bootstrapping tests revealed that the specific indirect effects of attachment on BMI through restrained, external, and emotional eating were not moderated by ethnicity (i.e. White versus Other), while controlling for age, gender, and 
SES, for dichotomous and continuous attachment, as none of the interaction terms were significant (all BCa 95\% CIs contained zero).

SES as moderator. Bootstrapping tests revealed that the specific indirect effect of attachment on BMI through restrained eating was significantly moderated by SES for dichotomous $(B=.3306)$ and continuous $(B=-.0288)$ attachment, while controlling for age, gender, and ethnicity. Examination of the conditional specific indirect effects by SES level revealed that the effect was stronger for higher SES than for lower SES, and in fact was not significant for lower SES.

Table 11

Parameter Estimates of Interaction Effects Predicting the Eating Behaviour Mediators and the Outcome of Body Mass Index

\begin{tabular}{cccccc}
\hline & Interaction & Restrained & External & Emotional & BMI \\
\hline & $\mathrm{A} \times \mathrm{Age}$ & .0082 & -.0454 & -.0161 & .4703 \\
& & $(.0933)$ & $(.0863)$ & $(.0960)$ & $(.4027)$ \\
Dichotomous & $\mathrm{A} \times \mathrm{G}$ & $-.2552 * * *$ & -.0149 & -.1497 & .1667 \\
& & $(.0770)$ & $(.0784)$ & $(.0792)$ & $(.3479)$ \\
& $\mathrm{A} \times \mathrm{E}$ & .1206 & .0744 & -.0287 & .0740 \\
& & $(.0995)$ & $(.0916)$ & $(.0946)$ & $(.3941)$ \\
& $\mathrm{A} \times \mathrm{S}$ & $.3306^{* *}$ & .0760 & -.1531 & -.1149 \\
& & $(.1136)$ & $(.1135)$ & $(.1276)$ & $(.8260)$ \\
\hline \multirow{6}{*}{ Continuous } & $\mathrm{A} \times \mathrm{Age}$ & .0084 & .0001 & .0015 & .0120 \\
& & $(.0107)$ & $(.0099)$ & $(.0103)$ & $(.0466)$ \\
& $\mathrm{A} \times \mathrm{G}$ & $.0285^{*} *$ & .0003 & .0129 & -.0268 \\
& $\mathrm{~A} \times \mathrm{E}$ & $(.0087)$ & $(.0089)$ & $(.0088)$ & $(.0406)$ \\
& & -.0120 & -.0177 & -.0137 & .0108 \\
& $\mathrm{~A} \times \mathrm{S}$ & $(.0116)$ & $(.0107)$ & $(.0107)$ & $(.0458)$ \\
& & $\left(.0288^{*}\right.$ & -.0134 & .0175 & .0147 \\
& & $(.0139)$ & $(.0119)$ & $(.0149)$ & $(.0568)$ \\
\hline
\end{tabular}

Note. $\mathrm{A}=$ attachment; $\mathrm{G}=$ gender; $\mathrm{E}=$ ethnicity; $\mathrm{S}=$ socioeconomic status. Standard errors are presented in parentheses.

${ }^{*} p<.05 .{ }^{* *} p<.01 .{ }^{* * *} p<.001$. 
Table 12

Conditional Specific Indirect Effects for Restrained Eating by Gender and Socioeconomic Status

\begin{tabular}{|c|c|c|}
\hline Attachment & $\mathrm{BCa} 95 \% \mathrm{CI}$ & $\mathrm{BCa} 95 \% \mathrm{CI}$ \\
\hline \multirow{4}{*}{ Dichotomous } & Female & Male \\
\hline & $.5624 *(.0992) \quad[.3850, .7780]$ & $.1760 *(.0756)$ \\
\hline & Low SES & High SES \\
\hline & $-.0269(.1569)$ & $.4732 *(.0749)$ \\
\hline \multirow{4}{*}{ Continuous } & Female & Male \\
\hline & $-.0765 *(.0121) \quad[-.1022,-.0551]$ & $-.0338 *(.0087) \quad[-.0521,-.0182]$ \\
\hline & Low SES & High SES \\
\hline & $-.0210(.0194)$ & $-.0640 *(.0089)$ \\
\hline
\end{tabular}

Note. $\mathrm{SES}=$ socioeconomic status. $\mathrm{CI}=$ confidence interval. $\mathrm{BCa}=$ bias corrected and accelerated.

\section{Underweight Sample (Objective 5)}

A sample of 191 underweight youth with a mean age of 14.28 years $(S D=1.68)$ were analyzed separately. Sample frequencies and demographics are presented in Tables 13 and 14 respectively.

Table 13

Descriptives of the Underweight Sample for Categorical Variables

\begin{tabular}{lc}
\hline \multicolumn{1}{c}{ Indicator } & $n(\%)$ \\
\hline Gender $(n=191)$ & $77(40.3)$ \\
Male & $114(59.7)$ \\
Female & \\
Parental Education (proxy measure of SES) $(n=156)$ & $15(9.6)$ \\
$\quad$ Neither parent completed college or higher & $141(90.4)$ \\
At least one parent complete college or higher & \\
Ethnicity $(n=186)$ & $132(71.0)$ \\
White-Caucasian & $54(29.0)$ \\
Other & $114(71.7)$ \\
Attachment style $(n=159)$ & $45(28.3)$ \\
$\quad$ Secure & \\
Insecure &
\end{tabular}

Note. SES = socioeconomic status. 
Table 14

Descriptives of the Underweight Sample for Continuous Variables

\begin{tabular}{lcccc}
\hline \multicolumn{1}{c}{ Indicator } & $n$ & $M$ & $S D$ & Range \\
\hline Age (years) & 191 & 14.28 & 1.68 & $11.83-20.42$ \\
Body mass index $\left(\mathrm{kg} / \mathrm{m}^{2}\right)$ & 153 & 16.01 & .93 & $14.14-18.36$ \\
Eating behaviours (DEBQ) & & & & \\
$\quad$ Restrained & 170 & 2.83 & .74 & $1.0-5.0$ \\
$\quad$ Emotional & 170 & 1.79 & .73 & $1.0-5.0$ \\
$\quad$ External & 170 & 2.83 & .74 & $1.0-5.0$ \\
Depression (CDI) & 159 & 7.59 & 7.06 & $0-34.0$ \\
Anxiety (MASC) & 154 & 11.66 & 5.08 & $0-24.0$ \\
\hline
\end{tabular}

Note. DEBQ $=$ Dutch Eating Behavior Questionnaire; CDI = Children's Depression Inventory; MASC = Multidimensional Anxiety Scale for Children.

Bivariate correlations between the variables were examined and these are presented in Tables 15 and 16 for dichotomous and continuous attachment, respectively. Because none of the correlations exceeded .90, it is unlikely that the assumption of no multicollinearity was violated (Field, 2009). 
Table 15

Correlations between Dichotomous Attachment and Untransformed Variables of Interest of the Underweight Sample

\begin{tabular}{|c|c|c|c|c|c|c|c|c|c|c|}
\hline & 1 & 2 & 3 & 4 & 5 & 6 & 7 & 8 & 9 & 10 \\
\hline 1. Attachment & - & & & & & & & & & \\
\hline 2. BMI & .121 & - & & & & & & & & \\
\hline 3. Age & $.213^{* *}$ & $.699^{* * *}$ & - & & & & & & & \\
\hline 4. Gender & .061 & -.100 & .139 & - & & & & & & \\
\hline 5. Ethnicity & -.059 & $-.213^{* *}$ & $-.148^{*}$ & -.098 & - & & & & & \\
\hline 6. SES & $-.211^{*}$ & -.167 & $-.185^{*}$ & .083 & .089 & - & & & & \\
\hline 7. DEBQ-R & -.011 & -.087 & -.022 & -.055 & .104 & -.122 & - & & & \\
\hline 8. DEBQ-Ex & -.056 & .092 & $.161^{*}$ & -.054 & $.187^{*}$ & .031 & -.065 & - & & \\
\hline 9. DEBQ-Em & .002 & .076 & .081 & $-.270^{* * *}$ & .105 & -.056 & .063 & $.464^{* * * *}$ & - & \\
\hline 10. CDI & $.384^{* * *}$ & $.186^{*}$ & $.342^{* * * *}$ & -.011 & .006 & $.214^{*}$ & $.184^{*}$ & .124 & $.245^{* *}$ & - \\
\hline 11. MASC & $.389^{* * *}$ & .029 & .058 & $-.270^{* * *}$ & .011 & -.114 & .143 & .156 & $.260^{* * * *}$ & $.396^{* * *}$ \\
\hline
\end{tabular}

Note. Participants include only those in the underweight sample $\left(\mathrm{BMI}<16^{\text {th }}\right.$ percentile $)$. Attachment $(0=$ secure; $1=$ insecure $) ; \mathrm{BMI}=$ body mass index $\left(\mathrm{kg} / \mathrm{m}^{2}\right)$; age in years; gender $(0=$ female; $1=$ male $)$; ethnicity $(1=$ White; $2=$ Other $)$, SES = socioeconomic status $(0=$ low; $1=$ high $)$, DEBQ-R = Dutch Eating Behavior Questionnaire restrained eating subscale; DEBQ-Ex = external eating subscale; DEBQ-Em = emotional eating subscale; $\mathrm{CDI}=$ Children's Depression Inventory; MASC = Multidimensional Anxiety Scale for Children.

$* p \leq .05$, two-tailed. $* * p \leq .01$, two-tailed. $* * * p \leq .001$, two-tailed. 
Table 16

Correlations between Continuous Attachment and Untransformed Variables of Interest of the Underweight Sample

\begin{tabular}{|c|c|c|c|c|c|c|c|c|c|c|}
\hline & 1 & 2 & 3 & 4 & 5 & 6 & 7 & 8 & 9 & 10 \\
\hline 1. TAS & - & & & & & & & & & \\
\hline 2. BMI & -.164 & - & & & & & & & & \\
\hline 3. Age & $-.206^{* *}$ & $.699^{* * *}$ & - & & & & & & & \\
\hline 4. Gender & -.017 & -.100 & .139 & - & & & & & & \\
\hline 5. Ethnicity & -.009 & $-213^{* *}$ & $-.148^{*}$ & -.098 & - & & & & & \\
\hline 6. SES & .117 & -.167 & $-.185^{*}$ & .083 & .089 & - & & & & \\
\hline 7. DEBQ-R & $-.211^{* *}$ & -.087 & -.022 & -.055 & .104 & -.122 & - & & & \\
\hline 8. DEBQ-Ex & .015 & .092 & $.161^{*}$ & -.054 & $.187^{*}$ & .031 & -.065 & - & & \\
\hline 9. DEBQ-Em & -.138 & .076 & .081 & $-.270^{* * *}$ & .105 & -.056 & .063 & $.464^{* * *}$ & - & \\
\hline 10. CDI & $-.552^{* * *}$ & $.186^{*}$ & $.342^{* * *}$ & -.011 & .006 & $-.214^{*}$ & $.184^{*}$ & .124 & $.245^{* *}$ & - \\
\hline 11. MASC & $-.440^{* * *}$ & .029 & .058 & $-.270^{* * *}$ & .011 & -.114 & .143 & .156 & $.260^{* * *}$ & $.396^{* * *}$ \\
\hline
\end{tabular}

Note. Participants include only those in the underweight sample (BMI $<16^{\text {th }}$ percentile). TAS $=$ Total Attachment

Style Score as derived from the Relationship Questionnaire (lower scores $=$ less secure); BMI $=$ body mass index

$\left(\mathrm{kg} / \mathrm{m}^{2}\right)$; age in years; gender $(0=$ female; $1=$ male $)$; ethnicity $(1=$ White; $2=$ Other $)$; SES $=$ socioeconomic status $(0$

$=$ low; 1 = high); DEBQ-R = Dutch Eating Behavior Questionnaire - restrained eating subscale; DEBQ-Ex = external eating subscale; DEBQ-Em = emotional eating subscale; CDI = Children's Depression Inventory; MASC =

Multidimensional Anxiety Scale for Children.

${ }^{*} p \leq .05$, two-tailed. $* * p \leq .01$, two-tailed. $* * * p \leq .001$, two-tailed. 
Dichotomous and continuous attachment. Although underweight youth were excluded from the main analysis, the underweight subsample was examined separately in a multiple mediation analysis to investigate whether emotional, external, or restrained eating mediate the relationship between attachment style and BMI without controlling for covariates (models 1c and 1d), while controlling for socio-demographic variables (age, gender, ethnicity, and SES; models 2c and 2d), as well as mood (depression and anxiety; models $3 \mathrm{c}$ and $3 \mathrm{~d}$ ). Unlike for previous analyses, body esteem and physical activity were not controlled for because the sample size was not large enough; as a minimum of 10 cases are required per predictor variable or covariate (Tabachnick \& Fidell, 2007). Results with dichotomous attachment as the predictor are presented in Table 17 and Figure 3, and results where continuous attachment was the predictor are presented in Table 18 and Figure 4. There was no evidence of mediation as the BCa 95\% CIs of the total indirect effects contained zero. Moreover, none of the specific indirect effects were significant, as demonstrated by confidence intervals that contained zero. Therefore, it appears as though the dysregulated eating behaviours did not mediate the relationship between attachment style and BMI in underweight youth. 

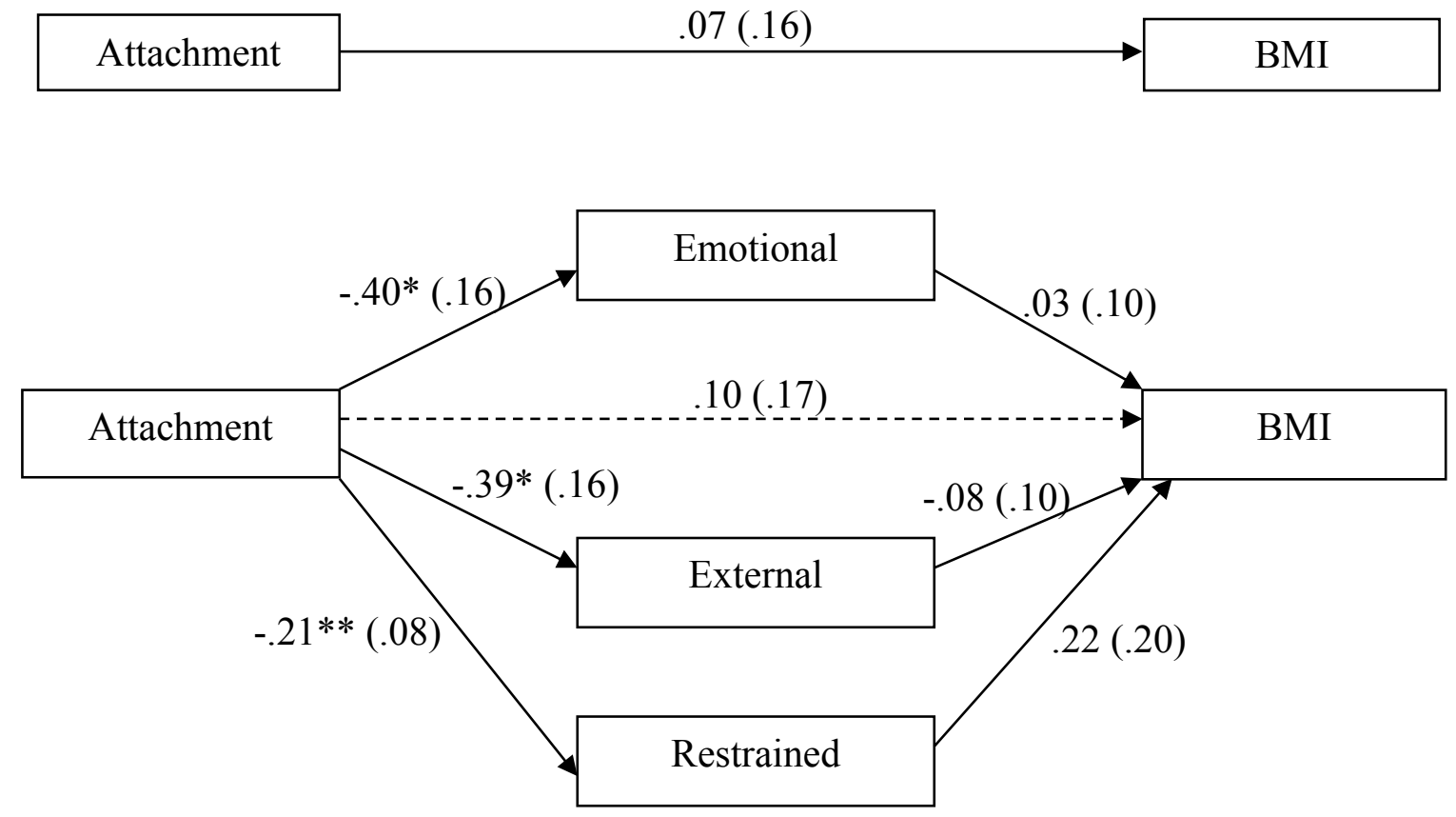

Figure 3. Multiple parallel mediation model (model 3c) examining eating behaviours (emotional, external, and restrained) as mediating mechanisms between attachment style ( secure $=0$, insecure $=1$ ) and body mass index (BMI) in a subsample of 114 underweight youth. Control variables include age, gender, ethnicity, socioeconomic status, depression and anxiety. Unstandardized regression coefficients ( $B$ values or slopes) generated using bootstrapping with 5,000 samples with replacement are presented, and standard errors are presented in parentheses.

$* p \leq .05 .{ }^{* *} p \leq .01$. 
Table 17

Total and Specific Indirect Effects of Dichotomous Attachment Style on Body Mass Index through Eating Behaviours (restrained, external, and emotional eating) presented with Bias Corrected and Accelerated (BCa) 95\% Confidence Intervals (CI), for Underweight Youth

$$
\text { Effect } \quad \text { Parameter Estimate }(S E) \quad B C a 95 \% C I
$$

\begin{tabular}{llll} 
& & Lower & Upper \\
\hline Model 1c $(n=143)$ & & & \\
\hline Total indirect effect & $-.0073(.0417)$ & -.0968 & .0754 \\
Restrained Eating & $-.0041(.0288)$ & -.0808 & .0432 \\
External Eating & $-.0036(.0211)$ & -.0649 & .0303 \\
Emotional Eating & $.0004(.0233)$ & -.0487 & .0563 \\
Contrasts & & & \\
Restrained versus External & $-.0005(.0344)$ & -.0807 & .0625 \\
Restrained versus Emotional & $-.0045(.0373)$ & -.0786 & .0755 \\
External versus Emotional & $-.0041(.0339)$ & -.0709 & .0742 \\
\hline Model 2c $(n=116)$ & & & \\
\hline Total indirect effect & $.0036(.0441)$ & -.0858 & .0966 \\
Restrained Eating & $-.0148(.0328)$ & -.1229 & .0266 \\
External Eating & $.0172(.0281)$ & -.0147 & .1130 \\
Emotional Eating & $.0011(.0190)$ & -.0305 & .0546 \\
Contrasts & & & \\
Restrained versus External & $-.0320(.0432)$ & -.1570 & .0281 \\
Restrained versus Emotional & $-.0159(.0376)$ & -.1102 & .0453 \\
External versus Emotional & $.0161(.0380)$ & -.0361 & .1297 \\
\hline Model 3c $(n=114)$ & & & \\
\hline Total indirect effect & $-.0169(.0806)$ & -.2091 & .1215 \\
Restrained Eating & $-.0416(.0568)$ & -.2169 & .0330 \\
External Eating & $.0323(.0446)$ & -.0390 & .1425 \\
Emotional Eating & $-.0076(.0499)$ & -.1419 & .0759 \\
Contrasts & & & \\
Restrained versus External & $-.0739(.0717)$ & -.2594 & .0376 \\
Restrained versus Emotional & $-.0340(.0719)$ & -.1987 & .0945 \\
External versus Emotional & $-.0793)$ & -.0919 & .2428 \\
\hline Note. Based on 5,000 bootstrap & & & \\
\hline
\end{tabular}

Note. Based on 5,000 bootstrap samples. Model 1c does not control for covariates. Model $2 \mathrm{c}$ controls for age, gender, ethnicity, and socioeconomic status. Model $3 \mathrm{c}$ controls for age, gender, ethnicity, socioeconomic status, depression, and anxiety. $S E=$ standard error; $\mathrm{BCa}=$ bias corrected and accelerated; $\mathrm{CI}=$ confidence interval.

$* p \leq .05$. 


\begin{tabular}{|c|c|c|}
\hline Attachment & $-.02(.02)$ & BMI \\
\cline { 2 - 4 } & & \\
\hline
\end{tabular}

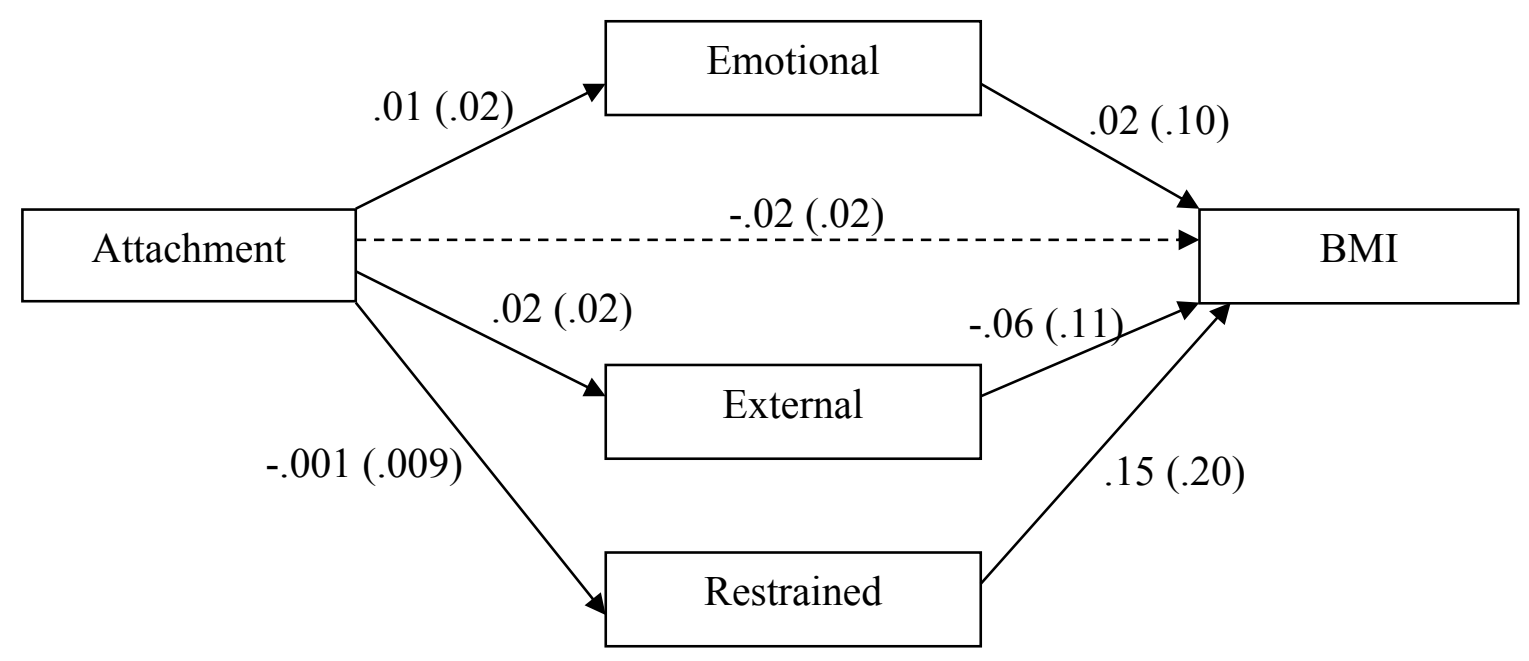

Figure 4. Multiple parallel mediation model (model 3d) examining eating behaviours (emotional, external, and restrained) as mediating mechanisms between continuous attachment style (lower scores = less secure) and body mass index (BMI) in a subsample of 111 underweight youth. Control variables include age, gender, ethnicity, socioeconomic status, depression and anxiety. Unstandardized regression coefficients $(B$ values or slopes) generated using bootstrapping with 5,000 samples with replacement are presented, and standard errors are presented in parentheses.

$* p \leq .05 . * * \leq .01$. 
Table 18

Total and Specific Indirect Effects of Continuous Attachment Style on Body Mass Index through Eating Behaviours (restrained, external, and emotional eating) presented with Bias Corrected and Accelerated (BCa) 95\% Confidence Intervals (CI), for Underweight Youth

$$
\text { Effect } \quad \text { Parameter Estimate }(S E) \quad B C a 95 \% C I
$$

\begin{tabular}{llll} 
& & Lower & Upper \\
\hline Model 1d $(n=138)$ & & & \\
\hline Total indirect effect & $.0006(.0056)$ & -.0121 & .0108 \\
Restrained Eating & $.0015(.0045)$ & -.0058 & .0136 \\
External Eating & $.0000(.0024)$ & -.0093 & .0024 \\
Emotional Eating & $-.0009(.0049)$ & -.0135 & .0076 \\
Contrasts & & & \\
Restrained versus External & $.0015(.0051)$ & -.0064 & .0158 \\
Restrained versus Emotional & $.0024(.0076)$ & -.0126 & .0187 \\
External versus Emotional & $.0010(.0060)$ & -.0144 & .0112 \\
\hline Model 2d $(n=112)$ & & & \\
\hline Total indirect effect & $.0000(.0049)$ & -.0098 & .0097 \\
Restrained Eating & $-.0009(.0029)$ & -.0084 & .0039 \\
External Eating & $.0002(.0022)$ & -.0025 & .0073 \\
Emotional Eating & $.0007(.0032)$ & -.0045 & .0090 \\
Contrasts & & & \\
Restrained versus External & $-.0011(.0036)$ & -.0108 & .0043 \\
Restrained versus Emotional & $-.0016(.0041)$ & -.0113 & .0059 \\
External versus Emotional & $-.0004(.0040)$ & -.0067 & .0112 \\
\hline Model 3d $(n=111)$ & & & \\
\hline Total indirect effect & & & \\
Restrained Eating & $-.0017(.0046)$ & -.0104 & .0088 \\
External Eating & $-.0001(.0031)$ & -.0078 & .0056 \\
Emotional Eating & $-.0013(.0030)$ & -.0113 & .0024 \\
Contrasts & $-.0003(.0027)$ & -.0032 & .0093 \\
Restrained versus External & & & \\
Restrained versus Emotional & & -.0061 & .0120 \\
External versus Emotional & & -.0100 & .0070 \\
\hline Note. Based & & -.0173 & .0048 \\
\hline
\end{tabular}

Note. Based on 5,000 bootstrap samples. Control variables include age, gender, ethnicity, socioeconomic status, depression, and anxiety. $S E=$ standard error; $B C a=$ bias corrected and accelerated; $C I=$ confidence interval.

$* p \leq .05$. 


\section{Discussion}

The overall aim of the present study was to examine and qualify the role that three types of dysregulated eating behaviours play in the relationship between general attachment style and BMI in a large community sample of adolescents. Regression, multiple parallel mediation, and moderated multiple parallel mediation analyses were used to examine these cross-sectional relationships. Analyses were first conducted in a sample of normal weight, overweight, and obese youth (main sample), followed by analyses in a sample of underweight youth. Results of the main sample will be discussed first, followed briefly by the underweight sample.

\section{Attachment Predicting Body Mass Index (Main Sample)}

The first objective of this study was to determine if attachment style predicts BMI. As hypothesized, dichotomous and continuous attachment significantly predicted BMI, such that secure attachment was more strongly associated with lower (healthier) BMIs and insecure attachment with higher BMIs. Although statistically significant, dichotomous attachment style only contributed $0.6 \%$ of the unique variance $\left(s r^{2}=.006\right)$. Attachment remained a significant predictor after controlling for the socio-demographic covariates, however its unique contribution fell to $0.24 \%\left(s r^{2}=.0024\right)$ in this model. Once psychological and behavioural covariates were added to the model, attachment style was no longer a significant predictor. Similar patterns of results emerged when the models were run with the continuous attachment measure (TAS). The similar conclusions drawn when both the dichotomous and continuous measures of attachment were used 
provide some support for the use of Matsuoka and colleagues' (2006) continuous measure of attachment derived from the RQ.

Findings of the present study are consistent with previous research (Anderson et al., 2012; Anderson \& Whitaker, 2011; Goossens, Braet, Van Durme, Decaluwé, \& Bosmans, 2012; Stenhammar et al., 2010). For example, Anderson and Whitaker (2011) demonstrated that two-year old children with an insecure attachment pattern were at increased risk for obesity at 4.5 years, after controlling for maternal interaction with the child, child interaction with the mother, parenting practices, maternal health, and sociodemographic characteristics. However, in the present study, attachment style was no longer significant after controlling for psychological and behavioural factors. Given that the covariates used by Anderson and Whitaker (2011) differed from the present study, and anxiety, depression, and body esteem were shown in the current study to be correlated with attachment (Tables 3 and 4), this may explain, in part, the discrepant findings between the present study and the study by Anderson and Whitaker (2011). The present study builds on the findings of Anderson and colleagues (2012), who found that a poorer mother-child relationship in childhood was associated with a higher risk of obesity in adolescence. Although Anderson and colleagues (2012) found a relationship between insecure attachment and obesity without controlling for covariates, after controlling for socio-demographic variables (gender, ethnicity, maternal education, SES, maternal obesity, and child birth weight), the contribution of attachment style was attenuated. The results of the present study found that after controlling for socio-demographic variables, attachment style was still a significant predictor of BMI in the hierarchical regression 
(Table 6), and the contribution of attachment was only attenuated after including behavioural and psychological covariates (Table 7).

Goossens and colleagues (2012) found that insecure attachment longitudinally predicted increases in restrained eating and BMI after controlling for gender, baseline eating psychopathology, and baseline weight. It is difficult to determine if these results are generalizable to other populations, as researchers did not control for other potential confounding variables such as age, ethnicity, or SES (Goossens et al., 2012). Results of the present study, even though cross-sectional, may be more generalizable than findings from Goossens et al., (2012), as the present study controlled for numerous confounding variables and had a larger sample size. In general, cross-study comparisons are challenging given the various methodologies and control variables used.

Even though dichotomous and continuous attachment emerged as statistically significant predictors in the hierarchical linear regressions that controlled for sociodemographic variables, attachment style did not uniquely contribute a large proportion of the variance, especially when compared with the contribution of weight dissatisfaction. The small contribution of attachment style could partially be explained by how attachment style was measured. The RQ questionnaire is a 4-item questionnaire, with each item addressing an attachment style. When the responses of the RQ are categorized as either secure or insecure, variability is decreased. Therefore, it may appear as though attachment style has a smaller effect than it actually does. The same logic applies to the continuous measure of attachment, as the TAS score is derived from the RQ. It is possible that if a more robust attachment measure were utilized, such as an interview, 
attachment style may have explained a greater amount of variance in the regression. Of course another possible explanation as to why attachment style contributed little unique variance, is that it may not have an effect on the outcome, BMI. However, based on the theory reviewed and the significant correlation between attachment style and BMI, this may not be a likely explanation. Lastly, it is conceivable that attachment style impacts BMI and weight status through another variable. For example, weight dissatisfaction, which contributed approximately $14.5 \%$ of the unique variance in BMI appears to be an important explanatory variable. It is also possible that unmeasured variables, such as selfesteem, could better predict BMI and future research should broaden the scope of measurement to attain a better understanding of the relationship between attachment style and BMI.

\section{Mediation Analyses (Main Sample)}

The multiple parallel mediation models add to the limited research on attachment and BMI by examining the specific indirect effects of dysregulated eating behaviours in the relationship between attachment style and BMI in one parsimonious model, which represented objectives 2 and 3. Although previous pediatric studies have demonstrated that an insecure attachment style increases the risk of overweight and obesity (Anderson et al., 2012; Anderson \& Whitaker, 2011; Goossens et al., 2012), no research to date has explored the mechanisms responsible for this relationship in a community sample of midto late adolescents. Goossens and colleagues (2012) recently examined whether attachment style predicted eating pathology and weight gain among younger children (8 to 11 years) using hierarchical regression analyses. Although Goossens and colleagues 
(2012) found that insecure attachment predicted restrained eating and weight gain, the present study adds to their findings by examining emotional and external eating, as well as using a mediational analysis to better understand the relationship between variables.

There was a significant total indirect effect of attachment on BMI through dysregulated eating in four of the six models tested. The set of dysregulated eating behaviours (emotional, restrained, and external eating) significantly mediated the relationship between attachment style and BMI in the two models without covariates (model 1a and 1b), and in the two models controlling for socio-demographic variables (models $2 \mathrm{a}$ and $2 \mathrm{~b}$ ). There was no evidence of mediation in the two models controlling for socio-demographic, psychological, and behavioural covariates (models $3 \mathrm{a}$ and $3 \mathrm{~b}$ ). This non-significant finding could be partially due to the fact that attachment was highly significantly correlated with the psychological and behavioural covariates (body esteem, depression, anxiety, and physical activity; see Tables 3 and 4), and therefore when the covariates were entered in the model before attachment, there was little variance left to be predicted by attachment style. In other words, any overlapping variance between attachment and the covariates was assigned to the covariates.

Emotional eating. Some researchers (Anderson \& Whitaker, 2011) have speculated that poor emotional regulation is the driving force linking insecure attachment and increased BMI, drawing on the work of Bruch (1975) and psychosomatic theory (Kaplan \& Kaplan, 1957;Van Strien, Frijters, Bergers, \& Defares, 1986) for theoretical support. In fact, that is what was hypothesized in the present study; that poor interoceptive awareness, a characteristic of insecurely attached individuals, would predict 
increased emotional eating (Van Strien \& Ouwens, 2003), which, in turn, would predict increased BMI. The results of the present study are partially consistent with this hypothesis, in that insecure attachment style did indeed predict increased emotional eating after controlling for socio-demographic variables; however, emotional eating was not significantly associated with increased BMI. The bivariate correlation between emotional eating and BMI was statistically significant in the hypothesized direction, but with two other dysregulated eating behaviours in the mediation model, emotional eating did not emerge as a significant pathway. This suggests that although insecurely attached youth may overeat in response to emotional arousal or distress, this maladaptive eating behaviour is not likely a major mechanism responsible for increased weight in youth who have poor attachment, at least compared to the other types of dysregulated eating behaviours. Although this is not consistent with psychosomatic theory, which postulates that emotional eating is partly responsible for the development of overweight and obesity (Kaplan \& Kaplan, 1957; Van Strien, Frijters, Bergers, \& Defares, 1986), it is consistent with several studies that have not found an association between emotional eating and increased BMI (Belcher et al., 2011; Goldfield et al., 2010a; Nguyen-Rodriguez, Chou, Unger, \& Spruijt-Metz, 2008; Snoek et al., 2007).

It is possible that emotional eating did not emerge as a significant pathway because emotional eating tends to be more common in adults (van Strien et al., 2009), and has a lower prevalence in children (van Strien \& Oosterveld, 2008). In fact, emotional eating was positively correlated with age in this sample, so this explanation is possible. In line with previous research, emotional eating was significantly positively 
correlated with body dissatisfaction, depression, and anxiety (Stice et al., 2002), and was significantly negatively correlated with physical activity (Andrade et al., 2010). Emotional eating may play a more prominent role in clinical samples of overweight youth, or in older adolescents and young adults, but does not seem to be the primary mechanism linking attachment and BMI in the present community sample of youth.

Restrained eating. Restraint theory postulates that the cognitive restriction of food will reach a breaking point and result in disinhibited eating and subsequent weight gain (Polivy \& Herman, 1985). As predicted and as can be seen in Figures 1 and 2, insecure attachment was significantly associated with restrained eating after controlling for socio-demographic covariates. That is, youth with an insecure attachment style were more likely to be cognitively and behaviourally restraining their food intake, when compared with securely attached youth. This is in agreement with previous work by Goossens and colleagues (2012) who found that 8 to 11 year olds who were insecurely attached to their mothers had higher levels of restrained eating one year later, and were also at increased risk of weight gain one year later. This result is very compelling considering that Goossens and colleagues (2012) found no association between attachment and BMI at baseline, but did find an association between restrained eating and insecure attachment at baseline. This suggests that the mother-child attachment relationship may first influence eating behaviour, which in turn may influence BMI (Goossens et al., 2012).

Restrained eating behaviour was significantly associated with higher BMI (after controlling for socio-demographic factors), in the present study. This finding is in 
accordance with Goossens and colleagues' (2012) finding that insecure attachment predicted restrained eating and increased the risk of weight gain one year later. However, it is important to note that although the vast majority of studies have found a relationship between increased restrained eating behaviour and increased BMI, there is debate about the directionality of this relationship. Some have proposed that restrained eating is a response to increased weight and represents an individual's attempt to lose weight (Forrester-Knauss et al., 2012; Snoek et al., 2008), and others have suggested that increased restraint will lead to weight gain through counter-regulation, or subsequent disinhibited eating (Field et al., 2003; Stice et al., 1999, 2005). Longitudinal research supports this latter hypothesis (Field et al, 2003). The present study cannot speak to the directionality of this relationship given the cross-sectional design.

Regardless of whether restrained eating is a cause or consequence of weight gain, it emerged as the strongest mediator in the four significant mediation models (models 1a, $1 b, 2 a$, and $2 b)$. The relative strength of the restrained eating mediational pathway, while the emotional and external eating pathways were controlled, suggests that restrained eating likely plays a central role in maintaining an unhealthy weight trajectory in youth, more so than emotional or external eating. For example, adolescents trying to lose weight or who have gained weight may be more likely to restrict eating, which could result in increased weight gain, and subsequently further food restriction, creating a vicious cycle. Even though restrained eating emerged as the strongest mediator, the results of the present study only partially support restraint theory. Based on restraint theory, one may expect that higher restrained eating would lead to increased BMI due to increased 
disinhibited eating. In other words, one might expect both restrained eating and emotional eating to emerge as significant pathways, but this was not the case. As seen in Tables 3 and 4, restrained and emotional eating were significantly correlated $(r=.30$ and $r=.31)$, but this co-occurrence is not enough to fully support restraint theory. Other than resulting in disinhibited eating, restrained eating can lead to weight gain due to a decrease in metabolic rate that results when food is restricted (Stiegler \& Cunliffe, 2006). It is further possible that other factors contribute to increased weight in restrained eaters, for instance, low levels of physical activity. However, restrained eating behaviour was not significantly correlated with physical activity in this sample. As can be seen in Table 5, mean scores on restrained eating were significantly higher for higher weight categories, and emotional eating scores did not differ across weight categories.

Despite the popularity of restraint theory in the literature, there is limited understanding as to what causes restrained eating behaviour. Studies looking at the transmission of restrained eating through parental modelling have reached mixed conclusions (de Lauzon-Guillain et al., 2009; Snoek, van Strien, Janssens, \& Engels, 2009). Some have demonstrated that parental pressure to eat more is related to restrained eating (i.e. Carper, Orlet Fisher, \& Birch, 2000), while others have conceptualized restrained eating as a reaction to weight gain (Papies, Stroebe, \& Aarts, 2008). However, the most common and evidenced-based conceptualization for the development of restrained eating in youth is the notion that adolescents are dissatisfied with their body shape and weight, and restrict food intake to strive to attain unrealistic beauty standards portrayed in the media (Rodin, Silberstein, \& Striegel-Moore, 1984; Stice \& Shaw, 
2002). Regardless of the complex etiology of restrained eating and how it relates to weight regulation, the current study is the first to establish that restrained eating is a strong mediator of the relationship between insecure attachment and increased BMI.

External eating. Laboratory studies have consistently supported externality theory (Schachter \& Rodin, 1974), demonstrating that overweight and obese individuals are more responsive to external food cues when compared with those who are more normal weight (for a review, see Stroebe, 2008). Findings from the present study do not entirely support this idea. Consistent with other studies (Goldfield et al., 2010; Snoek et al., 2013), the mean scores on external eating were more problematic than scores on external or restrained eating (Table 5). External eating also emerged as a statistically significant mediator of the relationship between attachment style and BMI, after controlling for socio-demographic variables. Even though external eating was a significant mediator, albeit not as strong as restrained eating, the overall findings do not fully support externality theory because external eating was associated with lower BMI.

The results of the present study may be in direct contrast to externality theory (Schachter \& Rodin, 1974), as well as previous work demonstrating that external eating patterns are associated with increased weight in youth (Braet \& Van Strien, 1997; Fisher \& Birch, 2002; Hill et al., 2008; Shomaker et al., 2010). However, the results are in line with other studies that have demonstrated either that normal weight youth score higher than obese youth on external eating, or there is no statistical difference in external eating scores based on weight (Braet et al., 2008; Goldfield et al., 2010a; Snoek et al., 2007). In a recent longitudinal study of 328 Dutch adolescents ranging in age from 13 to 15 years, 
external eating did not significantly differ across BMI categories, but mean scores on external eating were consistently higher for lower BMI groups (Snoek et al., 2013). A similar trend is seen in the present study; external eating scores were highest in underweight youth, followed by normal weight youth, and finally followed by overweight and obese youth (see Table 5).

Similar to emotional and restrained eating, insecure attachment was significantly related to increased external eating, after controlling for socio-demographic factors, suggesting that insecurely attached youth may be more likely to eat in response to external cues in their environment, rather than relying on biological cues of hunger and satiety. A body of research shows that insecurely attached youth have more difficulty with impulse control (e.g. Farrell Erickson, Sroufe, \& Egeland, 2008). Given today’s obesogenic environment, it is not surprising then that insecure attachment was related to external eating. What is surprising, however, is that increased external eating was associated with lower BMI in this sample. This result is somewhat counterintuitive given that, based on externality theory, one may predict that higher levels of external eating would be associated with increased BMI. But as discussed above, other studies have also found either a null or negative relationship, thereby not supporting externality theory.

It is possible that because externality theory was largely born out of laboratory studies, that once external eating is observed in the real world, the findings are no longer replicable, especially when the vast majority of youth today are equally exposed to energy-dense and highly palatable foods. Therefore, although insecure attachment may increase the incidence of external eating, this eating behaviour does not adequately 
explain the relationship between attachment style and BMI in a community sample when other eating behaviours are considered in the same model.

Possible explanations for these results include bias in responding; maybe youth with higher BMIs are cognizant of the negative stereotypes associated with being overweight or obese, and may be under-reporting external eating behaviours. However, another study found high correlations between child and parent reports on the external eating subscale (Braet \& Van Strien, 1997), and the DEBQ has been shown to correlate positively with energy intake in boys and girls (Lluch et al., 2000), so it is unlikely that under-reporting is the reason. But, since the present study did not collect parent data or caloric intake, bias in reporting cannot be ruled out. It is further possible that lower scores on external eating are a function of higher scores on the restrained eating subscale. For instance, if a youth is restraining his or her eating, and therefore his or her eating is under cognitive control, it makes sense for external eating scores to be lower if restrained eating scores are higher. In fact, when the means of external and restrained eating are examined, this trend is seen; as restrained eating scores increase, external eating scores decrease (see Table 5). This is in accordance with previous work by Goldfield and colleagues (2010a) and a recent longitudinal study that found a similar trend (Snoek et al., 2013). Even though the bivariate correlation between restrained and external eating is weakly positive in the present study $(r=.076, p<.001)$, the inverse trend is evident in the means (see Table 5). 


\section{Moderation Analyses (Main Sample)}

The moderated multiple parallel mediation analyses, representing objective 4, allowed us to examine if the significant specific indirect effects were consistent across age, gender, ethnicity, and SES. In terms of moderating effects in multiple mediation models that controlled for socio-demographic covariates (models $2 \mathrm{a}$ and $2 \mathrm{~b}$ ), external eating was equally significant across age groups (early versus late adolescence), gender, ethnicity (Caucasian versus other), and SES. Restrained eating remained equally significant across age and ethnicity, but differed across gender and SES. As discussed, the relationship between attachment and BMI was significantly mediated by restrained eating behaviour. The mediation effect of restrained eating was stronger for females than for males, but significant for both. Similar results have been found in previous research; females tend to restrict their eating more than males, possibly because of poorer body or weight satisfaction (Anderson \& Bulik, 2004). The bivariate correlations between gender and appearance and weight esteem support this, as females felt worse about their bodies than males (see Tables 3 and 4).

The specific indirect effect of restrained eating was also moderated by SES, such that the effect through restrained eating was significant for youth from higher SES families, and not for youth from lower SES families. The research on SES and eating behaviours is mixed. Some studies have found that restrained eating is more common among girls from higher SES families (e.g. Paxton, Sculthorpe, \& Gibbons, 1994), whereas other studies have found no differences in eating behaviours across SES groups (e.g. Story, French, Resnick, \& Blum, 1995). 
Moreover, the research on SES and BMI is also inconsistent, with both positive (e.g. Gibbs \& Forste, 2013), and null (Sobal \& Stunkard, 1989) associations in the literature. One study found that in Canada, the risk of overweight and obesity was more related to province than SES, with higher obesity rates in the East and decreasing toward the West (Willms, Tremblay, \& Katzmarzyk, 2003). The bivariate correlation between SES and BMI in the present study is in line with findings from the Canadian Community Healthy Survey, which found that children and adolescents were more likely to be overweight or obese if no members of the household had completed postsecondary school, than if at least one member of the household had (Shields, 2005). Although the bivariate correlation between SES and BMI supports this, the fact that the mediational effect of restrained eating was statistically significant for youth with at least one parent who attended postsecondary school, but was not significant for youth from families where neither parent attended postsecondary school, suggests that insecurely attached youth from higher SES families score higher on restrained eating resulting in higher BMIs. However, the bivariate correlation between restrained eating and SES was not significant in the current study, suggesting that the moderating effects of SES should be interpreted with caution as they could be somewhat inconclusive. Moreover, because parental education was used as a proxy measure of SES, unfortunately any conclusions drawn based on SES are very speculative and need replication.

\section{Hierarchical Multiple Regression (Main Sample)}

The hierarchical multiple regression analyses, representing objective 1, revealed that attachment style significantly predicted BMI after controlling for socio-demographic 
variables (see Tables 6 and 7), however once psychological and behavioural correlates were added to the model, the contribution of attachment style was attenuated. Of interest, body esteem, more specifically weight dissatisfaction, was the strongest predictor of BMI in the hierarchical regression model contributing $6.15 \%$ of unique variance, followed by increased age which contributed $5.43 \%$ of unique variance. Given the cross-sectional nature of this study, it cannot be said with certainty whether or not weight dissatisfaction is a contributor or consequence of increased BMI in youth, although previous longitudinal studies have suggested that it is a predictor of overweight and obesity. The positive association between age and BMI is well documented and considered to be a natural part of growth and development (Kuczmarski et al., 2002). Contrary to previous research on depression and obesity, higher levels of depression did not emerge as one of the strongest predictors. In fact, higher levels of depression significantly predicted lower BMI, but only accounted for $0.19 \%$ of the variance. Higher levels of anxiety also predicted lower BMI, and accounted for $0.59 \%$ of the variance.

\section{Mediation Analyses (Underweight Sample)}

A multiple mediation analysis was conducted in a sub-sample of underweight (thinness grades 1 and 2) youth to determine if dysregulated eating behaviours mediated the relationship between attachment style and BMI, represented by objective 5 . Results indicate that as a set, the dysregulated eating behaviours did not mediate the relationship between attachment style and BMI, whether any covariates were controlled for or not. In the dichotomous attachment model only, while controlling for socio-demographic factors, depression, and anxiety, insecure attachment significantly predicted lower levels of 
restrained, emotional, and external eating, however none of the eating behaviours significantly predicted BMI (see Figure 3). The fact that insecure attachment significantly predicted lower levels of dysregulated eating behaviours is not in agreement with previous research that has demonstrated the opposite relationship (Goossens et al., 2012). It is surprising that none of the three dysregulated eating behaviours predicted BMI in the underweight sample, even without controlling for any covariates, but this result is supported by the non-significant bivariate correlations between BMI and restrained, emotional, and external eating (see Table 15). This suggests that secure attachment may be associated with unhealthy eating behaviours in underweight youth, suggesting that there is some other mechanism at play that influences BMI in underweight youth. These results should be interpreted with caution given the small sample size, and the nonsignificant bivariate correlation between attachment style and BMI in the underweight sample. In fact, the bivariate correlation between attachment and BMI was larger but not significant in the underweight sample (see Tables 15 and 16), and was smaller but significant in the main sample (see Tables 3 and 4). This could be due to lack of power as a result of the small sample size of underweight youth, and should be replicated with a larger sample size in the future. Unfortunately, a measure of effect size is not possible in the multiple mediator case (Hayes, 2013).

\section{Validity of the Relationship Questionnaire}

Although not an explicit objective of the present study, the validity of the RQ was indirectly assessed by examining if attachment style correlated in expected directions with other validated measures. The present study adds validity to the use of the RQ as 
correlations with attachment were in expected directions in the main sample. As seen in Tables 3 and 4, insecure attachment was significantly correlated with poorer body esteem (BESAA), higher levels of dysregulated eating (DEBQ), more severe symptoms of depression (CDI), higher levels of anxiety (MASC), lower levels of physical activity (GODIN), and lower levels of SES (parental education as a proxy measure of SES). This validates our use of these variables as covariates in the mediation analyses of the main sample. In the underweight sample, when attachment was dichotomized, insecure attachment was significantly correlated with increased depression, increased anxiety, and lower SES (see Table 15). These correlations are in the expected direction. However, when attachment was measured continuously, it was significantly correlated with lower levels of restrained eating (see Table 16). This is opposite to what would be expected, and justifies the decision to analyze underweight youth separately. Analyses involving the main sample also add support to the use of Matsuoka and colleagues' (2006) continuous measure of attachment (TAS) derived from the RQ, as similar results were found when the dichotomous or continuous measure of attachment was used.

\section{Limitations and Strengths}

Although important novel findings emerged from the present study, several limitations should be recognized. First, and possibly the largest limitation of the present study, is its cross-sectional design. Theoretically, because attachment style begins to develop in infancy and is relatively stable throughout life, it should precede the development of dysregulated eating behaviours. However, due to the cross-sectional nature of this study, it cannot be said with certainty whether or not the model was 
correctly specified. For example, it is possible that individuals with dysregulated eating behaviours have difficulty relating with others, and may therefore respond to the attachment questionnaire differently. Moreover, the cross-sectional design does not allow for causality inferences, therefore it is impossible to know whether restrained eating is a cause or consequence of increased BMI. Another limitation is that BMI was used to assess adiposity. Even though BMI is one of the most commonly used measures of adiposity due to its easy collection and reliability, it does not account for fat distribution nor does it discriminate between fat and muscle (Stevens, McClain, \& Truesdale, 2008). More specific measures of adiposity include Dual-energy X-ray absorptiometry (DEXA) or Magnetic Resonance Imaging (MRI), but of course, the cost and logistics of including such measures in large community-based studies is prohibitive. Another limitation is the attachment questionnaire (RQ). Although the RQ is one of the most widely used measure of attachment style, and was used in the REAL study due to its ease of administration, there are more robust measures available that should be used in future studies.

Limitations of the present study are balanced with several strengths including a large representative sample of Ontario youth, and the fact that height and weight of youth were objectively measured by research staff. Objectively measuring BMI decreases the possibility of any bias in self-reporting. Another strength of this study is that it was the first to examine three types of dysregulated eating behaviours in one parsimonious model, using a robust test of multiple mediation developed by Preacher and Hayes (2008). By including all three dysregulated eating behaviours in the same model, we were able to pit three theories of obesity against one another (restraint theory, externality 
theory, and psychosomatic theory) and determine that restrained eating was the strongest mediational pathway between insecure attachment and BMI in this sample. A final strength of this study is the large number of covariates included in the analyses. Not only is this the first study to examine three dysregulated eating behaviours as mediating mechanisms between attachment and BMI, but it is also the first to include several sociodemographic, psychological, and behavioural covariates. The mediation models that included all covariates were not significant, likely because after all covariates were entered in the model, there was little variance left to be predicted by attachment style. Given that negative body esteem, more specifically negative appearance and weight esteem, were such strong predictors of increased BMI in the hierarchical multiple regression, and given that insecure attachment is an important factor in the development of body esteem (Bamford \& Halliwell, 2009; Cheng \& Mallinckrodt, 2009; Hardit \& Hannum, 2012), future research should examine the role of body dissatisfaction in the relationship between attachment and BMI. For instance, it is possible that a serial mediation model would better explain the relationship between insecure attachment and BMI; insecure attachment could predict negative body esteem, which could lead to restrained eating behaviour, and subsequent weight gain.

\section{Conclusions and Future Directions}

The most significant finding of the present study was that insecure attachment significantly predicted increased BMI in youth, and this relationship was significantly mediated by restrained eating behaviour. Gender significantly moderated this mediational pathway, and although the mediational pathway was significant for both males and 
females, it was slightly stronger for females. SES (as assessed by parental education) also significantly moderated the mediational pathway such that it was significant for higher SES families, but not for lower SES families. This is rather counterintuitive given that some research has shown that lower SES increases the risk of overweight and obesity. However, the relationship between SES and obesity in Canada in somewhat unclear, therefore the moderating effect of SES should be interpreted with caution, and should most definitely be investigated further.

Future research should build on these initial findings by using a longitudinal design to better understand the directionality of the relationships discussed in the present study. Longitudinal studies would also help determine if the mediation model was correctly specified in terms of the temporal order of attachment, dysregulated eating, and BMI. Future studies should also entertain the possibility of using more specific measures of adiposity, such as Dual-energy X-ray absorptiometry (DEXA), to better define overweight and obesity. Attachment style could also be assessed more precisely in the future using more robust measures. Furthermore, extending the age ranges of the sample would improve our understanding of how dysregulated eating behaviours may change throughout development. For instance, emotional eating is fairly rare in youth, but it is possible that emotional eating may be a stronger mediational pathway in adults.

In spite of its limitations, the present study adds to a growing body of literature investigating how attachment style may contribute to the development or maintenance of overweight and obesity in youth. The gold standard treatment for pediatric obesity is behavioural family-based interventions (Goldfield, Raynor, \& Epstein, 2002; Skelton, 
Buehler, Irby, \& Grzywacz, 2012). The rationale behind family-based interventions is that parents play a pivotal role in influencing a child's health behaviours (Davison \& Birch, 2001), and that a child's weight problems develop and can be maintained in the family environment (Golan \& Weizman, 2001). Therefore, family-based interventions focus on changing the behaviour of the overweight or obese youth as well as the behaviours of other family members. However, if family-based approaches are the recommended treatment, the dearth of empirical research examining the role of individual factors that develop in the family context, such as attachment style, contribute to the development of obesity is noteworthy. Attachment not only develops in the family context, but is relevant in day-to-day family interactions, extends beyond interactions within the family to other relationships in a youth's life, and plays a role in how an individual feels about him or herself (i.e. body esteem). Therefore, a greater effort should be made to consider attachment style in the development of obesity prevention and treatment strategies. For example, many behavioural family-based interventions include a caloric restriction component. Given that restrained eating was found to mediate the relationship between insecure attachment and BMI in the present study, instructing insecurely attached youth to restrain their caloric intake may be contraindicated. Instead, exploring ways of increasing attachment security before embarking on other components of treatment may be more appropriate for insecurely attached youth.

In conclusion, the novel findings of the present study support attachment style as a possible etiological pathway in the development of overweight and obesity, as well as suggest that restrained eating may be a possible mediating modifiable risk factor and 
hence an intervention target. These findings suggest a shift from caloric restriction to healthy balanced diet may be most effective for optimal weight management in insecurely attached youth. Future research that builds on the present study's novel findings is needed in order to replicate and further examine how attachment style relates to overweight and obesity in youth, and the specific effects that dysregulated eating behaviours, as well as other potential modifiable mediating variables, contribute to this relationship. 


\section{References}

Ainsworth, M. D., \& Bowlby, J. (1991). An ethological approach to personality development. American Psychologist, 46(4), 333-341. doi:10.1037/0003066X.46.4.333

Alberga, A. S., Sigal, R. J., Goldfield, G., Prud'homme, D., \& Kenny, G. P. (2012). Overweight and obese teenagers: Why is adolescence a critical period? Pediatric Obesity, 7(4), 261-73. doi:10.1111/j.2047-6310.2011.00046.x

Ammaniti, M., Ambruzzi, A. M., Lucarelli, L., Cimino, S., \& D’Olimpio, F. (2004). Malnutrition and dysfunctional mother-child feeding interactions: Clinical assessment and research implications. Journal of the American College of Nutrition, 23(3), 259-71. doi:10.1080/07315724.2004.10719369

Anderson, C. B., \& Bulik, C. M. (2004). Gender differences in compensatory behaviors, weight and shape salience, and drive for thinness. Eating Behaviors, 5(1), 1-11. doi:10.1016/j.eatbeh.2003.07.001

Anderson, S. E., Cohen, P., Naumova, E. N., \& Must, A. (2006). Association of depression and anxiety disorders with weight change in a prospective communitybased study of children followed up into adulthood. Archives of Pediatrics \& Adolescent Medicine, 160(3), 285-91. doi:10.1001/archpedi.160.3.285

Anderson, S. E., Gooze, R. a, Lemeshow, S., \& Whitaker, R. C. (2012). Quality of early maternal-child relationship and risk of adolescent obesity. Pediatrics, 129(1), 13240. doi:10.1542/peds.2011-0972 
Anderson, S. E., \& Whitaker, R. C. (2011). Attachment security and obesity in US preschool-aged children. Archives of Pediatrics \& Adolescent Medicine, 165(3), 235-42. doi:10.1001/archpediatrics.2010.292

Andrade, A. M., Coutinho, S. R., Silva, M. N., Mata, J., Vieira, P. N., Minderico, C. S., ... Teixeira, P. J. (2010). The effect of physical activity on weight loss is mediated by eating self-regulation. Patient Education and Counseling, 79(3), 320-6. doi:10.1016/j.pec.2010.01.006

Anis, A. H., Zhang, W., Bansback, N., Guh, D. P., Amarsi, Z., \& Birmingham, C. L. (2010). Obesity and overweight in Canada: An updated cost-of-illness study. Obesity Reviews, 11(1), 31-40. doi:10.1111/j.1467-789X.2009.00579.x

Austin, S. B., Haines, J., \& Veugelers, P. J. (2009). Body satisfaction and body weight: Gender differences and sociodemographic determinants. BMC Public Health, 9(1), 313. doi:10.1186/1471-2458-9-313

Bamford, B., \& Halliwell, E. (2009). Investigating the role of attachment in social comparison theories of eating disorders within a non-clinical female population. European Eating Disorders Review: The Journal of the Eating Disorders Association, 17(5), 371-9. doi:10.1002/erv.951

Bartholomew, K., \& Horowitz, L. M. (1991). Attachment styles among young adults: A test of a four-category model. Journal of Personality and Social Psychology, 61(2), 226-44. doi:10.1037/0022-3514.61.2.226 
Baumrind, D. (1991). The influence of parenting style on adolescent competence and substance use. Journal of Early Adolescence, 11(1), 56-95. doi:10.1177/0272431691111004

Baumrind, D., Larzelere, R. E., \& Owens, E. B. (2010). Effects of preschool parents' power assertive patterns and practices on adolescent development. Parenting: Science and Practice, 10(3), 157-201. doi:10.1080/15295190903290790

Belcher, B. R., Nguyen-Rodriguez, S. T., McClain, A. D., Hsu, Y.-W., Unger, J. B., \& Spruijt-Metz, D. (2011). The influence of worries on emotional eating, weight concerns, and body mass index in Latina female youth. The Journal of Adolescent Health: Official Publication of the Society for Adolescent Medicine, 48(5), 487-92. doi:10.1016/j.jadohealth.2010.08.008

Bifulco, A., Mahon, J., Kwon, J. H., Moran, P. M., \& Jacobs, C. (2003). The Vulnerable Attachment Style Questionnaire (VASQ): An interview-based measure of attachment styles that predict depressive disorder. Psychological Medicine, 33(6), 1099-110. doi:10.1017/S0033291703008237

Birch, L. L., \& Deysher, M. (1985). Conditioned and unconditioned caloric compensation: Evidence for self-regulation of food intake in young children. Learning and Motivation, 16(3), 341-355. doi:10.1016/0023-9690(85)90020-7 Blaine, B. (2008). Does depression cause obesity?: A meta-analysis of longitudinal studies of depression and weight control. Journal of Health Psychology, 13(8), 1190-7. doi:10.1177/1359105308095977 
Boone, J. E., Gordon-Larsen, P., Adair, L. S., \& Popkin, B. M. (2007). Screen time and physical activity during adolescence: Longitudinal effects on obesity in young adulthood. International Journal of Behavioral Nutrition and Physical Activity, 10(26), 1-10. doi:10.1186/1479

Bosmans, G., Braet, C., Koster, E., \& De Raedt, R. (2009). Attachment security and attentional breadth toward the attachment figure in middle childhood. Journal of Clinical Child and Adolescent Psychology, 38(6), 872-82.

doi:10.1080/15374410903258926

Bosmans, G., Braet, C., Leeuwen, K. Van, \& Beyers, W. (2006). Do parenting behaviors predict externalizing behavior in adolescence, or is attachment the neglected $3 \mathrm{rd}$ factor? Journal of Youth and Adolescence, 35(3), 354-364. doi:10.1007/s10964005-9026-1

Bowlby, J. (1970). Disruption of affectional bonds and its effects on behavior. Journal of Contemporary Psychotherapy, 2(2), 75-86. doi: 10.1007/BF02118173

Bradley, R. H., \& Corwyn, R. F. (2002). Socioeconomic status and child development. Annual Review of Psychology, 53, 371-399.

doi:10.1146/annurev.psych.53.100901.135233

Braet, C., Claus, L., Goossens, L., Moens, E., Van Vlierberghe, L., \& Soetens, B. (2008). Differences in eating style between overweight and normal-weight youngsters. Journal of Health Psychology, 13(6), 733-43. doi:10.1177/1359105308093850 
Braet, C., \& Van Strien, T. (1997). Assessment of emotional, externally induced and restrained eating behaviour in nine to twelve-year-old obese and non-obese children. Behaviour Research and Therapy. doi.org/10.1016/S0005-7967(97)00045-4

Britz, B., Siegfried, W., Ziegler, A., Lamertz, C., Herpertz-Dahlmann, B. M., Remschmidt, H., ... Hebebrand, J. (2000). Rates of psychiatric disorders in a clinical study group of adolescents with extreme obesity and in obese adolescents ascertained via a population based study. International Journal of Obesity, 24(12), 1707-14. Retrieved from http://www.ncbi.nlm.nih.gov/pubmed/11126229

Brownell, K. D., Schwartz, M. B., Puhl, R. M., Henderson, K. E., \& Harris, J. L. (2009). The need for bold action to prevent adolescent obesity. The Journal of Adolescent Health, 45(Suppl 3), S8-S17. doi:10.1016/j.jadohealth.2009.03.004

Caron, A., Lafontaine, M.-F., Bureau, J.-F., Levesque, C., \& Johnson, S. M. (2012). Comparisons of close relationships: An evaluation of relationship quality and patterns of attachment to parents, friends, and romantic partners in young adults. Canadian Journal of Behavioural Science/Revue canadienne des sciences du comportement, 44(4), 245-256. doi:10.1037/a0028013

Carper, J. L., Orlet Fisher, J., \& Birch, L. L. (2000). Young girls' emerging dietary restraint and disinhibition are related to parental control in child feeding. Appetite, 35(2), 121-9. doi:10.1006/appe.2000.0343

Carson, V., Pickett, W., \& Janssen, I. (2011). Screen time and risk behaviors in 10- to 16year-old Canadian youth. Preventive Medicine, 52(2), 99-103. doi:10.1016/j.ypmed.2010.07.005 
ATTACHMENT AND OBESITY

Cheng, H.-L., \& Mallinckrodt, B. (2009). Parental bonds, anxious attachment, media internalization, and body image dissatisfaction: Exploring a mediation model. Journal of Counseling Psychology, 56(3), 365-375. doi:10.1037/a0015067

Clark, H. R., Goyder, E., Bissell, P., Blank, L., \& Peters, J. (2007). How do parents' child-feeding behaviours influence child weight? Implications for childhood obesity policy. Journal of Public Health, 29(2), 132-41. doi:10.1093/pubmed/fdm012

Cole, T. J., Bellizzi, M. C., Flegal, K. M., \& Dietz, W. H. (2000). Establishing a standard definition for child overweight and obesity worldwide: international survey. British Medical Journal, 320(7244), 1240-1240. doi:10.1136/bmj.320.7244.1240

Cole, T. J., Flegal, K. M., Nicholls, D., \& Jackson, A. A. (2007). Body mass index cut offs to define thinness in children and adolescents: international survey. $B M J$ (Clinical research ed.), 335(7612), 194. doi:10.1136/bmj.39238.399444.55

Cooper, M. J., \& Warren, L. (2011). The relationship between body weight (body mass index) and attachment history in young women. Eating Behaviors, 12(1), 94-6. doi:10.1016/j.eatbeh.2010.11.006

Cutting, T. M., Fisher, J. O., Grimm-Thomas, K., \& Birch, L. L. (1999). Like mother, like daughter: Familial patterns of overweight are mediated by mothers' dietary disinhibition. The American Journal of Clinical Nutrition, 69(4), 608-13. Retrieved from http://www.ncbi.nlm.nih.gov/pubmed/10197561

D’Argenio, A., Mazzi, C., Pecchioli, L., Di Lorenzo, G., Siracusano, A., \& Troisi, A. (2009). Early trauma and adult obesity: is psychological dysfunction the mediating 
ATTACHMENT AND OBESITY

mechanism? Physiology \& Behavior, 98(5), 543-6.

doi:10.1016/j.physbeh.2009.08.010

Davison, K. K., \& Birch, L. L. (2001). Childhood overweight: A contextual model and recommendations for future research. Obesity Reviews, 2(3), 159-171.

doi:10.1046/j.1467-789x.2001.00036.x

De Lauzon-Guillain, B., Romon, M., Musher-Eizenman, D., Heude, B., Basdevant, A., \& Charles, M. A. (2009). Cognitive restraint, uncontrolled eating and emotional eating: correlations between parent and adolescent. Maternal \& Child Nutrition, 5(2), 1718. doi:10.1111/j.1740-8709.2008.00164.x

Due, P., Damsgaard, M., Rasmussen, M., Holstein, B., Wardle, J., Merlo, J., ... Lynch, J. (2009). Socioeconomic position, macroeconomic environment and overweight among adolescents in 35 countries. International Journal of Obesity, 33(10), 10841093. doi:10.1038/ijo.2009.128

Epstein, L. H., Raja, S., Daniel, T. O., Paluch, R. A., Wilfley, D. E., Saelens, B. E., \& Roemmich, J. N. (2012). The built environment moderates effects of family-based childhood obesity treatment over 2 years. Annals of Behavioral Medicine, 44(2), 248-58. doi:10.1007/s12160-012-9383-4

Eriksson, J. G., Forsen, T., Tuomilehto, J., Osmond, C., \& Barker, D. J. P. (2001). Early growth and coronary heart disease in later life: Longitudinal study. British Medical Journal, 322, 949-953. 
Farrell Erickson, M., Sroufe, L. A., \& Egeland, B. (2008). The relationship between quality of attachment and behavior problems in preschool in a high-risk sample. Monographs of the Society for Research in Child Development, 50(1), 147-166.

Field, A. E., Austin, S. B., Taylor, C. B., Malspeis, S., Rosner, B., Rockett, H. R., ... Colditz, G. A. (2003). Relation between eating and weight change among preadolescents and adolescents. Pediatrics, 112(4), 900-906.

doi:10.1542/peds. 112.4.900

Fisher, J. O., \& Birch, L. L. (2002). Eating in the absence of hunger and overweight in girls from 5 to 7 y of age. American Journal of Clinical Nutrition, 76(1), 226-231. Retrieved from: http://www-ncbi-nlm-nihgov.proxy.bib.uottawa.ca/pmc/articles/PMC2604807/pdf/nihms61915.pdf

Forrester-Knauss, C., Perren, S., \& Alsaker, F. D. (2012). Does body mass index in childhood predict restraint eating in early adolescence? Appetite, 59(3), 921-6. doi:10.1016/j.appet.2012.08.026

Francis, L. A., \& Susman, E. J. (2009). Self-regulation and rapid weight gain in children from age 3 to 12 years. Archives of Pediatrics \& Adolescent Medicine, 163(4), 297302. doi:10.1001/archpediatrics.2008.579

Freedman, D. S., Khan, L. K., Serdula, M. K., Dietz, W. H., Srinivasan, S. R., \& Berenson, G. S. (2005). The relation of childhood BMI to adult adiposity: the Bogalusa Heart Study. Pediatrics, 115(1), 22-7. doi:10.1542/peds.2004-0220 
Gibbs, B. G., \& Forste, R. (2013). Socioeconomic status, infant feeding practices and early childhood obesity. Pediatric obesity, 1-12. doi:10.1111/j.2047$6310.2013 .00155 . \mathrm{x}$

Gilliland, J. A., Rangel, C. Y., Healy, M. A., Tucker, P., Loebach, J. E., Hess, P. M., ... Wilk, P. (2012). Linking childhood obesity to the built environment: A multi-level analysis of home and school neighbourhood factors associated with body mass index. Canadian Journal of Public Health, 103(Supp1 3), S15-S21. Retrieved from http://journal.cpha.ca/index.php/cjph/article/view/3283/2676

Gillman, M. W., Rifas-Shiman, S. L., Camargo, C. A., Berkey, C. S., Frazier, A. L., Rockett, H. R., ... Colditz, G. A. (2001). Risk of overweight among adolescents who were breastfed as infants. The Journal of the American Medical Association, 285(19), 2461-7. doi:10.1001/jama.285.19.2461

Golan, M., \& Weizman, A. (2001). Familial approach to the treatment of childhood obesity: Conceptual model. Society for Nutrition Education, 33(2), 102-107. doi:10.1016/S1499-4046(06)60173-5

Goldfield, G., Moore, C., Henderson, K., Buchholz, A., Obeid, N., \& Flament, M. (2010). The relation between weight-based teasing and psychological adjustment in adolescents. Paediatrics \& Child Health, 15(4), 283-8. Retrieved from http://www.pubmedcentral.nih.gov/articlerender.fcgi?artid=2912633\&tool=pmcentr ez\&rendertype $=$ abstract

Goldfield, G. S., Moore, C., Henderson, K., Buchholz, A., Obeid, N., \& Flament, M. F. (2010). Body dissatisfaction, dietary restraint, depression, and weight status in 
ATTACHMENT AND OBESITY

adolescents. The Journal of School Health, 80(4), 186-92. doi:10.1111/j.17461561.2009.00485.x

Goodman, E., \& Whitaker, R. C. (2002). A prospective study of the role of depression in the development and persistence of adolescent obesity. Pediatrics, 110(3), 497-504. doi:10.1542/peds. 110.3 .497

Goossens, L., Braet, C., Van Durme, K., Decaluwé, V., \& Bosmans, G. (2012). The parent-child relationship as predictor of eating pathology and weight gain in preadolescents. Journal of Clinical Child and Adolescent Psychology, 41(4), 44557. doi:10.1080/15374416.2012.660690

Goossens, L., Braet, C., Van Vlierberghe, L., \& Mels, S. (2009). Loss of control over eating in overweight youngsters: The role of anxiety, depression and emotional eating. European Eating dDsorders Review, 17(1), 68-78. doi:10.1002/erv.892

Graziano, P. A., Calkins, S. D., \& Keane, S. P. (2010). Toddler self-regulation skills predict risk for pediatric obesity. International Journal of Obesity, 34(4), 633-41. doi:10.1038/ijo.2009.288

Greco, L., Power, C., \& Peckham, C. (1995). Adult outcome of normal children who are short or underweight at age 7 years. British Medical Journal, 310, 696-700.

Retrieved from http://www.pubmedcentral.nih.gov/articlerender.fcgi?artid=2549095\&tool=pmcentr ez\&rendertype $=$ abstract

Griffin, D., \& Bartholomew, K. (1994). Models of the self and other: Fundamental dimensions underlying measures of adult attachment. Journal of Personality and 
ATTACHMENT AND OBESITY

Social Psychology, 67(3), 430-445. Retrieved from

http://www.sfu.ca/psyc/faculty/bartholomew/research/publications/so1994.pdf

Halvarsson, K., \& Sjoden, P.-O. (1998). Psychometric properties of the Dutch Eating Behaviour Questionnaire (DEBQ) among 9-10-Year-Old Swedish girls. European Eating Disorders Review, 125(6), 115-125. doi: 10.1002/(SICI)10990968(199806)6:2<115::AID-ERV222>3.0.CO;2-M

Harder, T., Bergmann, R., Kallischnigg, G., \& Plagemann, A. (2005). Duration of breastfeeding and risk of overweight: A meta-analysis. American Journal of Epidemiology, 162(5), 397-403. doi:10.1093/aje/kwi222

Hardit, S. K., \& Hannum, J. W. (2012). Attachment, the tripartite influence model, and the development of body dissatisfaction. Body Image, 9(4), 469-75. doi:10.1016/j.bodyim.2012.06.003

Hazan, C., \& Shaver, P. (1987). Interpersonal relations and group process: Romantic love conceptualized as an attachment process. Journal of Personality and Social Psychology, 52(3), 511-524. Retrieved from http://www2.psych.ubc.ca/ schaller/Psyc591Readings/HazanShaver1987.pdf

Hendry, L. B., Roberts, W., Glendinning, A., \& Coleman, J. C. (1992). Adolescents' perceptions of significant individuals in their lives. Journal of Adolescence, 15(3), 255-70. doi:10.1016/0140-1971(92)90029-5

Herman, C. P., \& Polivy, J. (1975). Anxiety, restraint, and eating behavior. Journal of abnormal psychology, 84(6), 66-72. Retrieved from http://www.ncbi.nlm.nih.gov/pubmed/1194527 
Hill, C., Llewellyn, C. H., Saxton, J., Webber, L., Semmler, C., Carnell, S., ... Wardle, J. (2008). Adiposity and "eating in the absence of hunger" in children. International Journal of Obesity, 32, 1499-1505. doi:10.1038/ijo.2008.113

Hofer, M. (2006). Psychobiological roots of early attachment. Current Directions in Psychological Science, 15(2), 84-88. doi:10.1111/j.0963-7214.2006.00412.x

Holden, G. W., \& Miller, P. C. (1999). Eduring and Different: A meta-analysis of the similarity in parents' child rearing. Psychological Bulletin, 125(2), 223-254. doi:10.1037/0033-2909.125.2.223

Holterman, M. J., Holterman, A. Le, \& Browne, A. F. (2012). Pediatric Obesity. Surgical Clinics of North America, 92(3), 559-582. doi:10.1016/j.suc.2012.03.007

Jansen, P. W., Roza, S. J., Jaddoe, V. W., Mackenbach, J. D., Raat, H., Hofman, A., ... Tiemeier, H. (2012). Children's eating behavior, feeding practices of parents and weight problems in early childhood: results from the population-based Generation $\mathrm{R}$ Study. The International Journal of Behavioral Nutrition and Physical Activity, 9(1), 130. doi:10.1186/1479-5868-9-130

Janssen, I., Lam, M., \& Katzmarzyk, P. T. (2009). Influence of overweight and obesity on physician costs in adolescents and adults in Ontario, Canada. Obesity Reviews, 10(1), 51-7. doi:10.1111/j.1467-789X.2008.00514.x

Janssen, I., \& Leblanc, A. G. (2010). Systematic review of the health benefits of physical activity and fitness in school-aged children and youth. The International Journal of Behavioral Nutrition and Physical Activity, 7, 40. doi:10.1186/1479-5868-7-40 
Johnson, F., Pratt, M., \& Wardle, J. (2012). Dietary restraint and self-regulation in eating behavior. International Journal of Obesity, 36(5), 665-74. doi:10.1038/ijo.2011.156

Johnson, J. G., Cohen, P., Kasen, S., \& Brook, J. S. (2002). Childhood adversities associated with risk for eating disorders or weight problems during adolescence or early adulthood. The American Journal of Psychiatry, 159(3), 394-400. doi:10.1176/appi.ajp.159.3.394

Karavasilis, L., Doyle, A. B., \& Markiewicz, D. (2003). Associations between parenting style and attachment to mother in middle childhood and adolescence. International Journal of Behavioral Development, 27(2), 153-164.

doi: $10.1080 / 01650250244000155$

Katzmarzyk, P. T., \& Janssen, I. (2004). The economic costs associated with physical inactivity and obesity in Canada: An update. Canadian Journal of Applied Physiology, 29(1), 90-115. doi:10.1139/h04-008

Katzmarzyk, P. T., Janssen, I., Morrison, K. M., \& Tremblay, M. S. (2007). 2006 Canadian Clinical Practice Guidelines on the Management and Prevention of Obesity in Adults and Children. Canadian Medical Association Journal, 176(8), 1117. doi:10.1503/cmaj.061409

Koeppen-Schomerus, G., Wardle, J., \& Plomin, R. (2001). A genetic analysis of weight and overweight in 4-year-old twin pairs. International Journal of Obesity, 25(6), 838-844. doi:10.1038/sj.ijo.0801589 
ATTACHMENT AND OBESITY

Kramer, M. S. (1981). Do breast-feeding and delayed introduction of solid foods protect against subsequent obesity? The Journal of Pediatrics, 98(6), 883-7. doi:10.1016/S0022-3476(81)80579-3

Krebs, N. F., Himes, J. H., Jacobson, D., Nicklas, T. A., Styne, D., \& Guilday, P. (2007). Assessment of Child and Adolescent Overweight and Obesity. Pediatrics, 120(Supplement 4), S193-S228. doi:10.1542/peds.2007-2329D

Kuczmarski, R. J., Ogden, C. L., Guo, S. S., Grummer-Strawn, L., Flegal, K. M., Mei, Z., ... Johnson, C. L. (2002). 2000 CDC Growth Charts for the United States: methods and development. Vital and health statistics. Series 11, Data from the national health survey (pp. 1-190). Retrieved from http://www.ncbi.nlm.nih.gov/pubmed/12043359

Kuhn, C. M., \& Schanberg, S. M. (1998). Responses to maternal separation: Mechanisms and mediators. International Journal of Developmental Neuroscience, 16(3-4), 261270. doi:10.1016/S0736-5748(98)00034-3

Lanciano, T., Curci, A., Kafetsios, K., Elia, L., \& Zammuner, V. L. (2012). Attachment and dysfunctional rumination: The mediating role of emotional intelligence abilities. Personality and Individual Differences, 53(6), 753-758. doi:10.1016/j.paid.2012.05.027

Latner, J. D., \& Stunkard, A. J. (2003). Getting worse: The stigmatization of obese children. Obesity Research, 11(3), 452-6. doi:10.1038/oby.2003.61 
Lattimore, P. J., \& Halford, J. C. G. (2003). Adolescence and the diet-dieting disparity: Healthy food choice or risky health behaviour? British Journal of Health Psychology, 8, 451-63. doi:10.1348/135910703770238301

Leak, G. K., \& Parsons, C. J. (2001). The susceptibility of three attachment style measures to socially desirable responding. Social Behavior and Personality, 29(1), 21-30. doi:http://dx.doi.org/10.2224/sbp.2001.29.1.21

Li, R., Fein, S. B., \& Grummer-Strawn, L. M. (2010). Do infants fed from bottles lack self-regulation of milk intake compared with directly breastfed infants? Pediatrics, 125(6), e1386-93. doi:10.1542/peds.2009-2549

Lissau, I., \& Sorensen, T. I. (1994). Parental neglect young childhood and increased risk of obesity in young adulthood. Lancet, 343, 324-327. doi:10.1016/S01406736(94)91163-0

Liu, Q. (2009). The Effects of Adult Attachment and Life Stress on Daily Depression: A Sample of Japanese University Students, 65(7), 639-652. doi:10.1002/jclp

Lluch, A., Herbeth, B., Méjean, L., \& Siest, G. (2000). Dietary intakes, eating style and overweight in the Stanislas Family Study. International Journal of Obesity, 24(11), 1493-1499. doi:10.1038/sj.ijo.0801425

Lobstein, T., Baur, L., \& Uauy, R. (2004). Obesity in children and young people: A crisis in public health. Obesity Reviews, 5(Suppl 1), 4-85. doi:10.1111/j.1467789X.2004.00133.x

Luomala, H. T., Sirieix, L., \& Tahir, R. (2009). Exploring Emotional-Eating Patterns in Different Cultures: Toward a Conceptual Framework Model. Journal of 
ATTACHMENT AND OBESITY

International Consumer Marketing, 21(3), 231-245.

doi: $10.1080 / 08961530802202818$

Maffeis, C. (2000). Aetiology of overweight and obesity in children and adolescents. European Journal of Pediatrics, 159(Suppl 1), S35-S44. doi:10.1007/PL00014361

March, J. S., Parker, J. D. A., Sullivan, K., Stallings, P., \& Conners, K. (1997). The Multidimensional Anxiety Scale for Children (MASC): Factor Structure, Reliability, and Validity. Journal of the American Academy of Child and Adolescent Psychiatry, $36(4), 554-565$.

March, J. S., \& Sullivan, K. (1999). Test-retest reliability of the Multidimensional Anxiety Scale for Children. Journal of Anxiety Disorders, 13(4), 349-58. Retrieved from http://www.ncbi.nlm.nih.gov/pubmed/10504106

Matsuoka, N., Uji, M., Hiramura, H., Chen, Z., Shikai, N., Kishida, Y., \& Kitamura, T. (2006). Adolescents' attachment style and early experiences: A gender difference. Archives of Women's Mental Health, 9(1), 23-9. doi:10.1007/s00737-005-0105-9

McCabe, M. P., Waqa, G., Dev, A., Cama, T., \& Swinburn, B. a. (2013). The role of cultural values and religion on views of body size and eating practices among adolescents from Fiji, Tonga, and Australia. British Journal of Health Psychology, 18(2), 383-94. doi:10.1111/j.2044-8287.2012.02090.x

Mendelson, B. K., Mendelson, M. J., \& White, D. R. (2001). Body-esteem scale for adolescents and adults. Journal of Personality Assessment, 76(1), 90-106. doi:10.1207/S15327752JPA7601_6 
Moore, C. J., \& Cunningham, S. A. (2012). Social position, psychological stress, and obesity: A systematic review. Journal of the Academy of Nutrition and Dietetics, 112(4), 518-26. doi:10.1016/j.jand.2011.12.001

Negayama, K., Norimatsu, H., Barratt, M., \& Bouville, J.-F. (2012). Japan-France-US comparison of infant weaning from mother's viewpoint. Journal of Reproductive and Infant Psychology, 30(1), 77-91. doi:10.1080/02646838.2011.649473

Neumark-Sztainer, D., Paxton, S. J., Hannan, P. J., Haines, J., \& Story, M. (2006). Does body satisfaction matter? Five-year longitudinal associations between body satisfaction and health behaviors in adolescent females and males. The Journal of Adolescent Health, 39(2), 244-51. doi:10.1016/j.jadohealth.2005.12.001

Nguyen-Rodriguez, S. T., Chou, C.-P., Unger, J. B., \& Spruijt-Metz, D. (2008). BMI as a moderator of perceived stress and emotional eating in adolescents. Eating Behaviors, 9(2), 238-46. doi:10.1016/j.eatbeh.2007.09.001

O'Kearney, R. (1996). Attachment disruption in anorexia nervosa and bulimia nervosa: a review of theory and empirical research. The International Journal of Eating Disorders, 20(2), 115-27. doi:10.1002/(SICI)1098-108X(199609)20:2<115::AIDEAT1>3.0.CO;2-J

O’Loughlin, J., Gray-Donald, K., Paradis, G., \& Meshefedjian, G. (2000). One- and twoyear predictors of excess weight gain among elementary schoolchildren in multiethnic, low-income, inner-city neighborhoods. American Journal of Epidemiology, 152(8), 739-46. doi:10.1093/aje/152.8.739 
Ogden, C. L., Carroll, M. D., Curtin, L. R., Mcdowell, M. A., Tabak, C. J., \& Flegal, K. M. (2006). Prevalence of Overweight and Obesity in the United States, 1999-2004. The Journal of the American Medical Association, 295(13), 1999-2004. doi:10.1001/jama.295.13.1549

Osman, A., Williams, J. E., Espenschade, K., Gutierrez, P. M., Bailey, J. R., \& Chowdhry, O. (2008). Further evidence of the reliability and validity of the Multidimensional Anxiety Scale for Children (MASC) in psychiatric inpatient samples. Journal of Psychopathology and Behavioral Assessment, 31(3), 202-214. doi:10.1007/s10862-008-9095-z

Owen, C. G., Martin, R. M., Whincup, P. H., Smith, G. D., \& Cook, D. G. (2005). Effect of infant feeding on the risk of obesity across the life course: A quantitative review of published evidence. Pediatrics, 115(5), 1367-77. doi:10.1542/peds.2004-1176

Papies, E. K., Stroebe, W., \& Aarts, H. (2008). Healthy cognition: Processes of selfregulatory success in restrained eating. Personality \& Social Psychology Bulletin, 34(9), 1290-300. doi:10.1177/0146167208320063

Perrine, R. M., \& King, A. S. (2004). Why do you want to see me? Students' reactions to a professor's request as a function of attachment and note clarity. The Journal of Experimental Education, 73(1), 5-20. doi:10.3200/JEXE.71.1.5-22

Piernas, C., \& Popkin, B. M. (2011). Food portion patterns and trends among U.S. children and the relationship to total eating occasion size, 1977-2006. The Journal of Nutrition, 141(6), 1159-1164. doi:10.3945/jn.111.138727.in 
Pike, K. M., \& Rodin, J. (1991). Mothers, daughters, and disordered eating. Journal of Abnormal Psychology, 100(2), 198-204. doi:10.1037/0021-843X.100.2.198

Pine, D. S., Cohen, P., Brook, J., \& Coplan, J. D. (1997). Psychiatric symptoms in adolescence as predictors of obesity in early adulthood: A longitudinal study. American Journal of Public Health, 87(8), 1303-10. doi: 10.2105/AJPH.87.8.1303

Pine, D. S., Goldstein, R. B., Wolk, S., \& Weissman, M. M. (2001). The association between childhood depression and adulthood body mass index. Pediatrics, 107(5), 1049-1056. doi:10.1542/peds.107.5.1049

Pipp, S., Easterbrooks, M. a, \& Harmon, R. J. (1992). The relation between attachment and knowledge of self and mother in one to three-year-old infants. Child Development, 63(3), 738-50. doi: 10.1111/j.1467-8624.1992.tb01658.x

Polivy, J., \& Herman, C. P. (1985). Dieting and binging: A causal analysis. American Psychologist, 40(2), 193. doi:10.1037/0003-066X.40.2.193

Preacher, K. J., \& Hayes, A. F. (2008). Asymptotic and resampling strategies for assessing and comparing indirect effects in multiple mediator models. Behavior Research Methods, 40(3), 879-891. doi:10.3758/BRM.40.3.879

Puhl, R. M., \& Latner, J. D. (2007). Stigma, obesity, and the health of the nation's children. Psychological Bulletin, 133(4), 557-80. doi:10.1037/0033-2909.133.4.557

Rahman, T., Cushing, R. A., \& Jackson, R. J. (2011). Contributions of built environment to childhood obesity. Mount Sinai Journal of Medicine, 78(1), 49-57. doi:10.1002/MSJ 
ATTACHMENT AND OBESITY

Roberts, K., Shields, M., de Groh, M., Aziz, A., \& Gilbert, J.-A. (2012). Overweight and obesity in children and adolescents: Results from the 2009 to 2011 Canadian Health Measures Survey. Statistics Canada Health Reports, 23(3), 7. Retrieved from http://www.statcan.gc.ca/pub/82-003-x/82-003-x2012003-eng.pdf\#page=39

Rofey, D. L., Silk, J. S., \& Dahl, R. E. (2010). A longitudinal study of childhood depression and anxiety in relation to weight gain. Child Psychiatry and Human Development, 40(4), 517-526. doi:10.1007/s10578-009-0141-1.A

Ross, L. R., McKim, M. K., \& DiTommaso, E. (2006). How do underlying "self" and "other" dimensions define adult attachment styles? Canadian Journal of Behavioural Science, 38(4), 294-310. doi:10.1037/cjbs2006016

Russell-Mayhew, S., McVey, G., Bardick, A., \& Ireland, A. (2012). Mental health, wellness, and childhood overweight/obesity. Journal of Obesity, 2012, 281801. doi:10.1155/2012/281801

Schachter, S., \& Rodin, J. (Eds.). Obese humans and rats. Potomac, Md.: Lawrence Erlbaum Associates, 1974.

Scharfe, E., \& Bartholomew, K. (1994). Reliability and stability of adult attachment patterns. Personal Relationships, 1, 23-43. doi:10.1111/j.1475-6811.1994.tb00053.x

Schneiderman, J. U., Mennen, F. E., Negriff, S., \& Trickett, P. K. (2012). Overweight and obesity among maltreated young adolescents. Child Abuse \& Neglect, 36(4), 370-8. doi:10.1016/j.chiabu.2012.03.001 
Shanmugam, V., Jowett, S., \& Meyer, C. (2012). Eating psychopathology amongst athletes: links to current attachment styles. Eating Behaviors, 13(1), 5-12. doi:10.1016/j.eatbeh.2011.09.004

Shields, M. (2005). Measured obesity: Overweight Canadian children and adolescents (pp. 1-34). Ottawa.

Shields, M. (2006). Overweight and obesity among children and youth. Health reports / Statistics Canada, Canadian Centre for Health Information, 17(3), 27-42. Retrieved from http://www.geog.ubc.ca/courses/geob370/students/class10/ddchan/www/images/doc s/Shields.pdf

Shomaker, L. B., Tanofsky-kraff, M., Zocca, J. M., Courville, A., Kozlosky, M., Columbo, K. M., ... Yanovski, J. A. (2010). Eating in the absence of hunger in adolescents: Intake after a large-array meal compared with that after a standardized meal. American Journal of Clinical Nutrition, 92(4), 697-703. doi:10.3945/ajen.2010.29812.1

Silventoinen, K., Rokholm, B., Kaprio, J., \& Sørensen, T. I. a. (2010). The genetic and environmental influences on childhood obesity: A systematic review of twin and adoption studies. International Journal of Obesity, 34(1), 29-40. doi:10.1038/ijo.2009.177

Singh, A. S., Mulder, C., Twisk, J. W. R., van Mechelen, W., \& Chinapaw, M. J. M. (2008). Tracking of childhood overweight into adulthood: a systematic review of the literature. Obesity Reviews, 9(5), 474-88. doi:10.1111/j.1467-789X.2008.00475.x 
Singhal, A., \& Lanigan, J. (2007). Breastfeeding, early growth and later obesity. Obesity Reviews, 8(Suppl 1), 51-54. doi:10.1111/j.1467-789X.2007.00318.x

Skelton, J. A., Buehler, C., Irby, M. B., \& Grzywacz, J. G. (2012). Where are family theories in family-based obesity treatment?: Conceptualizing the study of families in pediatric weight management. International Journal of Obesity, 36(7), 891-900. doi:10.1038/ijo.2012.56

Snoek, H. M., Engels, R. C. M. E., van Strien, T., \& Otten, R. (2013). Emotional, external and restrained eating behaviour and BMI trajectories in adolescence. Appetite, 67, 81-7. doi:10.1016/j.appet.2013.03.014

Snoek, H. M., Van Strien, T., Janssens, J. M. a M., \& Engels, R. C. M. E. (2008). Restrained eating and BMI: A longitudinal study among adolescents. Health Psychology, 27(6), 753-9. doi:10.1037/0278-6133.27.6.753

Snoek, H. M., van Strien, T., Janssens, J. M. a M., \& Engels, R. C. M. E. (2009). Longitudinal relationships between fathers', mothers', and adolescents' restrained eating. Appetite, 52(2), 461-8. doi:10.1016/j.appet.2008.12.009

Snoek, H. M., Van Strien, T., Janssens, J. M. A. M., \& Engels, R. C. M. E. (2007). Emotional, external, restrained eating and overweight in Dutch adolescents. Scandinavian Journal of Psychology, 48(1), 23-32. doi:10.1111/j.14679450.2006.00568.x

Sobal, J., \& Stunkard, A. J. (1989). Socioeconomic status and obesity: A review of the literature. Psychological Bulletin, 105(2), 260-275. doi:10.1037/00332909.105.2.260 
ATTACHMENT AND OBESITY

Sotomayor-Peterson, M., De Baca, T. C., Figueredo, a. J., \& Smith-Castro, V. (2012). Shared Parenting, Parental Effort, and Life History Strategy: A Cross-Cultural Comparison. Journal of Cross-Cultural Psychology, 44(4), 620-639. doi: $10.1177 / 0022022112455456$

Stenhammar, C., Olsson, G., Bahmanyar, S., Hulting, A.-L., Wettergren, B., Edlund, B., \& Montgomery, S. (2010). Family stress and BMI in young children. Acta Paediatrica, 99(8), 1205-12. doi:10.1111/j.1651-2227.2010.01776.x

Stevens, J., McClain, J. E., \& Truesdale, K. P. (2008). Selection of measures in epidemiologic studies of the consequences of obesity. International Journal of Obesity (2005), 32 Suppl 3, S60-6. doi:10.1038/ijo.2008.88

Stice, E., Cameron, R. P., Killen, J. D., Hayward, C., \& Taylor, C. B. (1999). Naturalistic weight-reduction efforts prospectively predict growth in relative weight and onset of obesity among female adolescents. Journal of Consulting and Clinical Psychology, 67(6), 967-74. doi:10.1037/0022-006X.67.6.967

Stice, E., Presnell, K., Shaw, H., \& Rohde, P. (2005). Psychological and behavioral risk factors for obesity onset in adolescent girls: A prospective study. Journal of Consulting and Clinical Psychology, 73(2), 195-202. doi:10.1037/0022006X.73.2.195

Stice, E., Presnell, K., \& Spangler, D. (2002). Risk factors for binge eating onset in adolescent girls: A 2-year prospective investigation. Health Psychology, 21(2), 131138. doi:10.1037//0278-6133.21.2.131 
Stice, E., \& Shaw, H. E. (2002). Role of body dissatisfaction in the onset and maintenance of eating pathology: A synthesis of research findings. Journal of Psychosomatic Research, 53, 985-993. doi:org/10.1016/S0022-3999(02)00488-9

Stiegler, P., \& Cunliffe, A. (2006). The role of diet and exercise for the maintenance of fat-free mass and weight loss. Sports Medicine, 36(3), 239-262. Retrieved from http://www.healthprofessionalsolutions.com.au/v/vspfiles/assets/images/the\%20role $\% 20$ of $\% 20$ diet $\% 20$ and $\% 20$ exercise $\% 20$ for $\% 20$ the $\% 20$ maintenance $\% 20$ of $\% 20 \mathrm{ffm}$ \%20an\%20rmr\%20during\%20weight $\% 201$ loss.pdf

Stroebe, W. (2008). Dieting, overweight, and obesity: Self-regulation in a food-rich environment. doi:10.1037/11753-000

Tan, C. C., \& Holub, S. C. (2011). Children's self-regulation in eating: Associations with inhibitory control and parents' feeding behavior. Journal of Pediatric Psychology, 36(3), 340-5. doi:10.1093/jpepsy/jsq089

Tanaka, N., Hasui, C., Uji, M., Hiramura, H., Chen, Z., Shikai, N., \& Kitamura, T. (2008). Correlates of the categories of adolescent attachment styles: Perceived rearing, family function, early life events, and personality. Psychiatry and Clinical Neurosciences, 62(1), 65-74. doi:10.1111/j.1440-1819.2007.01777.x Tarride, J.-E., Haq, M., Taylor, V. H., Sharma, A. M., Nakhai-Pour, H. R., O’Reilly, D., ... Goeree, R. (2012). Health status, hospitalizations, day procedures, and physician costs associated with body mass index (BMI) levels in Ontario, Canada. ClinicoEconomics and Outcomes Research, 4, 21-30. doi:10.2147/CEOR.S24192 
Taveras, E. M., Scanlon, K. S., Birch, L., Rifas-Shiman, S. L., Rich-Edwards, J. W., \& Gillman, M. W. (2004). Association of breastfeeding with maternal control of infant feeding at age 1 year. Pediatrics, 114(5), e577-83. doi:10.1542/peds.2004-0801

Tiffin, P. A., Arnott, B., Moore, H. J., \& Summerbell, C. D. (2011). Modelling the relationship between obesity and mental health in children and adolescents: Findings from the Health Survey for England 2007. Child and Adolescent Psychiatry and Mental Health, 5(1), 31. doi:10.1186/1753-2000-5-31

Tomlinson, M., \& Landman, M. (2007). “It"s not just about food': Mother - infant interaction and the wider context of nutrition. Maternal and Child Nutrition, 3, 292302. doi:10.1111/j.1740-8709.2007.00113.x

Trost, S. G., Sirard, J. R., Dowda, M., Pfeiffer, K. A., \& Pate, R. R. (2003). Physical activity in overweight and nonoverweight preschool children. International Journal of Obesity, 27(7), 834-9. doi:10.1038/sj.ijo.0802311

Van Strien, T., Frijters, J. E. R., Bergers, G. P. A., \& Defares, P. B. (1986). The Dutch Eating Behavior Questionnaire (DEBQ) for assessment of restrained, emotional, and external eating behavior. International Journal of Eating Disorders, 5(2), 295-315. doi:10.1002/1098-108X(198602)5:2<295::AID-EAT2260050209>3.0.CO;2-T

Van Strien, T., Herman, C. P., \& Verheijden, M. W. (2009). Eating style, overeating, and overweight in a representative Dutch sample. Does external eating play a role? Appetite, 52(2), 380-7. doi:10.1016/j.appet.2008.11.010 
ATTACHMENT AND OBESITY

Van Strien, T., \& Oosterveld, P. (2008). The children's DEBQ for assessment of restrained, emotional, and external eating in 7- to 12-year-old children. International Journal of Eating Disorders, 41(1), 72-81. doi:10.1002/eat

Van Strien, T., \& Ouwens, M. A. (2003). Counterregulation in female obese emotional eaters: Schachter, Goldman, and Gordon's (1968) test of psychosomatic theory revisited. Eating Behaviors, 3(4), 329-340. doi:10.1016/S1471-0153(02)00092-2

Wang, L. C., Chyen, D., Lee, S., \& Lowry, R. (2008). The association between body mass index in adolescence and obesity in adulthood. The Journal of Adolescent Health, 42(5), 512-8. doi:10.1016/j.jadohealth.2007.10.010

Wardle, J. (1987). Eating style: A validation study of the Dutch Eating Behaviour Questionnaire in normal subjects and women with eating disorders. Journal of Psychosomatic Research, 31(2), 161-169. doi:10.1016/0022-3999(87)90072-9

Wardle, J., Carnell, S., Haworth, C. M., \& Plomin, R. (2008). Evidence for a strong genetic influence on childhood adiposity despite the force of the obesogenic environment. The American Journal of Clinical Nutrition, 87(2), 398-404. Retrieved from http://www.ncbi.nlm.nih.gov/pubmed/18258631

Wardle, J., Guthrie, C., Sanderson, S., Birch, L., \& Plomin, R. (2001). Food and activity preferences in children of lean and obese parents. International Journal of Obesity, 25(7), 971-7. doi:10.1038/sj.ijo.0801661

Waters, E., de Silva-Sanigorski, A., Hall, B. J., Brown, T., Campbell, K. J., Gao, Y., ... Summerbell, C. D. (2011). Interventions for preventing obesity in children (Review). The Cochrane Collaboration, (12), 1-212. doi:10.1002/14651858 
ATTACHMENT AND OBESITY

Waters, E., Merrick, S., Treboux, D., Crowell, J., \& Albersheim, L. (2000). Attachment security in infancy and early adulthood: A twenty-year longitudinal study. Child Development, 71(3), 684-9. doi:10.1111/1467-8624.00176

Wiesenfeld, A. R., Whitman, P. B., Granrose, C., \& Uili, R. (1985). Psychophysiological response of breast- and bottle-feeding mothers to their infants' signals. Psychophysiology, 22(1), 79-86. doi:10.1111/j.1469-8986.1985.tb01563.x

Wilkinson, L. L., Rowe, A. C., Bishop, R. J., \& Brunstrom, J. M. (2010). Attachment anxiety, disinhibited eating, and body mass index in adulthood. International Journal of Obesity, 34(9), 1442-5. doi:10.1038/ijo.2010.72

Willms, J. D., Tremblay, M. S., \& Katzmarzyk, P. T. (2003). Geographic and demographic variation in the prevalence of overweight Canadian children. Obesity Research, 11(5), 668-673. doi:10.1038/oby.2003.95

Yalenzuela, M. (1990). Attachment in Chronically Underweight Young Children. Child Development, 61, 1984-1996. doi:10.1111/j.1467-8624.1990.tb03580.x 
Appendix A

Relationship Questionnaire

\section{BelOW are FOUR DIFFERENT WAYS PEOPLE MAY FEEL ABOUT OTHERS}

\section{Read each paragraph carefully, then tell how much the description sounds like you by circling ONE number from 1= 'not at all like me' to $7=$ 'very much like me'}

A. It is easy for me to feel close to people. I feel OK asking people for help and I know that they will usually help me. When people ask me for help, they can count on me. I don't worry about being alone and I don't worry about others not liking me.

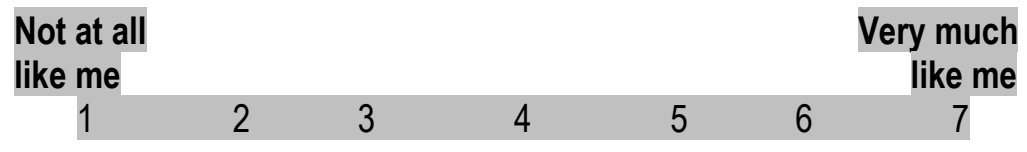

BB. It is hard for me to feel close to people. I want to be close to people, but I find it hard to trust them. I find it hard to ask people for help. I worry that if I get too close to people, they will end up hurting me

$\begin{array}{ccccccc}\begin{array}{l}\text { Not at all } \\ \text { like me }\end{array} & & & & & & \begin{array}{r}\text { Very much } \\ \text { like me }\end{array} \\ 1 & 2 & 3 & 4 & 5 & 6 & 7\end{array}$

C. I want to be really close to people, but they don't want to get that close to me. I am unhappy if I don't have people that I feel close to. I sometimes think that I care about people more than they care about me

$\begin{array}{ccccccc}\begin{array}{l}\text { Not at all } \\ \text { like me }\end{array} & & & & & & \begin{array}{r}\text { Very much } \\ \text { like me }\end{array} \\ 1 & 2 & 3 & 4 & 5 & 6 & 7\end{array}$

D. I don't care if I am close to people. It is very important for me not to ask for help, because I like to do things on my own. I don't like it if people ask me for help

$\begin{array}{ccccccc}\begin{array}{l}\text { Not at all } \\ \text { like me }\end{array} & & & & & & \begin{array}{r}\text { Very much } \\ \text { like me }\end{array} \\ 1 & 2 & 3 & 4 & 5 & 6 & 7\end{array}$

\section{Overall, which description sounds most like you? (circle only ONE letter)}
$\mathbb{A} \quad \mathbb{B}_{a} \quad C_{0} \quad \mathbb{D}_{0}$ 
Appendix B

Dutch Eating Behaviour Questionnaire

\section{WHEN AND HOW DO YOU EAT? \\ Circle the number that shows how often the statement is true for you}

\begin{tabular}{|c|c|c|c|c|c|}
\hline & Never & Seldom & $\begin{array}{l}\text { Some- } \\
\text { times }\end{array}$ & Often & $\begin{array}{l}\text { Very } \\
\text { Often }\end{array}$ \\
\hline $\begin{array}{l}\text { 1. If you have put on weight, do you eat less than you usually } \\
\text { do? }\end{array}$ & 1 & 2 & 3 & 4 & 5 \\
\hline $\begin{array}{l}\text { 2. Do you try to eat less at mealtimes than you would like to } \\
\text { eat? }\end{array}$ & 1 & 2 & 3 & 4 & 5 \\
\hline $\begin{array}{l}\text { 3. How often do you refuse food or drink offered because } \\
\text { you are concerned about your weight? }\end{array}$ & 1 & 2 & 3 & 4 & 5 \\
\hline 4. Do you watch exactly what you eat? & 1 & 2 & 3 & 4 & 5 \\
\hline 5. Do you deliberately eat foods that are slimming? & 1 & 2 & 3 & 4 & 5 \\
\hline $\begin{array}{l}\text { 6. When you have eaten too much, do you eat less than } \\
\text { usual the following days? }\end{array}$ & 1 & 2 & 3 & 4 & 5 \\
\hline $\begin{array}{l}\text { 7. Do you deliberately eat less in order not to become } \\
\text { heavier? }\end{array}$ & 1 & 2 & 3 & 4 & 5 \\
\hline $\begin{array}{l}\text { 8. How often do you try not to eat between meals because you } \\
\text { are watching your weight? }\end{array}$ & 1 & 2 & 3 & 4 & 5 \\
\hline $\begin{array}{l}\text { 9. How often in the evening do you try not to eat because you } \\
\text { are watching your weight? }\end{array}$ & 1 & 2 & 3 & 4 & 5 \\
\hline 10. Do you take into account your weight with what you eat? & 1 & 2 & 3 & 4 & 5 \\
\hline 11. Do you have the desire to eat when you are irritated? & 1 & 2 & 3 & 4 & 5 \\
\hline $\begin{array}{l}\text { 12. Do you have a desire to eat when you have nothing to } \\
\text { do? }\end{array}$ & 1 & 2 & 3 & 4 & 5 \\
\hline $\begin{array}{l}\text { 13. Do you have a desire to eat when you are depressed or } \\
\text { discouraged? }\end{array}$ & 1 & 2 & 3 & 4 & 5 \\
\hline 14. Do you have a desire to eat when you are feeling lonely? & 1 & 2 & 3 & 4 & 5 \\
\hline $\begin{array}{l}\text { 15. Do you have a desire to eat when somebody lets you } \\
\text { down? }\end{array}$ & 1 & 2 & 3 & 4 & 5 \\
\hline 16. Do you have a desire to eat when you are cross? & 1 & 2 & 3 & 4 & 5 \\
\hline $\begin{array}{l}\text { 17. Do you have a desire to eat when you are approaching } \\
\text { something unpleasant to happen? }\end{array}$ & 1 & 2 & 3 & 4 & 5 \\
\hline $\begin{array}{l}\text { 18. Do you have a desire to eat when you are anxious, } \\
\text { worried or tense? }\end{array}$ & 1 & 2 & 3 & 4 & 5 \\
\hline $\begin{array}{l}\text { 19. Do you have a desire to eat when things are going } \\
\text { against you or when things have gone wrong? }\end{array}$ & 1 & 2 & 3 & 4 & 5 \\
\hline 20. Do you have a desire to eat when you are frightened? & 1 & 2 & 3 & 4 & 5 \\
\hline 21. Do you have a desire to eat when you are disappointed? & 1 & 2 & 3 & 4 & 5 \\
\hline $\begin{array}{l}\text { 22. Do you have a desire to eat when you are emotionally } \\
\text { upset? }\end{array}$ & 1 & 2 & 3 & 4 & 5 \\
\hline
\end{tabular}




\begin{tabular}{|l|c|c|c|c|c|}
\hline $\begin{array}{l}\text { 23. Do you have a desire to eat when you are bored or } \\
\text { restless? }\end{array}$ & 1 & 2 & 3 & 4 & 5 \\
\hline 24. If food tastes good to you, do you eat more than usual? & 1 & 2 & 3 & 4 & 5 \\
\hline $\begin{array}{l}\text { 25. If food smells and looks good, do you eat more than } \\
\text { usual? }\end{array}$ & 1 & 2 & 3 & 4 & 5 \\
\hline $\begin{array}{l}\text { 26. If you see or smell something delicious, do you have the } \\
\text { desire to eat it? }\end{array}$ & 1 & 2 & 3 & 4 & 5 \\
\hline $\begin{array}{l}\text { 27. If you have something delicious to eat, do you eat it } \\
\text { straight away? }\end{array}$ & 1 & 2 & 3 & 4 & 5 \\
\hline $\begin{array}{l}\text { 28. If you walk past the bakery, do you have a desire to buy } \\
\text { something delicious? }\end{array}$ & 1 & 2 & 3 & 4 & 5 \\
\hline $\begin{array}{l}\text { 29. If you walk past a snack bar or a café, do you have a } \\
\text { desire to buy something delicious? }\end{array}$ & 1 & 2 & 3 & 4 & 5 \\
\hline $\begin{array}{l}\text { 30. If you see others eating, do you also have a desire to } \\
\text { eat? }\end{array}$ & 1 & 2 & 3 & 4 & 5 \\
\hline 31. Can you resist eating delicious foods & 1 & 2 & 3 & 4 & 5 \\
\hline 32. Do you eat more than usual when you see others eating? & 1 & 2 & 3 & 4 & 5 \\
\hline $\begin{array}{l}\text { 33. When preparing a meal, are you inclined to eat } \\
\text { something? }\end{array}$ & 1 & 2 & 3 & 4 & 5 \\
\hline
\end{tabular}




\section{Appendix C}

Demographics

For each question, please pick up the answer that is true (or most true) for you. There are no right or wrong answers. We just want to learn more about youth like you. Your answers are confidential (your name will not appear anywhere on the questionnaire). If you have problems with any questions, please raise your hand and we'll come to help.

\begin{tabular}{|l}
\hline Please give ONE answer for each question by circling the corresponding number \\
and/or filling in the blanks (arev zones)
\end{tabular}

2. What grade are you in? $1.7^{\text {th }} \quad 2.8^{\text {th }} \quad$ 3. $9^{\text {th }} 4.10^{\text {th }}$ 5. $11^{\text {th }} \quad 6.12^{\text {th }}$

$\begin{array}{lll}\text { 3. What is your gender? } & \text { 1. Male } & \text { 2. Female }\end{array}$

4. How much school has your mother had?

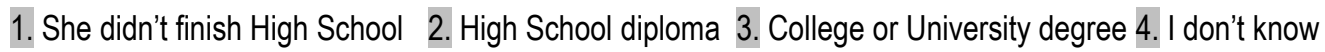

5. How much school has your father had?

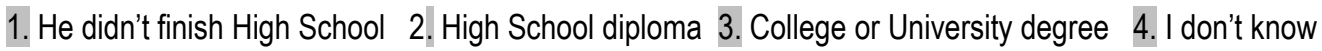

6. Which of the following groups best describes your ethnic origin? (you can mark two responses IF YOUR PARENTS each have a DIFFERENT origin)

\section{European 2. Aboriginal 3. Caribbean 4. Central or South American}

\section{Oceanian (Australia, New Zealand) $\quad$ 6. North American (Canada, US) $\quad$ 7. African}

\section{Asian 9. Middle Eastern 10. Other (which one?):}

7. What is the main language you speak at home with your parents? (mark ONLY ONE)

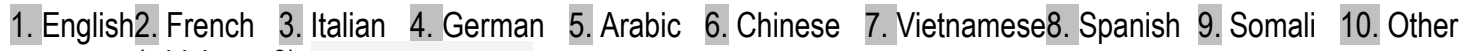
(which one?):

* IF YOU WERE NOT BORN IN CANADA, ANSWER QUESTIONS 8 to 16 (IF YOU WERE BORN IN CANADA, GO THE NEXT PAGE)

\begin{tabular}{|l|c|c|c|c|}
\hline 8. I have been living in Canada for I I I years & Canada & $\begin{array}{c}\text { The country my } \\
\text { family is from }\end{array}$ & Both & Neither \\
\hline 9. I am most comfortable being with people from & 1 & 2 & 3 & 4 \\
\hline 10. My best friends are from & 1 & 2 & 3 & 4 \\
\hline 11. The people I fit in best are from & 1 & 2 & 3 & 4 \\
\hline 12. My favorite music is from & 1 & 2 & 3 & 4 \\
\hline 13. My favorite TV show is from & 1 & 2 & 3 & 4 \\
\hline 14. The holidays I celebrate are from & 1 & 2 & 3 & 4 \\
\hline 15. The food I eat at home is from & 1 & 2 & 3 & 4 \\
\hline $\begin{array}{l}\text { 16. The way I do things and the way I think about things } \\
\text { are from }\end{array}$ & 1 & 2 & 3 & 4 \\
\hline
\end{tabular}


Appendix D

\section{Children's Depression Inventory}

\begin{tabular}{|c|c|}
\hline \multicolumn{2}{|c|}{$\begin{array}{l}\text { Youth sometimes have DIFFERENT FEELINGS AND IDEAS } \\
\text { From each group of } 3 \text { sentences, pick one sentence that describes you BEST for THE PAST } \\
\text { TWO WEEKS }\end{array}$} \\
\hline $\begin{array}{l}\text { 1. I am sad once in a while } \\
\square \text { I am sad many times } \\
\square \text { I am sad all the time }\end{array}$ & $\begin{array}{l}14 . \\
\square \text { I look OK } \\
\square \text { There are some bad things about my looks } \\
\square \text { I look ugly }\end{array}$ \\
\hline $\begin{array}{l}2 . \\
\square \text { Nothing will ever work out for me } \\
\square \text { I am not sure if things will work out for me } \\
\square \text { Things will work out for me }\end{array}$ & $\begin{array}{l}15 \text {. } \\
\square \text { I have to push myself all the time to do my } \\
\text { schoolwork } \\
\square \text { I have to push myself many times to do my } \\
\text { schoolwork } \\
\square \text { Doing my schoolwork is not a big problem }\end{array}$ \\
\hline $\begin{array}{l}3 . \\
\square \text { I do most things OK } \\
\square \text { I do many things wrong } \\
\square \text { I do everything wrong }\end{array}$ & $\begin{array}{l}16 . \\
\square \text { I have trouble sleeping every night } \\
\square \text { I have trouble sleeping many nights } \\
\square \text { I sleep pretty well }\end{array}$ \\
\hline $\begin{array}{l}4 . \\
\square \text { I have fun in many things } \\
\square \text { I have fun in some things } \\
\square \text { Nothing is fun at all }\end{array}$ & $\begin{array}{l}17 . \\
\square \text { I am tired once in a while } \\
\square \text { I am tired many days } \\
\square \text { I am tired all the time }\end{array}$ \\
\hline $\begin{array}{l}5 . \\
\square \text { I am bad all the time } \\
\square \text { I am bad many times } \\
\square \text { I am bad once in a while }\end{array}$ & $\begin{array}{l}18 . \\
\square \text { Most days I do not feel like eating } \\
\square \text { Many days I do not feel like eating } \\
\square \text { I eat pretty well }\end{array}$ \\
\hline $\begin{array}{l}6 . \\
\square \text { I think about bad things happening to me once in } \\
\text { a while } \\
\square \text { I worry that bad things will happen to me } \\
\square \text { I am sure that terrible things will happen to me }\end{array}$ & $\begin{array}{l}19 . \\
\square \text { I do not worry about aches and pains } \\
\square \text { I worry about aches and pains many times } \\
\square \text { I worry about aches and pains all the time }\end{array}$ \\
\hline $\begin{array}{l}7 . \\
\square \text { I hate myself } \\
\square \text { I do not like myself } \\
\square \text { I like myself }\end{array}$ & $\begin{array}{l}20 . \\
\square \text { I do not feel alone } \\
\square \text { I feel alone many times } \\
\square \text { I feel alone all the time }\end{array}$ \\
\hline $\begin{array}{l}\text { 8. } \\
\square \text { All bad things are my fault } \\
\square \text { Many bad things are my fault } \\
\square \text { Bad things are not usually my fault }\end{array}$ & $\begin{array}{l}\text { 21. } \\
\square \text { I never have fun at school } \\
\square \text { I have fun at school only once in a while } \\
\square \text { I have fun at school many times. }\end{array}$ \\
\hline $\begin{array}{l}9 . \\
\square \text { I do not think about killing myself } \\
\square \text { I think about killing myself but I would not do it } \\
\square \text { I want to kill myself }\end{array}$ & $\begin{array}{l}22 . \\
\square \text { I have plenty of friends } \\
\square \text { I have some friends but I wish I had more } \\
\square \text { I do not have any friends }\end{array}$ \\
\hline $\begin{array}{l}10 . \\
\square \text { I feel like crying every day } \\
\square \text { I feel like crying many days } \\
\square \text { I feel like crying once in a while }\end{array}$ & $\begin{array}{l}23 \text {. } \\
\square \text { My schoolwork is all right } \\
\square \text { My schoolwork is not as good as before } \\
\square \text { I do very badly in subjects I used to be good in }\end{array}$ \\
\hline $\begin{array}{l}11 . \\
\square \text { Things bother me all the time } \\
\square \text { Things bother me many times } \\
\square \text { Things bother me once in a while }\end{array}$ & $\begin{array}{l}24 . \\
\square \text { I can never be as good as other kids } \\
\square \text { I can be as good as other kids if I want to } \\
\square \text { I am just as good as other kids }\end{array}$ \\
\hline
\end{tabular}




\begin{tabular}{|l|l|}
\hline 12. & 25 . \\
$\square$ I like being with people & $\square$ Nobody really loves me \\
$\square$ I do not like being with people many times & $\square$ I am not sure if anybody loves me \\
$\square$ I do not want to be with people at all & $\square$ I am sure that somebody loves me \\
\hline 13. & 26. \\
$\square$ I cannot make up my mind about things & $\square$ I usually do what I am told \\
$\square$ It is hard to make up my mind about things & $\square$ I do not do what I am told most times \\
$\square$ I make up my mind about things easily & $\square$ I never do what I am told \\
\hline 27. \\
$\square$ I get along with people \\
$\square$ I get into fights many times \\
$\square$ I get into fights all the time
\end{tabular}




\section{ATTACHMENT AND OBESITY}

\section{Appendix E}

Multidimensional Anxiety Scale for Children-10

\section{The following questions ask how you have been thinking, feeling, or acting recently.} For each, please circle the number that shows HOW OFTEN THE STATEMENT IS TRUE for you

\begin{tabular}{|l|c|c|c|c|}
\hline & $\begin{array}{c}\text { Never true } \\
\text { about me }\end{array}$ & $\begin{array}{c}\text { Rarely } \\
\text { true about } \\
\text { me }\end{array}$ & $\begin{array}{c}\text { Sometime } \\
\text { s true } \\
\text { about me }\end{array}$ & $\begin{array}{c}\text { Often } \\
\text { true } \\
\text { about me }\end{array}$ \\
\hline 1. The idea of going away to camp scares me & 0 & 1 & 2 & 3 \\
\hline 2. I'm afraid that other kids will make fun of me & 0 & 1 & 2 & 3 \\
\hline 3. I try to stay near my mom or dad & 0 & 1 & 2 & 3 \\
\hline 4. I get dizzy or faint feelings & 0 & 1 & 2 & 3 \\
\hline 5. I feel restless and on edge & 0 & 1 & 2 & 3 \\
\hline 6. I feel sick to my stomach & 0 & 1 & 2 & 3 \\
\hline 7. I get nervous if I have to perform in public & 0 & 1 & 2 & 3 \\
\hline $\begin{array}{l}\text { 8. Bad weather, the dark, heights, animals, or bugs } \\
\text { scare me }\end{array}$ & 0 & 1 & 2 & 3 \\
\hline 9. I check to make sure things are safe & 0 & 1 & 2 & 3 \\
\hline 10. I feel shy & 0 & 1 & 2 & 3 \\
\hline
\end{tabular}


Appendix F

Body Esteem Scale for Adolescents and Adults

Indicate HOW OFTEN YOU AGREE with the following statements ABOUT YOURSELF by circling the appropriate number

\begin{tabular}{|l|c|c|c|c|c|}
\hline 1. I like what I look like in pictures & Never & Seldom & Sometimes & Often & Always \\
\hline 2. Other people consider me good looking & 0 & 1 & 2 & 3 & 4 \\
\hline 3. I'm proud of my body & 0 & 1 & 2 & 3 & 4 \\
\hline $\begin{array}{l}\text { 4. I am preoccupied with trying to change my body } \\
\text { weight }\end{array}$ & 0 & 1 & 2 & 3 & 4 \\
\hline 5. I think my appearance would help me get a job & 0 & 1 & 2 & 3 & 4 \\
\hline 6. I like what I see when I look in the mirror & 0 & 1 & 2 & 3 & 4 \\
\hline $\begin{array}{l}\text { 7. There are lots of things I'd change about my looks if I } \\
\text { could }\end{array}$ & 0 & 1 & 2 & 3 & 4 \\
\hline 8. I am satisfied with my weight & 0 & 1 & 2 & 3 & 4 \\
\hline 9. I wish I looked better & 0 & 1 & 2 & 3 & 4 \\
\hline 10. I really like what I weigh & 0 & 1 & 2 & 3 & 4 \\
\hline 11. I wish I looked like someone else & 0 & 1 & 2 & 3 & 4 \\
\hline 12. People my own age like my looks & 0 & 1 & 2 & 3 & 4 \\
\hline 13. My looks upset me & 0 & 1 & 2 & 3 & 4 \\
\hline 14. I'm as nice looking as most people & 0 & 1 & 2 & 3 & 4 \\
\hline 15. I'm pretty happy about the way I look & 0 & 1 & 2 & 3 & 4 \\
\hline 16. I feel I weigh the right amount for my height & 0 & 1 & 2 & 3 & 4 \\
\hline 17. I feel ashamed of how I look & 0 & 1 & 2 & 3 & 4 \\
\hline 18. Weighing myself depresses me & 0 & 1 & 2 & 3 & 4 \\
\hline 19. My weight makes me unhappy & 0 & 1 & 2 & 3 & 4 \\
\hline 20. My looks help me to get dates & 0 & 1 & 2 & 3 & 4 \\
\hline 21. I worry about the way I look & 0 & 1 & 2 & 3 & 4 \\
\hline 22. I think I have a good body & 0 & 1 & 2 & 3 & 4 \\
\hline 23. I'm looking as nice as l'd like to & & 1 & 2 & 3 & 4 \\
\hline
\end{tabular}


Appendix G

Godin Leisure-Time Exercise Questionnaire

How many times per week, on average, do you do the following types of exercise for more than 15 minutes at a time, during your free time (not part of a mandatory school schedule)?

울

A. Strenuous Exercise (heart beats rapidly)

i.e., running, jogging, hockey, football, soccer, squash, basketball, cross country skiing, judo, roller skating, vigorous swimming, vigorous long distance bicycling

B. Moderate Exercise (not exhausting)

i.e., fast walking, baseball, tennis, easy bicycling, volleyball, badminton, easy swimming, alpine skiing, popular and folk dancing

C. Mild Exercise (minimal effort)

i.e., yoga, archery, fishing from river band, bowling, horseshoes, golf, snowmobiling,

easy walking

D. During your leisure time, how often per week do you engage in any activity long enough to work up a sweat (heart beats rapidly)?

$\begin{array}{lll}\text { 1. Never/Rarely 2. Sometimes } & \text { 3. Often }\end{array}$

E. Do you feel 'guilty' that you have 'let yourself down' when you miss an exercise session?

$\begin{array}{llll}\text { 1. Never 2. Rarely } & \text { 3. Sometimes } & \text { 4. Often } \quad \text { Always }\end{array}$ 